\begin{tabular}{|c|c|c|}
\hline Beitr. Ent. & Berlin & ISSN 0005-805X \\
\hline $\mathbf{5 0}(2000) 1$ & S. $3-64$ & 11.04 .2000 \\
\hline
\end{tabular}

\title{
A taxonomic and phylogenetic revision of Maorothiini trib. $n$. from the New Zealand subregion
}

\section{(Coleoptera: Staphylinidae, Staphylininae)}

With 2 tables, 22 figure plates, and 3 maps

\section{VOLKER ASSING}

\section{Summary}

The types of the New Zealand species previously attributed to the genus Othius STEPHENS and additional material are revised. A phylogenetic analysis including the New Zealand species, all the genera of Othiini from the Holarctic region, several representative taxa of all other staphylinine tribes, and the genus Lathrobium GRAVENHORST of the Paederinae as outgroup yielded the following major results: (a) the New Zealand species form a monophylum; (b) Othius STEPHENS is a Palaearctic genus and not the sister group of the New Zealand species, but the adelphotaxon of the Holarctic monophylum Atrecus JACQUELIN DU VAL + Caecolinus JEANNEL + Parothius CASEY; (c) a sister group relationship between the New Zealand species and Holarctic Othiini is doubtful, if not unlikely. Therefore, the tribe Maorothiini trib. n. is established to accommodate the New Zealand taxa previously attributed to Othius. The new tribe is attributed to the Staphylininae and distinguished from other tribes of the subfamily. It includes only the type genus Maorothius gen. n., whose designated type species is Othius adustus BRoun and whose distribution is apparently confined to the New Zealand subregion. In all, 20 species of Maorothius are distinguished and (re-)described: $M$. adustus (BROUN), comb. n., M. hamifer sp. n., M. setiger sp. n., $M$. longispinosus sp. n., M. brevispinosus sp. n., M. insulanus sp. m., M. brookesi (CAMERON), comb. n., $M$. hammondi sp. n., $M$. pubescens sp. n., $M$. effeminatus sp. n., $M$. pectinatus sp. n., $M$. puncticeps (BRouN), comb. n., $M$. coalitus sp. n., $M$. tridens sp.n., $M$. volans sp. n., $M$. dispar sp. n., $M$. brouni (STEEL), comb. n., M. tonsor sp. n., $M$. torquatus $\mathbf{s p . ~} \mathbf{n}$., and $M$. solus sp. $\mathbf{n}$. Lectotypes are designated for M. adustus (BROUN), M. brookesi (CAMERON), and M. brouni (STEEL). The phylogenetic affiliations among the species of Maorothius are analyzed, discussed, and figured. Drawings illustrating distinguishing characters and a key to the species are provided. Bionomical and biogeographical data are compiled and mapped, respectively.

\section{Key words}

Coleoptera - Staphylinidae - Staphylininae - Othiini - Diochini - Staphylinini - Platyprosopini Maorothiini - Maorothius - Othius - New Zealand - phylogeny - taxonomy - revision - distribution bionomics - endoparasitism - new tribe - new genus - new species - new combinations - lectotype designations

\section{Zusammenfassung}

Die Typen der aus Neuseeland bekannten, bisher der Gattung Othius STEPHENs zugeordneten Arten sowie weiteres Material werden revidiert. Eine phylogenetische Analyse unter Einschluss der neuseeländischen Arten, aller Gattungen holarktischer Othiini, repräsentativer Taxa aller übrigen Staphy- 
lininentriben sowie der Paederinengattung Lathrobium GRAVENHORST als Außengruppe ergab: (a) die neuseeländischen Arten bilden ein Monophylum; (b) Othius STEPHENS ist eine paläarktische Gattung und nicht Adelphotaxon der neuseeländischen Arten, sondern die Schwestergruppe des holarktischen Monophylums Atrecus JACQUELIN DU VAL + Caecolinus JEANNEL + Parothius CASEY; (c) eine Schwestergruppenbeziehung zwischen den neuseeländischen Arten und den holarktischen Othiini ist zweifelhaft, wenn nicht unwahrscheinlich. Die in Neuseeland verbreiteten und bisher zu Othius gestellten Arten werden daher der Tribus Maorothiini trib. n. zugeordnet, die beschrieben und von anderen Triben der Staphylininae unterschieden wird. Einzige Gattung der offenbar in Neuseeland endemischen Tribus ist die Typusgattung Maorothius gen. n. mit der designierten Typusart Othius adustus BroUN. Insgesamt werden 20 Maorothius-Arten beschrieben bzw. redescribiert: $M$. adustus (BROUN), comb. n., $M$. hamifer sp. n., $M$. setiger sp. n., $M$. longispinosus sp. n., $M$. brevispinosus sp. n., $M$. insulanus sp. n., $M$. brookesi (CAMERON), comb. n., M. hammondi sp. n., M. pubescens sp. n., M. effeminatus sp. n., M. pectinatus sp. n., $M$. puncticeps (BROUN), comb. n., $M$. coalitus sp. n., M. tridens $\mathbf{s p . ~ n . , ~} M$. volans $\mathbf{s p .} \mathbf{n} ., M$. dispar $\mathbf{s p}$. n., $M$. brouni (STEEL), comb. n., M. tonsor $\mathbf{s p .}$ n., $M$. torquatus sp. n. und $M$. solus $\mathbf{s p .} \mathbf{n}$. Für $M$. adustus (BROUN), M. brookesi (CAMERON) und $M$. brouni (STEEL) werden Lectotypen designiert. Die phylogenetischen Beziehungen der Arten werden analysiert, diskutiert und illustriert. Die Beschreibungen werden durch Abbildungen von Differentialmerkmalen, eine Bestimmungstabelle, Daten zur Bionomie sowie durch Verbreitungskarten ergänzt.

\section{Table of contents}

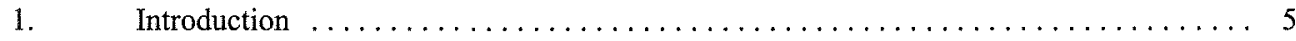

2. Material, measurements, and abbreviations $\ldots \ldots \ldots \ldots \ldots \ldots \ldots \ldots \ldots \ldots$

3. The phylogenetic position of New Zealand "Othius" in Staphylininae . . . . . . . 6

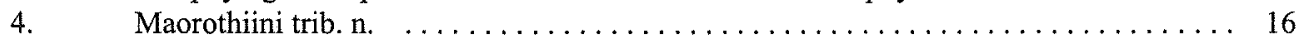

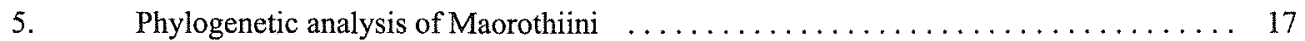

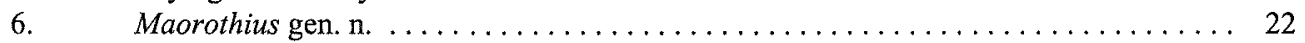

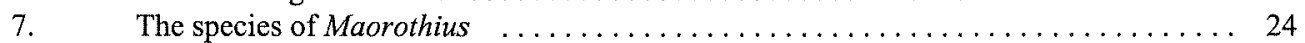

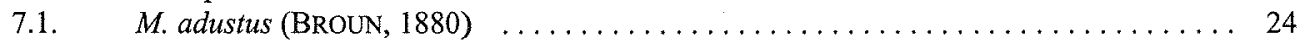

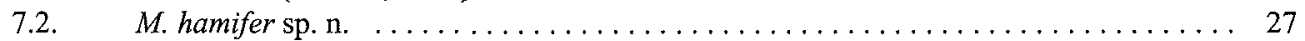

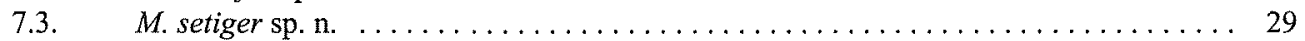

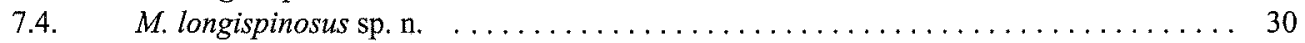

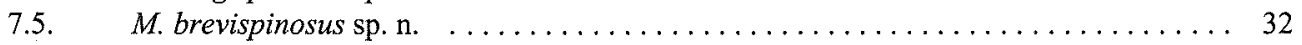

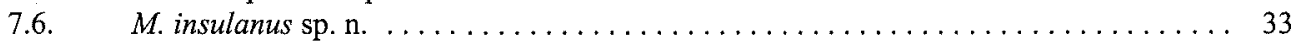

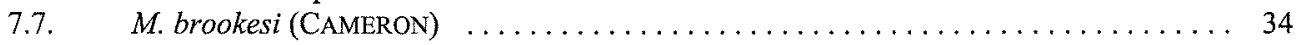

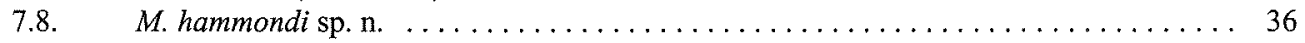

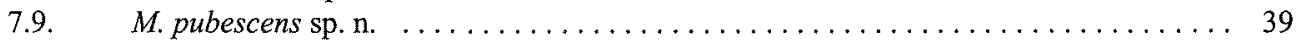

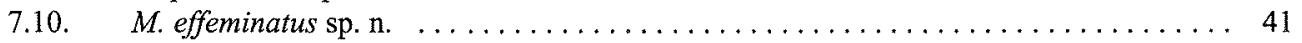

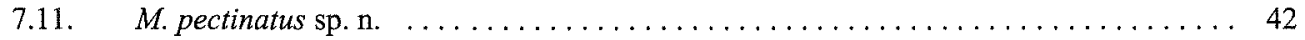

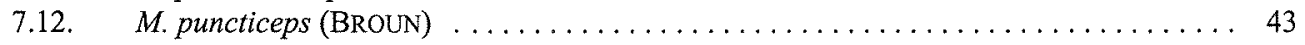

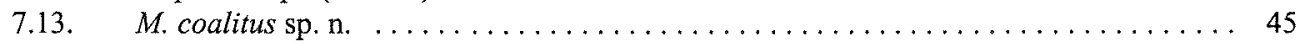

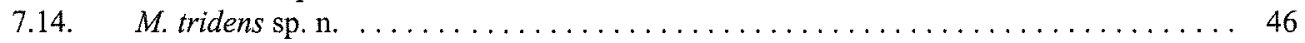

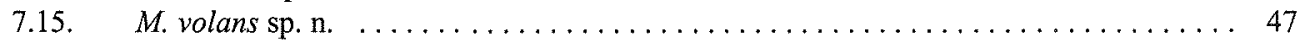

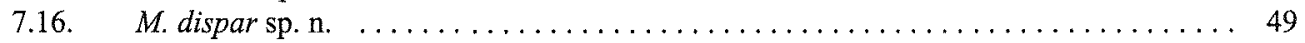

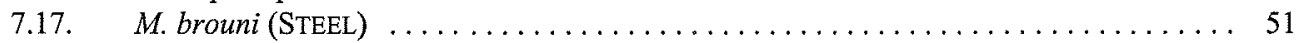

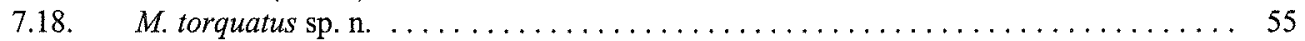

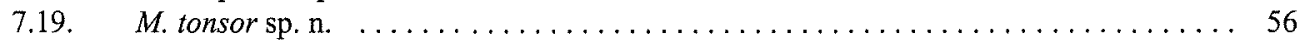

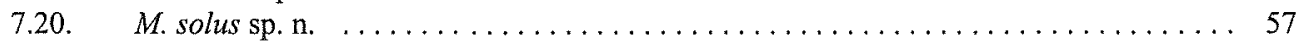

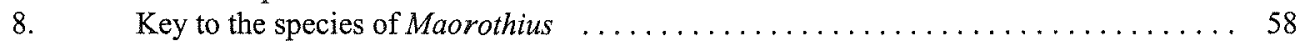

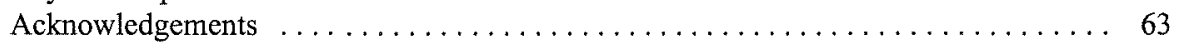

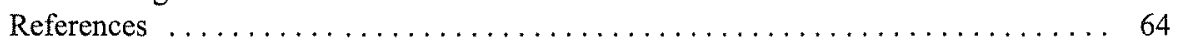




\section{Introduction}

After the species of Othius STEPHENS of the northern hemisphere had been revised in several steps (e. g. ASSING, 1997, 1998a, 1998b, 1999a, 1999b), the only species originally described in the genus and left to be examined were four taxa described from New Zealand: $O$. adustus Broun, 1880, O. angustus Broun, 1893, O. puncticeps BRoun, 1894, and O. brookesi CAMERON, 1952. O. angustus BROUN, a primary homonym of $O$. angustus STEPHENS, was later renamed as Gyrohypnus brouni by STEEL (1948). According to a recent review by KLIMASZEWSKI et al. (1996), Othius is represented in New Zealand by four described (see above) and ten new (undescribed) species, and an example of extensive radiation in this region.

In the northern hemisphere, Othius has a Palaearctic distribution. Strictly speaking, some species occur in the Oriental region, but here they are confined to higher altitudes, where a large proportion of the flora and fauna is of Palaearctic affiliations (ASSING, 1999a). Against this background, the remarkably disjunct, amphipolar distribution seemed surprising, particularly in view of the long geological time of isolation of the New Zealand archipelago, of the high degree of endemism of staphylinid genera (43\%) and species $(>90 \%)$ in these islands (KLIMASZEWSKI et al., 1996), and also considering the fact that the genus is apparently absent from Australia and other temperate regions of the southern hemisphere. The only further genus described from the southern hemisphere and originally placed in Othiini is Antarctothius COIFFAIT \& SAIZ from southern South America (COIFFAIT \& SAIZ, 1969), but this taxon was later transferred to Diochini (NEWTON, 1985). As was expected, an examination of the types and additional material of the New Zealand species and a phylogenetic approach including representatives of all taxa of Othiini and selected representatives of other tribes of Staphylininae and Paederinae eventually revealed that the New Zealand species previously attributed to Othius had to be excluded from the genus.

\section{Material, measurements, and abbreviations}

Types and additional material from the following collections were examined:

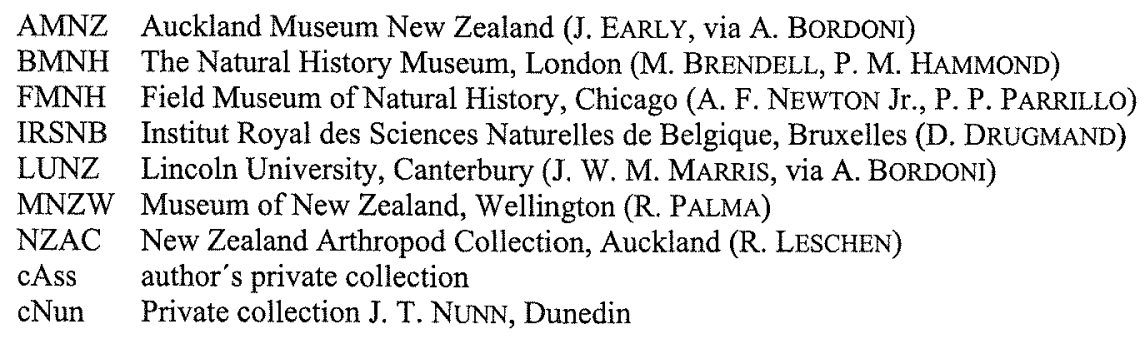

The measurements in the descriptions and the key are indicated in $\mathrm{mm}$ and abbreviated as follows:

HW: maximal head width

HL: $\quad$ head length from front margin of frons to neck

PW: maximal width of pronotum

PL: $\quad$ length of pronotum along median line

EL: $\quad$ length of elytra from apex of scutellum to elytral hind margin

TiL: length of metatibiae (external aspect, from knee to insertion of first metatarsomere)

TaL: $\quad$ length of metatarsi (claws not included)

AL: $\quad$ length of median lobe of aedeagus from apex of ventral process to base of bulbus

TL: total length from apex of mandibles to hind margin of tergum VII.

Holotypes, paratypes, lectotypes, paralectotypes, and syntypes are abbreviated as HT, PT, LT, PLT, and ST, respectively. 


\section{The phylogenetic position of New Zealand "Othius" in Staphylininae}

In order to assess the phylogenetic relationships among Othiini and of the "Othius" described from New Zealand, the latter of which are below described and referred to as Maorothius gen. $n$, a phylogenetic analysis based on these taxa and including representatives of several tribes of Staphylininae - among them all the tribes of Xantholininae sensu SMETANA (1982), i. e. Othiini, Diochini, Platyprosopini, and Xantholinini - was attempted. A genus of Paederinae, according to SMETANA (1995) possibly the sister group of Staphylininae, was chosen as outgroup. The following taxa were examined (systematic classification according to NEWTON \& THAYER 1992):

\begin{tabular}{|c|c|c|c|}
\hline subfamily & $\begin{array}{l}\text { tribe } \\
\text { (subtribe) }\end{array}$ & genus & species \\
\hline Staphylininae & Othiini & Othius STEPHENS & all species \\
\hline Staphylininae & Othiini & $\begin{array}{l}\text { Atrecus JACQUELIN } \\
\text { DU VAL }\end{array}$ & $\begin{array}{l}\text { A. affinis (PAYKULL), A. longiceps (FAU- } \\
\text { VEL), A. pilicornis (PAYKULL), A. parvio- } \\
\text { culatus ASSING }\end{array}$ \\
\hline Staphylininae & Othiini & Parothius CASEY & P. californicus (MANNERHEIM) \\
\hline Staphylininae & Othiini & Caecolinus JEANNEL & C. endogaeus JEANNEL \\
\hline & & Maorothius gen. n. & $\begin{array}{l}\text { M. adustus (BROUN), M. brookesi (CAME- } \\
\text { RON), M. puncticeps (BROUN), } M \text {. brouni } \\
\text { (STEEL), and taxa described in this paper }\end{array}$ \\
\hline Staphylininae & Xantholinini & Xantholinus DEJEAN & $X$ linearis (OLIVIER), $X$. gallicus COIFFAIT \\
\hline Staphylininae & Xantholinini & $\begin{array}{l}\text { Gyrohypnus LEACH } \\
\text { in SAMOUELLE }\end{array}$ & $\begin{array}{l}\text { G. fracticomis (MÜLLER), G. angustatus } \\
\text { STEPHENS }\end{array}$ \\
\hline Staphylininae & Diochini & Diochus ERICHSON & D. staudingeri KRAATZ \\
\hline Staphylininae & Diochini & $\begin{array}{l}\text { Antarctothius COIF- } \\
\text { FAIT \& SAIZ }\end{array}$ & $\begin{array}{l}\text { A. antarcticus (FAIRMAIRE) (LT); } A \text {. fue- } \\
\text { gius COIFFAIT \& SAIZ (HT) }\end{array}$ \\
\hline Staphylininae & Platyprosopini & $\begin{array}{l}\text { Platyprosopus MAN- } \\
\text { NERHEIM }\end{array}$ & $\begin{array}{l}\text { P. elongatus MANNERHEIM, } P \text {. hierochon- } \\
\text { ticus REICHE, } P \text {. indicus MOTSCHULSKY, } \\
\text { and unidentified species }\end{array}$ \\
\hline Staphylininae & $\begin{array}{l}\text { Staphylinini } \\
\text { (Philonthina) }\end{array}$ & Philonthus CURTIS & $\begin{array}{l}\text { P. laminatus (CREUTZER), P. carbonarius } \\
\text { (GRAVENHORST) }\end{array}$ \\
\hline Staphylininae & $\begin{array}{l}\text { Staphylinini } \\
\text { (Quediina) }\end{array}$ & Quedius STEPHENS & $\begin{array}{l}\text { Q. levicollis (BRULLÉ), Q. boops (GRA- } \\
\text { VENHORST) }\end{array}$ \\
\hline Paederinae & $\begin{array}{l}\text { Paederini } \\
\text { (Lathrobiina) }\end{array}$ & $\begin{array}{l}\text { Lathrobium GRA- } \\
\text { VENHORST }\end{array}$ & $\begin{array}{l}\text { L. fulvipenne (GRAVENHORST), L. longu- } \\
\text { lum GRAVENHORST, and other species }\end{array}$ \\
\hline
\end{tabular}

Character selection was primarily based on Othiini and Maorothius gen. n., since the objective of this study was to study their phylogenetics rather than attempt a phylogenetic analysis of Staphylininae as a whole. For this reason, apomorphies constituting the monophyly e. g. of Quedius or Philonthus were partly neglected, as the corresponding plesiomorphies are of no significance for the taxa in the focus of interest. Whenever in doubt regarding the polarity of character states, especially those relevant for phylogenetic relationships at a higher systematic level, the plesiomorphic character states were inferred from the conditions in other subfamilies representing more distant outgroups, in particular Aleocharinae, Omaliinae, Steninae, and Tachyporinae (see discussions of character polarities below). 
Discussion of character states and polarities:

1 Head: \pm oblong, usually narrower and shorter than pronotum (0); of \pm distinctly subquadrate outline, as wide as or wider than pronotum (1); of ovoid shape, approximately as wide and as long as pronotum (2); with very large and bulging eyes, shape of head therefore \pm transverse, usually slightly narrower than pronotum (3). The conditions here regarded as apomorphic are treated as discrete characters states (not a trend), all of which are likely to be derived from the condition here considered plesiomorphic. The wide head in some species of Othius and Maorothius is here considered an autapomorphy of those species. Head shape is subject to considerable intrageneric variation in Lathrobium, the head is sometimes wider than pronotum, but not as distinctly subquadrate as in Atrecus and related genera. In Antarctothius, the head is approximately as wide as and almost as long as the pronotum, but in general outline represents the condition here considered plesiomorphic.

2 Postgenae: without conspicuously dense punctation (0); with conspicuously dense punctation (1). The dense punctation in Platyprosopus and Gyrohypnus is clearly not homologous.

3 Microsculpture of head and pronotum: transverse to weakly isodiametric, sometimes absent (0); distinctly and strongly isodiametric (1). A distinctly isodiametric microsculpture is exceptionally present in some Othius, but here considered an autapomorphy of those species; in Antarctothius, the microsculpture is isodiametric, but rather shallow and less distinct than in Maorothius.

$4 \quad$ Anterior margin of frons: simply truncate $(0)$; with weak median protrusion (1); with distinct median protrusion (2).

5 Antero-lateral margins of frons: not extending posteriorly beyond antennal fossae (0); extending posteriorly beyond antennal fossae (1).

6 Anterior margin of frons: not separated from clypeus by distinct ridge (0); separated from the sclerotized postclypeus by distinct ridge (1). It is not certain if the ridge in Diochus in fact forms the anterior margin of the frons or if it delimits the postclypeus from the (sclerotized) anteclypeus; whatever sclerite this ridge refers to, it is here considered an apomorphy of Diochus.

7 Frons: frontal punctures absent or not distinct from dorsal punctation (0); present (1). Even if such punctures are usually absent in Omaliinae, Steninae, Tachyporinae, and Aleocharinae, there is some doubt regarding the polarity of this character. If the polarity assumed here is correct, the absence of these punctures in some Maorothius and Quedius is very likely to be the result of a secondary reduction.

8 Frons: frontal furrows absent or very weakly impressed $(0)$, usually present, only exceptionally very shallow (1). This character was found to be subject to some intrageneric variation especially in Othius, Atrecus and related genera, and in Maorothius. Consequently, it is attributed little phylogenetic significance.

9 Labrum: undivided and with \pm truncate to weakly concave front margin, anterior angles distinct $(0)$; front margin moderately emarginate; anterior angles indistinct or distinct, but not protruding (1); front margin moderately emarginate; anterior angles protruding (2); front margin strongly incised, labrum distinctly bilobed (3); anterior margin \pm truncate to arcuate, anterior angles indistinct, rounded (4). A simple undivided labrum is here considered the plesiomorphic state also found in many other staphylinid subfamilies (e. g. Omaliinae, Steninae, Aleocharinae). The apomorphic conditions are treated as discrete states. The similar shapes in Othius and Philonthus as well as in Lathrobium and the examined Xantholinini are very unlikely to be homologous and here considered homoplasies. 
10 Labrum: anteriorly without membranous extension (0); with distinct membranous extension (1). This membranous extension is narrow in Quedius; in Philonthus and Platyprosopus it is prominent and pubescent. Whether or not the similarities in Platyprosopus and Philonthus are homologous is uncertain.

11 Mandibles: of usual length, \pm evenly bent (0); long, straight, and apically weakly bent (1); apically strongly bent and very acute, inner margin with conspicuously long teeth (2). The apomorphic conditions are treated as discrete states.

12 Maxillary palpi, shape: apical segment slender and of subconical shape (0); apical segment broad and apically \pm truncate (1); apical segment very short and conical (2). The apomorphic conditions are treated as discrete states.

13 Maxillary palpi, relative width: apical segment slightly narrower than preapical segment (0); apical segment distinctly narrower than preapical segment, but not aciculate (1); apical segment aciculate (2). The narrow apical segments in Caecolinus and Lathrobium are without doubt homoplastic. It is uncertain whether the apormorphic conditions represent an evolutionary trend or discrete character states. In Xantholinini and Paederinae, the morphology of the apical segment of the maxillary palpi is highly diverse.

14 Maxillary palpi: without dense and fine pubescence $(0)$; with \pm dense and fine pubescence (1).

15 Labial palpi: apical segment subconical, only slightly narrower than preceding segment (0); apical segment distinctly narrower than preceding segment, but not aciculate (1); apical segment aciculate (2); apical segment distinctly truncate, preapical segment very short (3). It is uncertain whether the apormorphic conditions 1 and 2 represent an evolutionary trend or discrete character states. The derived condition 3 is treated as a discrete character state. The similar shapes in Caecolinus and the examined Xantholinini as well as in Diochini and Lathrobium are without doubt homoplastic.

16 Gular sutures separate (though often very narrowly), posteriorly distinctly diverging, gula present (0); gular sutures in posterior half of head \pm contiguous, posteriorly not or only weakly diverging (1); gular sutures fused, gula absent (2). Character states 0 2 are likely to reflect an evolutionary trend.

17 Mentum as wide as submentum or nearly so, submentum anteriorly weakly concave $(0)$; mentum distinctly narrower than submentum, submentum anteriorly strongly concave (1).

18 Relative antennal length: \pm distinctly more than $1.5 x$ (usually ca. $2 x$ ) longer than head width (0); ca. $1.5 x$ the width of head or shorter, only exceptionally longer (1). The relative lengths of the antennae in Atrecus and Quedius are due to the wide head and the large bulging eyes, respectively, rather than to the reduced length of the antennae and for this reason considered to represent the plesiomorphic condition.

19 Antennae: not geniculate (0); geniculate (1).

20 Antennal insertions: near lateral margin of head $(0)$; clearly distant from lateral margin of head (1).

21 Antennae: antennomere X subquadrate to moderately transverse (0); antennomere X strongly transverse (1); antennomere X weakly to distinctly oblong and flattened (2). The apomorphic conditions are treated as discrete states. The derived character states in Atrecus + Parothius + Caecolinus, in Antarctothius, and in Gyrohypnus + Xantholinus are very likely to be homoplastic. 
22 Neck: broad, usually $1 / 2$ the width of head or slightly wider $(0)$; distinctly narrower than $1 / 2$ head width (1); very broad, almost as wide as head without eyes (2). The apomorphic conditions are treated as discrete character states. In Gyrohypmus and Antarctothius, the neck is only slightly narrower than $1 / 2$ head width.

23 External face of metatibia: with several spines (0); at most with 1-2 spines (1); the character states in Atrecus and related genera on the one hand and Diochus and Antarctothius on the other hand are without doubt homoplastic.

24 Antesternal plate: absent (0); present (1).

25 Antesternal plate: distinctly sclerotized (0); semimembranous (1). The polarity of this character is doubtful, but the reverse alternative would be in conflict with character 22 .

26 Antesternal plate: undivided, \pm flattened (0); divided (1).

27 Antesternal plate: without median elevation (0); with median elevation (1).

28 Prosternum: basisternum with median carina, at least in posterior half $(0)$; without median carina, but posteriorly with weak elevation (1); without elevation or carina (2). The apomorphic conditions are treated as discrete character states. In the examined species of Philonthus, this character is somewhat intermediate between character states 0 and 1 and here treated as the plesiomorphic condition.

29 Prosternum: basisternum strongly transverse (0); basisternum weakly transverse (1). The polarity is much more parsimonious than the reverse alternative; the similar condition in Diochini and Lathrobium is consequently regarded as a homoplasy.

30 Mesosternal process: short (0); very long (1).

31 Mesosternal process: apically acute (0); apically rounded or obtuse (1).

32 Mesosternum: without or with very indistinct median carina (0); with distinct median carina (1). There is some doubt regarding the polarity of the presence/absence of a median carina, since this character is rather variable also in other staphylinid taxa. Here, the absence of such a carina is considered the plesiomorphic state for reasons of parsimony.

33 Mesosternum: of normal length (0); of reduced length (1).

34 Pronotum: without two distinct rows of dorsal punctures, but with \pm evenly distributed punctures (only median line free of punctures (0); with two rows of dorsal punctures, which may be reduced to various degrees (1). The dorsal punctation is composed of two rows of punctures in Othius, Atrecus, Diochus, and Quedius (1a), of two rows of 2 coarser dorsal punctures and numerous additional finer punctures in Caecolinus (1b), of two rows of 4 or more dorsal punctures in Parothius, Xantholinus, Gyrohypnus, and Antarctothius (1c), or reduced to one pair of dorsal punctures near anterior margin in Maorothius (1d). The pair of median dorsal punctures in two species of Maorothius is here considered an autapomorphy of those species. The number of dorsal punctures is subject to considerable intrageneric variation in Philonthus and Platyprosopus, but rather constant in the other genera examined. In Antarctothius fuegius, the dorsal rows are difficult to distinguish from the numerous additional punctures. As substates a - $d$ are subject to considerable intrageneric variation in some taxa and in conflict with several other characters, they are listed in Tab. 1, but excluded from the analysis and Fig. 1.

35 Elytra: inner margins not overlapping at suture (0); inner margins overlapping (1).

36 Abdominal sterna IV-VI: at most with weak basal impression (0); with distinct basal impression (1). 
37 Hind margin of $\sigma^{*}$ sternum VIII: \pm narrowly and triangularly emarginate $(0)$; weakly concave or \pm truncate (1); usually broadly concave, in the middle often convex and membranous (2); unmodified (3). The apomorphic conditions $1-3$ are treated as discrete states. The unmodified sternum VIII in Xantholinini is here regarded as an apomorphic reduction corresponding to the reduction of the median lobe; the truncate or convex hind margin in some Lathrobium is considered an autapomorphy of those species. There is some doubt whether the triangularly emarginate sternum VIII in Philonthus and Quedius really represents the ancestral condition, but a similarly shaped sternum VIII is also present in most Paederinae, Steninae, and many Tachyporinae. In Maorothius, the shape of sternum VIII is highly variable; the usual condition is a broadly concave hind margin, but in some species it is not or only weakly concave, with or without a convex protrusion in the middle, or it is \pm pointed in the middle. For reasons of parsimony, the similar condition in Diochini and Othiini is here considered homoplastic.

$38 \quad \sigma^{7}$ sternum IX: distinctly oblong (0); weakly oblong to transverse (1).

39 Hind margin of $\sigma^{*}$ sternum IX: simply convex, truncate or weakly concave, without dentate hind angles $(0)$; concave and with \pm dentate hind angles (1); deeply and narrowly bifid (2). The apomorphic conditions are treated as discrete states. The truncate or convex hind margin in some species of Othius is most likely to represent an autapormorphy of these species or species groups.

$40 \quad \sigma^{\pi}$ sternum IX, posterior pair of macrosetae: present $(0)$; without distinct pair of posterior macrosetae (1). The presence of a posterior pair of macrosetae is here considered to be the plesiomorphic concidition, as these macrosetae also occur in Omaliinae, some Tachyporinae, and some Paederinae. In the holotype of Antarctothius antarcticus, a posterior pair of macrosetae was absent, but they may have broken off; according to COIFFAIT \& SAIZ (1969) these macrosetae are present. The reduction of posterior macrosetae in some Maorothius is considered an autapomorphy of these species.

$41 \sigma^{x}$ sternum $I X$, posterior pair of macrosetae: insertions widely separated $(0)$; insertions narrowly separated (see e. g. Fig. 3b) (1).

42 of sternum IX: anteriorly simply tapering or truncate (0); anteriorly usually bifid (1). In some Othius species the $\sigma^{x}$ sternum IX is not bifid anteriorly; this condition, however, is without doubt apomorphic. Whether the same applies to the of sternum IX in Maorothius or whether it represents the ancestral state - as is assumed here fore reasons of parsimony - is somewhat doubtful. The similar condition in Othiini and in Diochini is without doubt homoplastic.

$43 \sigma^{x}$ sternum IX: without anteriorly converging longitudinal carinae $(0)$; with anteriorly converging carinae (paederine type) (1). The longitudinal carinae are present also in several other genera of Paederinae. The presence of this character state in Maorothius is remarkable, but unlikely to be homologous, because it would conflict with various other characters.

$44 \quad \sigma$ sternum IX: \pm symmetric (0); weakly to distinctly asymmetric (1).

$45 \quad \sigma^{\pi}$ tergal sclerites IX: dorsally fused (0); dorsally separated, distance between margins \pm gradually increasing posteriorly (1); dorsally separated, anteriorly \pm contiguous, margins \pm abruptly diverging posteriorly (2); dorsally widely separated by tergum $X$ (3). An - at least anteriorly - undivided tergum LX is here considered to represent the ancestral state, as this condition also occurs in Omaliinae, Steninae, Paederinae, and some Tachyporinae. As this character is subject to intrageneric variation in Atrecus and Maorothius, it is not accounted for these genera in Fig. 1. 
$46 \quad \sigma^{\prime \prime}$ and 9 tergal sclerites IX: apically without spine-like process (0); apically with spine-like process (1). The presence of such a process in some Eastern Palaearctic Othius is most likely a synapomorphy of that particular species group. There is some doubt regarding the polarity of this character among staphyliniform Staphylinidae. A spine-like process is usually absent in Omaliinae, Steninae, Tachyporinae, and Aleocharinae. In view of the other characters examined here, it seems likely that the presence of such a process in Paederinae, Diochus+Antarctothius, and Platyprosopus is the result of a parallel evolution rather than a synapomorphy of these taxa.

47 o tergum $\mathrm{X}$ : weakly to distinctly oblong, posteriorly convex (0); of triangular shape with truncate hind margin (1).

48 sternum IX: central sclerite long and distinctly sclerotized (0); central sclerite of reduced size and weakly sclerotized (1); central sclerite reduced (2); central sclerite broad, forming a plate posterior to lateral sclerites (3). The apomorphic conditions are treated as discrete states.

49 i sternum IX: lateral sclerites (valvifers) not contiguous or fused (0); lateral sclerites contiguous or fused (1). Both the contiguous lateral sclerites in some species of Maorothius and Gyrohypus and the fused sclerites in the brouni-group of Maorothius and in Xantholinus are without doubt homoplasies, as, in other respects, the general morphology of the + segment IX is completely different in these taxa. The conditions found in Maorothius and in Gyrohypus/Xantholinus are very likely to be the result of parallel evolutionary trends.

50 sternum IX: lateral sclerites apically with membranous extension carrying one terminal seta (1); lateral sclerites apically without long terminal seta (0). The similar condition in Othiini and Platyprosopini is apparently homoplastic.

51 क sternum IX: lateral sclerites apically without brush-like pubescence (0); lateral sclerites apically with brush-like pubescence (1).

52 i sternum IX: posterior portion of lateral sclerites styliform, \pm oval or round in crosssection (0); flattened in cross-section (1). The character states in Atrecus and related genera, Maorothius, and Lathrobium are not likely to be homologous, as this would conflict with various other characters. The styliform sclerites are here considered to represent the ancestral condition, because it also occurs in Omaliinae, Proteininae, and some Tachyporinae.

$53 \quad+$ tergum $\mathrm{X}$ : of normal size $(0)$; very small (1).

54 \& lateral tergal sclerites IX: fused $(0)$; separated, dorsal margins anteriorly \pm contiguous (1); dorsal margins anteriorly widely separated (2). For further details see character 42 .

55 Parameres of aedeagus: separate, \pm long and slender ( 0$)$; \pm fused (1); morphology strongly modified, flap-shaped (2); reduced (3). The apomorphic conditions $1-3$ are treated as discrete character states. The reductions in Lathrobium and Xantholinus are clearly homoplastic. Related Paederinae and Xantholinini, respectively, still possess parameres, and the morphology of the aedeagus is completely different in other respects.

56 Median lobe of aedeagus: weakly modified; apical part fully developed (0); strongly modified, apical part \pm reduced (1).

57 Median lobe of aedeagus: basal bulbus \pm symmetric $(0)$; asymmetric (1).

58 Median lobe of aedeagus: whole dorsal side membranous (0); dorsal part of bulbus \pm sclerotized (1); all of median lobe very weakly sclerotized (2). The apomorphic conditions 1 and 2 are treated as discrete character states. A dorsally \pm completely membranous median lobe also occurs in Omaliinae, Steninae, and Tachyporinae. 
59 Internal sac of median lobe: without distinct flagellum (0); with coiled flagellum (1).

60 Internal sac of median lobe: without Atrecus-type basal structure (0); with Atrecustype basal structure (1).

61 Internal sac of median lobe: without long series of sclerotized spines (0); with series of \pm sclerotized spines, which may be reduced in size and number to various extents (1); the presence of such series of spines in Xantholinus and Maorothius is clearly a homoplasy. The low number of spines in some Xantholinus and Maorothius is very likely to represent a secondary reduction.

62 Internal sac of median lobe: with 1-2 pairs of sclerotized or semitransparent structures and/or 1-2 additional median structures (1); without such structures (0); the characteristic apical internal structures in Diochus and Platyprosopus are very unlikely to be homologous to those in Othius and Parothius and are here considered homoplastic.

63 Spermatheca absent or not sclerotized (0); spermatheca long and thin (1).

64 "Bursa copulatrix": absent or not distinctly sclerotized (0); sclerotized (1). The absence of a distinctly sclerotized "bursa copulatrix" in some species of Maorothius is apparently a secondary reduction. Note that a sclerotized "bursa copulatrix" occurs in several genera of Xantholinini. For comments on the structures here termed "bursa copulatrix" see section 6.

65 Ecology: epigeic (0); corticolous or hypogean (1). The adaptation to a subterranean habitat in two species of Othius and two species of Atrecus is without doubt a result of convergent evolution. The phylogenetic relationship with Atrecus and Parothius, a similar evolutionary trend in Atrecus, and morphological evidence (reduced number of tibial spines) suggest that Caecolinus is derived from corticolous ancestors.

66 Distribution: predominantly tropical (1); temperate regions of northern hemisphere (2); temperate regions of southern hemisphere (3); character states only of Othiini, Diochini and Platyprosopini considered.

Tab. 1: Character matrix $(\mathrm{L}=$ logically impossible $)$

\begin{tabular}{|l|l|l|l|l|l|l|l|l|l|l|l|l|l|l|l|l|l|}
\hline Character & $\mathbf{1}$ & $\mathbf{2}$ & $\mathbf{3}$ & $\mathbf{4}$ & $\mathbf{5}$ & $\mathbf{6}$ & $\mathbf{7}$ & $\mathbf{8}$ & $\mathbf{9}$ & $\mathbf{1 0}$ & $\mathbf{1 1}$ & $\mathbf{1 2}$ & $\mathbf{1 3}$ & $\mathbf{1 4}$ & $\mathbf{1 5}$ & $\mathbf{1 6}$ & $\mathbf{1 7}$ \\
\hline Othius & 0 & 0 & 0 & 0 & 0 & 0 & 1 & 1 & 3 & 0 & 0 & 0 & 0 & 0 & 0 & 0 & 0 \\
\hline Atrecus & 1 & 0 & 0 & 0 & 0 & 0 & 1 & 1 & 2 & 0 & 1 & 0 & 0 & 0 & 0 & 0 & 1 \\
\hline Parothius & 1 & 0 & 0 & 1 & 0 & 0 & 1 & 1 & 2 & 0 & 1 & 0 & 0 & 0 & 0 & 0 & 1 \\
\hline Caecolinus & 1 & 0 & 0 & 2 & 1 & 0 & 1 & 1 & 2 & 0 & 1 & 0 & 1 & 0 & 1 & 0 & 1 \\
\hline Maorothius & 0 & 0 & 1 & 0 & 0 & 0 & $0-1$ & 0 & 0 & 0 & 0 & 0 & 0 & 0 & 0 & 1 & 0 \\
\hline Diochus & 2 & 0 & 0 & 0 & 0 & 1 & 1 & 0 & 4 & 0 & 0 & 0 & 2 & 1 & 2 & 0 & 0 \\
\hline Antarctothius & 0 & 0 & 1 & 0 & 0 & 0 & $0-1$ & 0 & 4 & 0 & 0 & 0 & 2 & 1 & 2 & 0 & 0 \\
\hline Platyprosopus & 0 & 1 & 0 & 0 & 0 & 0 & 1 & 0 & 0 & 1 & 0 & 1 & 0 & 0 & 3 & 0 & 0 \\
\hline Xantholinus & 2 & 0 & 0 & 2 & 0 & 0 & 1 & 1 & 1 & 0 & 0 & 0 & 0 & 0 & 1 & 2 & 0 \\
\hline Gyrohypnus & 0 & 1 & 0 & 2 & 0 & 0 & 1 & 1 & 1 & 0 & 0 & 0 & 0 & 0 & 1 & 2 & 0 \\
\hline Philonthus & $0-1$ & 0 & 0 & 0 & 0 & 0 & 1 & 0 & 3 & 1 & 0 & 0 & 0 & 0 & 0 & 0 & 0 \\
\hline Quedius & 0,3 & 0 & 0 & 0 & 0 & 0 & 0,1 & 0 & 0 & 1 & 0 & 0 & 0 & 0 & 0 & 0 & 0 \\
\hline Lathrobium & 0 & 0 & 0 & 0 & 0 & 0 & 0 & 0 & 1 & 0 & 2 & 2 & 1 & 0 & 2 & 0 & 0 \\
\hline
\end{tabular}

\begin{tabular}{|l|l|l|l|l|l|l|l|l|l|l|l|l|l|l|l|l|l|}
\hline Character & $\mathbf{1 8}$ & $\mathbf{1 9}$ & $\mathbf{2 0}$ & $\mathbf{2 1}$ & $\mathbf{2 2}$ & $\mathbf{2 3}$ & $\mathbf{2 4}$ & $\mathbf{2 5}$ & $\mathbf{2 6}$ & $\mathbf{2 7}$ & $\mathbf{2 8}$ & $\mathbf{2 9}$ & $\mathbf{3 0}$ & $\mathbf{3 1}$ & $\mathbf{3 2}$ & $\mathbf{3 3}$ & $\mathbf{3 4}$ \\
\hline Othius & 0 & 0 & 1 & 0 & 0 & 0 & 1 & 0 & 0 & 1 & 0 & 0 & 0 & 0 & 0 & 0 & $1 \mathrm{a}$ \\
\hline Atrecus & 0 & 0 & 1 & 1 & 0 & 1 & 1 & 0 & 0 & 0 & 0 & 0 & 1 & 0 & 1 & 0 & $1 \mathrm{a}$ \\
\hline Parothius & 0 & 0 & 1 & 1 & 0 & 1 & 1 & 0 & 0 & 0 & 0 & 0 & 1 & 0 & 1 & 0 & $1 \mathrm{c}$ \\
\hline Caecolinus & 0 & 0 & 1 & 1 & 0 & 1 & 1 & 0 & 0 & 0 & 0 & 0 & 1 & 0 & 1 & 0 & $1 \mathrm{~b}$ \\
\hline
\end{tabular}




\begin{tabular}{|l|l|l|l|l|l|l|l|l|l|l|l|l|l|l|l|l|l|}
\hline Maorothius & 1 & 0 & 1 & 0 & 0 & 0 & 1 & 0 & 0 & 0 & 1 & 0 & 0 & 0 & 0 & 0 & $1 \mathrm{~d}$ \\
\hline Diochus & 0 & 0 & 1 & 0 & 1 & 1 & 1 & 1 & 0 & 0 & 0 & 1 & 0 & 0 & 1 & 0 & $1 \mathrm{a}$ \\
\hline Antarctothius & 0 & 0 & 1 & 1 & 1 & 1 & 1 & 1 & 0 & 0 & 0 & 1 & 0 & 0 & 0 & 0 & $1 \mathrm{a}$ \\
\hline Platyprosopus & 0 & 0 & 1 & 2 & 2 & 0 & 0 & $\mathrm{~L}$ & $\mathrm{~L}$ & $\mathrm{~L}$ & 0 & 0 & 0 & 0 & 0 & 1 & $1 \mathrm{a}, \mathrm{c}, \mathrm{d}$ \\
\hline Xantholinus & 0 & 1 & 1 & 1 & 1 & 0 & 1 & 0 & 1 & 0 & 2 & 0 & 0 & 1 & 0 & 0 & $1 \mathrm{c}$ \\
\hline Gyrohypnus & 0 & 1 & 1 & 1 & 1 & 0 & 1 & 0 & 1 & 0 & 2 & 0 & 0 & 1 & 0 & 0 & $1 \mathrm{c}$ \\
\hline Philonthus & 0 & 0 & 1 & 0 & 0 & 0 & 0 & $\mathrm{~L}$ & $\mathrm{~L}$ & $\mathrm{~L}$ & $0-1$ & 0 & 0 & 0 & 0 & 0 & $1 \mathrm{a}-\mathrm{d}$ \\
\hline Quedius & 0 & 0 & 1 & 0 & 2 & 0 & 0 & $\mathrm{~L}$ & $\mathrm{~L}$ & $\mathrm{~L}$ & 0 & 0 & 0 & 0 & 0 & 0 & $1 \mathrm{a}$ \\
\hline Lathrobium & 0 & 0 & 0 & 0 & 0 & 0 & 0 & $\mathrm{~L}$ & $\mathrm{~L}$ & $\mathrm{~L}$ & 0 & 1 & 0 & 0 & 1 & 0 & 0 \\
\hline
\end{tabular}

\begin{tabular}{|l|l|l|l|l|l|l|l|l|l|l|l|l|l|l|l|l|l|}
\hline Character & $\mathbf{3 5}$ & $\mathbf{3 6}$ & $\mathbf{3 7}$ & $\mathbf{3 8}$ & $\mathbf{3 9}$ & $\mathbf{4 0}$ & $\mathbf{4 1}$ & $\mathbf{4 2}$ & $\mathbf{4 3}$ & $\mathbf{4 4}$ & $\mathbf{4 5}$ & $\mathbf{4 6}$ & $\mathbf{4 7}$ & $\mathbf{4 8}$ & $\mathbf{4 9}$ & $\mathbf{5 0}$ & $\mathbf{5 1}$ \\
\hline Othius & 0 & 0 & 1 & 0 & 1 & 0 & 0 & 1 & 0 & 0 & 2 & 0 & 0 & 0 & 0 & 1 & 0 \\
\hline Atrecus & 0 & 0 & 1 & 0 & 0 & 0 & 0 & 1 & 0 & 0 & $0-2$ & 0 & 0 & 1 & 0 & 1 & 0 \\
\hline Parothius & 0 & 0 & 1 & 0 & 0 & 0 & 0 & 1 & 0 & 0 & 0 & 0 & 0 & 1 & 0 & 1 & 0 \\
\hline Caecolinus & 0 & 1 & 1 & 0 & 0 & 0 & 0 & 1 & 0 & 0 & 0 & 0 & 0 & $?$ & $?$ & $?$ & 0 \\
\hline Maorothius & 0 & 0 & 2 & 0 & 0 & 0 & 1 & 0 & 1 & 1 & 0,1 & 0 & 0 & 2 & 1 & 0 & 0 \\
\hline Diochus & 0 & 0 & 1 & 0 & 0 & 0 & 0 & 1 & 0 & 0 & 2 & 1 & 0 & 1 & 0 & 0 & 1 \\
\hline Antarctothius & 0 & 0 & 1 & 0 & 0 & 0 & 0 & 1 & 0 & 0 & 2 & 1 & 0 & 2 & 0 & 0 & 0 \\
\hline Platyprosopus & 0 & 0 & 1 & 0 & 0 & 0 & 0 & 0 & 0 & 0 & 1 & 1 & 0 & 2 & 0 & 1 & 0 \\
\hline Xantholinus & 1 & 0 & 3 & 1 & 0 & 1 & $\mathrm{~L}$ & 0 & 0 & 0 & 2 & 0 & 1 & 3 & 1 & 0 & 0 \\
\hline Gyrohypnus & 1 & 0 & 3 & 1 & 0 & 1 & $\mathrm{~L}$ & 0 & 0 & 0 & 2 & 0 & 0 & 3 & 1 & 0 & 0 \\
\hline Philonthus & 0 & 0 & 0 & 0 & 2 & 0 & 0 & 0 & 0 & 0 & 3 & 0 & 0 & 2 & 0 & 0 & 0 \\
\hline Quedius & 0 & 0 & 0 & 0 & 0 & 0 & 0 & 0 & 0 & 0 & 3 & 0 & 0 & 2 & 0 & 0 & 0 \\
\hline Lathrobium & 0 & 0 & 0 & 0 & 0 & 1 & $\mathrm{~L}$ & 0 & 1 & 0 & 0 & 1 & 0 & 0 & 0 & 0 & 0 \\
\hline
\end{tabular}

\begin{tabular}{|l|l|l|l|l|l|l|l|l|l|l|l|l|l|l|l|}
\hline Character & $\mathbf{5 2}$ & $\mathbf{5 3}$ & $\mathbf{5 4}$ & $\mathbf{5 5}$ & $\mathbf{5 6}$ & $\mathbf{5 7}$ & $\mathbf{5 8}$ & $\mathbf{5 9}$ & $\mathbf{6 0}$ & $\mathbf{6 1}$ & $\mathbf{6 2}$ & $\mathbf{6 3}$ & $\mathbf{6 4}$ & $\mathbf{6 5}$ & $\mathbf{6 6}$ \\
\hline Othius & 0 & 0 & 1 & 0 & 0 & 1 & 1 & 1 & 0 & 0 & 1 & 0 & 0 & 0,2 & 2 \\
\hline Atrecus & 1 & 0 & $0-1$ & 0 & 0 & 1 & 1 & 1 & 1 & 0 & 0 & 0 & 0 & 1,2 & 2 \\
\hline Parothius & 1 & 0 & 0 & 0 & 0 & 1 & 1 & 1 & 1 & 0 & 1 & 0 & 0 & 1 & 2 \\
\hline Caecolinus & $?$ & $?$ & $?$ & 0 & 0 & 1 & 1 & 1 & 1 & 0 & 0 & 0 & 0 & 2 & 2 \\
\hline Maorothius & 1 & 1 & 0 & 0 & 0 & 0 & 1 & 0 & 0 & 1 & 0 & 0 & $0-1$ & $0 ?$ & 3 \\
\hline Diochus & 0 & 0 & 2 & 0 & 0 & 0 & 2 & 0 & 0 & 0 & 1 & 1 & 0 & 0 & 1 \\
\hline Antarctothius & 0 & 0 & 0 & 0 & 0 & 0 & 0 & 0 & 0 & 0 & 0 & 0 & 0 & 0 & 3 \\
\hline Platyprosopus & 0 & 0 & 1 & 0 & 0 & 0 & 0 & 0 & 0 & 0 & 1 & 0 & 0 & 0 & 1 \\
\hline Xantholinus & $\mathrm{L}$ & 1 & 0 & 3 & 1 & 0 & $\mathrm{~L}$ & 0 & 0 & 1 & 0 & 0 & 0 & 0 & \\
\hline Gyrohypnus & 0 & 1 & 0 & 2 & 1 & 0 & $\mathrm{~L}$ & 0 & 0 & 0 & 0 & 0 & 0 & 0 & \\
\hline Philonthus & 0 & 0 & 2 & 1 & 0 & 0 & 0 & 0 & 0 & 0 & 0 & 0 & 0 & 0 & \\
\hline Quedius & 0 & 0 & 2 & 1 & 0 & 0 & 0 & 0 & 0 & 0 & 0 & 0 & 0 & 0 & \\
\hline Lathrobium & 1 & 0 & 0 & 3 & 0 & 0 & 0 & 0 & 0 & 0 & 0 & 0 & 0 & 0 & \\
\hline
\end{tabular}

\section{Discussion}

Based on the character states selected and the polarities discussed above, several phylogenetic trees were sketched based on hand analysis and compared. After appropriate character weighting the dendrogram shown in Fig. 1 appears to be the most plausible. The tree, however, is inadequate for an evaluation of the phylogenetics of Staphylininae as a whole, due to a bias resulting from the mode of character selection (see introduction to this chapter), which is one of the reasons why some of the basal staphylinine lineages seem to be weakly supported.

The dendrogram is based on the assumption of various homoplastic trends. However, considering the large number of taxa and the morphological diversity in Staphylininae and Paederinae, this is what is to be expected rather than particularly surprising. Without doubt, there would be even more homoplasies if the number of paederine (or staphylinine) taxa included in the analysis was raised. 


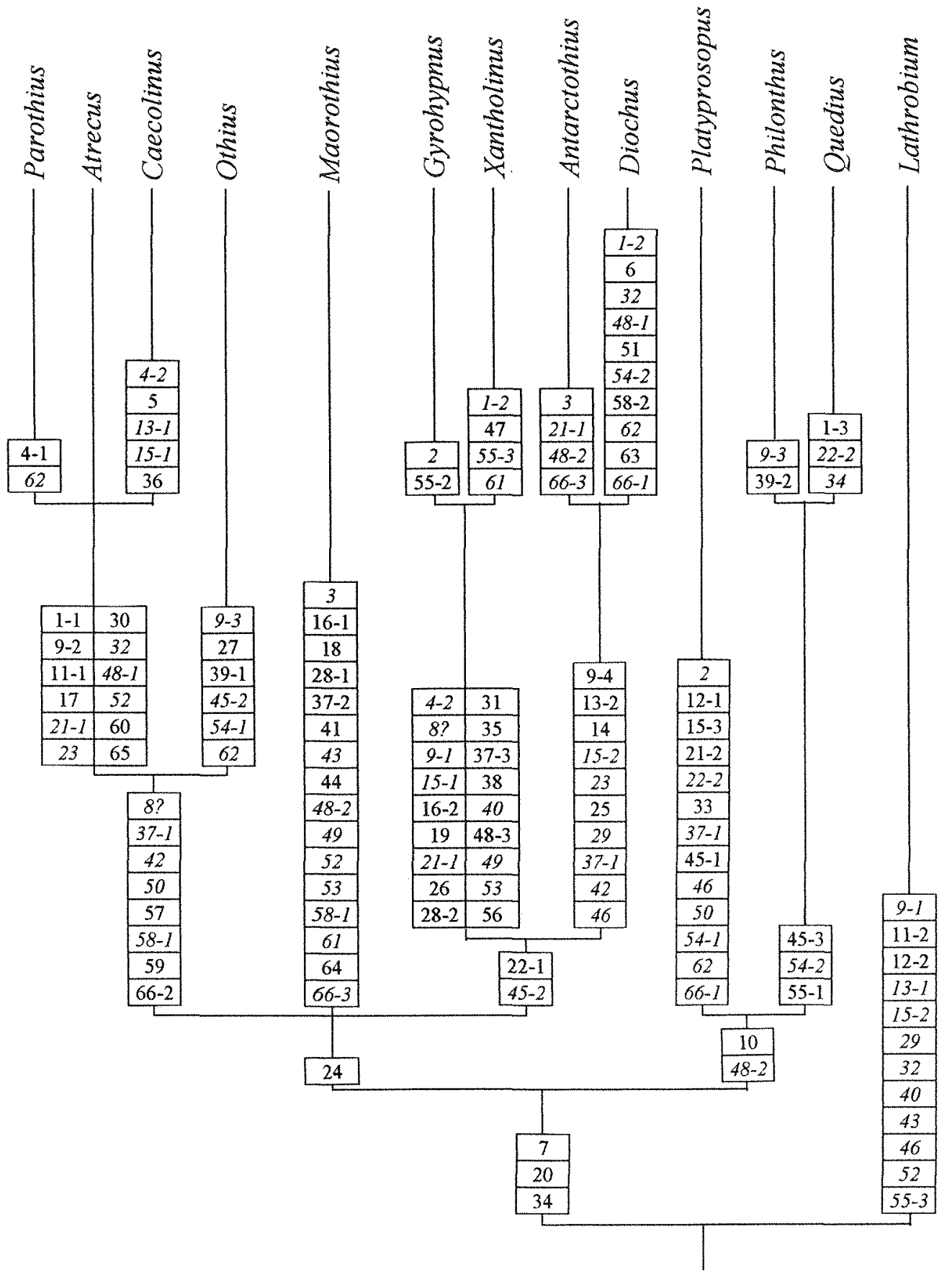

Fig. 1: Phylogenetic tree of Staphylininae based on the character matrix in Tab. 1. Homoplasies are given in italics. 
Part of the characters used in the phylogenetic analysis are multistate characters which do not reflect evolutionary trends, but are (or had to be) treated as discrete conditions, either because too little is known about how one condition has evolved from another or, above all, because an ancestral condition has evolved into different (often opposing) directions. In the latter case, breaking down a multistate character to subsets of two character states would have resulted in a loss of information (see e. g. character 1).

Three of the characters considered (no. 7, 20,34) can be regarded as synapomorphies supporting the monophyly of Staphylininae. A closer relationship between Platyprosopini and Staphylinini, as suggested in Fig. 1, is only weakly supported and probably due to a bias resulting from the mode of character selection (see above). Diochini, Xantholinini, and Othiini are obviously monophyla each constituted by numerous synapomorphies. However, apart from characters 22-1 and 45-2, which may be synapomorphies shared by Diochini and Xantholinini, the phylogenetic analysis did not produce any convincing evidence supporting a sister group relationship between any of these taxa. The only synapomorphy constituting a monophyly of the former xantholinine tribes Othiini, Xantholinini, Diochini, and, in addition, Maorothius is the presence of an antesternal plate (character 24). NEWTON's (1985) proposal to place Antarctothius, which had previously been attributed to Othiini, in Diochini is here confirmed.

Several synapomorphies were found to constitute the monophylum Othiini, a Holarctic tribe including four genera. The relative large Palaearctic genus Othius is characterized by several synapomorphies, in particular the deeply divided labrum, a divided antesternal plate, the punctation of the pronotum, the shape of the o ternum IX and further primary and secondary sexual characters. It represents the adelphotaxon of the monophylum Atrecus + Parothius + Caecolinus, which is constituted by rather numerous apomorphic characters (Fig. 1). No convincing evidence clarifying the phylogenetic relationships within this monophylum was found, apart from the distribution, which would suggest a closer relationship between the Holarctic genus Atrecus and the W-Palaearctic genus Caecolinus; hence the polytomy. Caecolinus is apparently a relict taxon distinguished from other Othiini by several derived character states.

The New Zealand species previously attributed to Othius (because of their superficial resemblance) form a distinct monophylum constituted by numerous synapomorphies (see also description of Maorothiini below). As is shown in Fig. 1, it can be regarded as certain that including these species in Othius would render the genus a polyphyletic taxon. Moreover, there is reasonable doubt that the New Zealand "Othius" should be the adelphotaxon of Othiini. Apart from a first-glance external resemblance, only character 58-1 would link Maorothius with Othiini, whereas various other characters (e. g. 3, 43, 48-2, 53, 66) would suggest closer relationships with other staphylinine lineages, especially Xantholinini, Antarctothius, Platyprosopini, or even Lathrobium; the similar morphology of the of ternum IX in Lathrobium (and other Paederinae) and Maorothius is indeed remarkable. Maorothius differs in so many significant characters (especially the mouthparts, terminalia, primary sexual characters) that even if they were the adelphotaxon of Othiini, attributing them to a distinct tribe appears to be justified. In view of this and the risk of rendering Othiini a polyphyletic taxon, it seems best to refer Maorothius to a distinct tribe. This conclusion would also be supported by biogeographic arguments. According to Crowson (1981), "the New Zealand fauna is notable for the present of evidently ancient relict types, without close relatives elsewhere in the modern world" (p. 640) and shows the closest affinities to the Australian, temperate South American and New Caledonian fauna. Othiini, as defined here, however, are absent from these regions and confined to the Holarctic realm. There are only very few examples of amphipolar distributions in Staphylinidae. CROwSON (1980) indicates such a distribution pattern merely for Coprophilini of the Oxytelinae, Siagoniini of the Piestinae, Gymnusini of the Aleocharinae, and possibly also 
Pseudopsinae. The conclusion that Maorothius is indeed a very old relict is not only suggested by its distribution, but also by its remarkable morphological diversity (particularly in the genital segments, see phylogenetic analysis of Maorothius below), which is comparable to intergeneric diversity in many other staphylinid taxa.

\section{Maorothiini trib. $n$.}

Type genus: Maorothius gen. $\mathrm{n}$.

\section{Description}

Among the Staphylininae, the monophylum Marothiini is characterized by the following apomorphies (for further morphological details see description of Maorothius gen. n.):

Integument of head and pronotum with distinctly isodiametric microsculpture and therefore \pm mat. Gular sutures in posterior half of head \pm contiguous, posteriorly not or only weakly diverging. Antennae short, usually ca. 1.5x longer than head width, only exceptionally longer. Prosternum without median carina, but posteriorly with weak elevation.

$\sigma^{x}$ : sternum VIII posteriorly usually broadly concave (ancestral condition), sometimes in the middle convex or otherwise modified (derived condition); sternum IX weakly to strongly asymmetric, with anteriorly converging carinae (paederine type), posterior pair of macrosetae usually present (rarely reduced), their insertions narrowly separated; median lobe of aedeagus with dorsal face of bulbus \pm sclerotized; internal sac of median lobe with series of \pm sclerotized spines, which may be reduced in size and number to various extents.

\$: central sclerite of sternum IX reduced; lateral sclerites (valvifers) of sternum IX contiguous or fused, flattened in cross-section; tergum X very small; "bursa copulatrix" partly or completely sclerotized (ancestral condition) or unsclerotized (derived condition).

\section{Systematics and distribution}

Maorothiini trib. $n$. is attributed to the subfamily Staphylininae; for details see section 3 . The known distribution of the new tribe is confined to New Zealand.

\section{Comparative notes}

In addition to the characters indicated in the description, Maorothiini are distinguished from other staphylinine tribes as follows:

In the Holarctic Othiini, the frontal furrows are usually distinct, the anterior margin of the labrum is emarginate or strongly incised, the o ternum IX is anteriorly usually bifid, the basal bulbus of the median lobe of the aedeagus is asymmetric, the internal sac of the median lobe contains a flagellum and further structures of different morphology and arrangement, and the lateral sclerites of the $o$ ternum IX have an apical membranous extension carrying one terminal seta.

In Xantholinini, the anterior margin of the frons between the antennal insertions has a distinct protrusion, the anterior margin of the labrum is moderately emarginate, the labial palpi are of different morphology, the gular sutures are fused, the antennae are geniculate, the preapical antennomeres are usually distinctly transverse, the neck is narrower, the antesternal plate is divided, the basisternum of the prosternum is flattened, the inner margins of the elytra overlap at the suture, the $\sigma^{x}$ sternum VIII is unmodified, the $\sigma^{x}$ tergal sclerites IX are dorsally separated, anteriorly contiguous and posteriorly abruptly diverging, the $\sigma^{*}$ sternum IX is weakly oblong to transverse and has no posterior pair of macrosetae, the aedeagus is of completely different morphology (parameres and median lobe strongly modified or completely reduced, and the central sclerite of the $q$ sternum IX forms a broad plate posterior to the lateral sclerites. 
In Diochini, the anterior angles of the labrum are indistinct, the maxillary palpi have a fine and dense pubescence, the neck is narrower, the exterior face of the metatibia has at most $1-2$ spines, the antesternal plate is \pm membranous, the basisternum of the prosternum is weakly transverse, the tergal sclerites IX have a spine-like process apically, the $\sigma^{*}$ sternum VIII is truncate or weakly concave posteriorly, the $\sigma^{x}$ sternum IX is anteriorly bifid, and the aedeagus is of different morphology.

In Staphylinini, the labrum has a membranous extension, the antesternal plate is absent, the tergal sclerites IX are dorsally widely separated by tergum $X$, and the morphology of the aedeagus is different (usually \pm fused parameres, internal structures of different morphology and arrangement).

In Platyprosopini, the punctation of the head is different, the apical segment of the maxillary and labial palpi is truncate, antennomere $\mathrm{X}$ is \pm oblong and flattened, the neck is very wide, the antesternal plate is absent, the mesosternum is shorter, the tergal sclerites IX have a spine-like apical process, the hind margin of the $\sigma^{7}$ sternum VIII is truncate or weakly concave, the internal structures of the aedeagus are of different morphology and arrangement, the $q$ tergal sclerites IX are separated, and the lateral sclerites of the + sternum IX have a membranous extension carrying one terminal seta.

\section{Phylogenetic analysis of Maorothiini}

Although a sister group relationship is uncertain, Othiini were chosen as outgroup to determine character polarity. In addition, other tribes of Staphylininae (see above) were considered, especially when in doubt that the respective condition in Othiini really represents the plesiomorphic character state.

1 Size moderate to moderately large (0); large to very large (1).

2 Frontal punctures: present (0); absent (1).

3 Punctation of dorsal surface of head and of postgenae: absent or very sparse (0); many punctures present (1). The polarity of this character is somewhat doubtful, as it is rather variable in other tribes of Staphylininae. Here, the presence of numerous punctures is regarded as the derived condition for reasons of parsimony.

4 Postocular puncture: present (0); absent (1).

5 Pronotum without pair of median punctures $(0)$; with pair of median punctures (1). This character, too, is rather variable in other Staphylininae. However, these punctures are present only in three closely related species of Maorothius and are consequently highly likely to represent the apomorphic character state. The missing punctures in part of the material of $M$. tridens is evidently a secondary reduction; the species is therefore attributed the derived condition.

6 Elytra relatively long, hind wings fully developed $(0)$; elytra short, hind wings reduced (1). The reduction of hind wings is known to have occurred independently in numerous taxa of Staphylinidae and is therefore of little phylogenetic significance.

7 Hind margin of abdominal tergum VII: palisade fringe present (0); absent (1). Here, the same applies as to character 6.

8 Hind margin of $\sigma^{\pi}$ sternum VII: without crista of spine-like setae (0); with crista(e) of spine-like setae (1).

$9 \quad$ Hind margin of $\sigma^{4}$ sternum VII: with one central crista of spine-like setae (0); with pair of cristae of spine-like setae (1). 
Hind margin of $\sigma^{*}$ sternum VII: \pm truncate, at most very weakly concave $(0)$; distinctly concave (1). The derived character states in $M$. adustus and related species on the one hand, and in $M$. coalitus and $M$. tridens on the other hand represent without doubt homoplasies.

1 Hind margin of $o^{x}$ sternum VII: pubescence \pm unmodified $(0)$; near posterior margin with dense stout setae (1). The derived character state in $M$. pectinatus is most likely an autapomorphy of that species.

2 Hind margin of $\sigma^{7}$ sternum VIII, basic outline (i. e. regardless of any modifications of middle): weakly concave, weakly convex, or \pm truncate $(0)$; moderately concave (1); broadly and deeply concave (2); distinctly convex (3). The derived character states in $M$. effeminatus and $M$. dispar are without doubt homoplastic.

13 Hind margin of $\sigma^{\pi}$ sternum VIII: middle not pointed or distinctly convex $(0)$; middle pointed or distinctly convex (1).

14 or sternum VIII: without extensive patterns of stout setae $(0)$; with dense stout setae at least near hind angles (1).

$\sigma^{\pi}$ sternum VIII: with dense stout setae at least near hind angles $(0)$; with dense stout setae on practically whole surface, at least in posterior half (1). M. brookesi, which is somewhat intermediate and variable in this respect, is attributed the plesiomorphic condition.

16 of sternum VIII: without pair of comb-like rows of stout setae (0); with pair of comblike rows of stout setae (1).

$17 \sigma^{\pi}$ sternum VIII: hind angles without hook-like processes $(0)$; with hook-like processes (1); with long brush-like processes (2). $\sigma^{x}$ sternum IX: \pm symmetric (0); asymmetric (1). $\sigma^{*}$ sternum IX: posterior pair of macrosetae present (0); absent (1).

$\sigma^{\prime}$ sternum IX: median pair of macrosetae present $(0)$; absent $(1)$; with numerous macrosetae (2). The absence of the macrosetae is here considered the plesiomorphic condition, as these setae are usually present in Othiini. There is, however, some doubt regarding the polarity of this character. $M$. brookesi, in which the median pair of macrosetae may occasionally be missing, is attributed the plesiomorphic condition. $\sigma^{\prime \prime}$ tergal sclerites fused, tergum $X$ not or only weakly oblong $(0)$; tergal sclerites separated, tergum $X$ distinctly oblong (1).

2 Aedeagus: parameres long (0); parameres of distinctly reduced length (1). For reasons of parsimony, the condition in $M$. pectinatus is here regarded as a secondary reappearance of the plesiomorphic character state.

24 Aedeagus: parameres weakly asymmetric (0); distinctly asymmetric (1). Whether the weakly asymmetric parameres in $M$. pectinatus represents the ancestral or a secondary return to the plesiomorphic condition is uncertain. It is here treated as plesiomorphic.

25 Aedeagus: parameres with thin, usually rather long apical setae (0); with stout short apical setae (1).

26 Aedeagus: parameres without subapical setae (0); with subapical setae (1). Subapical setae are usually absent in Othiini.

27 Median lobe of aedeagus: of normal relative size, approximately as long as head width or slightly $(<1.25 \mathrm{x})$ longer $(0)$; of reduced size, much shorter than head width (1); very large, approximately $1.5 x$ longer than head width (2).

Median lobe of aedeagus: \pm symmetric (0); distinctly asymmetric (1). 
29 Aedeagus, ventral process of median lobe: relatively short, at most only weakly bent (0); very long and distinctly bent (1).

30 Aedeagus, ventral process of median lobe: lateral parts dorsally not contiguous (0); lateral parts dorsally contiguous (1).

31 Aedeagus, ventral process of median lobe (ventral view): apex pointed in the middle $(0)$; apically \pm obliquely truncate, sometimes pointed laterally (1); apically with torsion (2); apically strongly bent and rounded (3). The pointed apex in $M$. insulanus is very unlikely to represent the plesiomorphic state. It is uncertain if the pointed median lobe in $M$. volans represents the plesiomorphic or a secondary return to the ancestral condition. It is here treated as plesiomorphic. The strongly modified apex of the ventral process in $M$. puncticeps is here regarded as derived from the obliquely truncate condition in its closest relatives.

32 Aedeagus: base of bulbus in lateral view \pm evenly convex (0); base of bulbus in lateral view moderately to strongly projecting ventrally (1).

33 Aedeagus, internal sac: with relatively large, \pm sclerotized spines $(0)$; without large sclerotized spines, but usually with numerous small semitransparent spines (1); (almost) completely without appreciable internal structures (2).

34 Aedeagus, internal sac: with \pm short series of spines $(0)$; with long and mostly \pm coiled series of numerous spines (1).

35 Aedeagus, internal sac: with long and mostly \pm coiled series of moderately numerous spines $(0)$; with long and mostly \pm coiled series of extremely numerous spines (1).

36 o sternum VIII: \pm truncate to moderately convex $(0)$; obtusely pointed, sometimes with weak central emargination (1); distinctly pointed, without central emargination (2). Character states 1-2 do not represent an evolutionary trend.

37 क sternum IX: valvifers contiguous (0); valvifers fused (1).

38 \& sternum IX: valvifers fused, suture visible (0); valvifers fused, suture obsolete (1).

39 "Bursa copulatrix": at most, only posterior parts \pm sclerotized (0); extensively sclerotized (1).

40 Distribution: North Island, south to Wanganui (1); South Island and extreme south of North Island (Wellington) (2). Apparently, the zoogeographic border separating the species of the $M$. brouni group, which is constituted by several derived characters and which doubtlessly forms a monophylum, and $M$. dispar from the remainder of $M a O-$ rothius is not the Cook Strait, but in the south of the North Island. $M$. coalitus, which is phylogenetically affiliated to the species from the North Island, is the only species occurring on both sides of this border.

Tab. 2: Character matrix for phylogenetic analysis of Maorothini ( $\mathrm{L}=$ logically impossible)

\begin{tabular}{|l|l|l|l|l|l|l|l|l|l|l|l|l|l|l|}
\hline Character & $\mathbf{1}$ & $\mathbf{2}$ & $\mathbf{3}$ & $\mathbf{5}$ & $\mathbf{5}$ & $\mathbf{6}$ & $\mathbf{7}$ & $\mathbf{8}$ & $\mathbf{9}$ & $\mathbf{1 0}$ & $\mathbf{1 1}$ & $\mathbf{1 2}$ & $\mathbf{1 3}$ & $\mathbf{1 4}$ \\
\hline adustus & 1 & 1 & 0 & 0 & 0 & 1 & 1 & 0 & $\mathrm{~L}$ & 1 & 1 & 2 & 0 & 1 \\
\hline hamifer & 1 & 1 & 0 & 0 & 0 & 1 & 1 & 0 & $\mathrm{~L}$ & 1 & 1 & 2 & 0 & 1 \\
\hline setiger & 1 & 1 & 0 & 0 & 0 & 1 & 1 & 0 & $\mathrm{~L}$ & 1 & 1 & 2 & 0 & 1 \\
\hline longispinosus & 1 & 1 & 0 & 0 & 0 & 1 & 1 & 0 & $\mathrm{~L}$ & 1 & 1 & 2 & 0 & 1 \\
\hline brevispinosus & 1 & 1 & 0 & 0 & 0 & 1 & 1 & 0 & $\mathrm{~L}$ & 1 & 1 & 2 & 0 & 1 \\
\hline insulanus & 1 & 1 & 0 & 0 & 0 & 1 & 1 & 0 & L & 1 & 1 & 2 & 0 & 1 \\
\hline brookesi & 1 & 1 & 0 & 0 & 0 & 1 & 1 & 0 & L & 0 & 0 & 2 & 0 & 1 \\
\hline hammondi & 1 & 1 & 0 & 0 & 0 & 1 & 1 & 0 & L & 0 & 0 & 2 & $0-1$ & 1 \\
\hline pubescens & 1 & 1 & 0 & 0 & 0 & 1 & 1 & 0 & L & 0 & 0 & 2 & 0 & 0 \\
\hline effeminatus & 1 & 1 & 0 & 0 & 0 & 1 & 1 & 0 & L & 0 & 0 & 3 & 1 & 0 \\
\hline pectinatus & 1 & 1 & 0 & 0 & 0 & 1 & 1 & 0 & L & 0 & 1 & 0 & 0 & 0 \\
\hline
\end{tabular}




\begin{tabular}{|l|l|l|l|l|l|l|l|l|l|l|l|l|l|l|}
\hline puncticeps & 0 & 0 & 1 & 0 & 1 & 1 & 1 & 0 & $\mathrm{~L}$ & 0 & 0 & 1 & 0 & 0 \\
\hline coalitus & 0 & 0 & 1 & 0 & 1 & 1 & 1 & 0 & $\mathrm{~L}$ & 1 & 0 & 1 & 1 & 0 \\
\hline tridens & 0 & 0 & 1 & 0 & 1 & 1 & 1 & 0 & $\mathrm{~L}$ & 1 & 0 & 0 & 0 & 0 \\
\hline volans & 0 & $0 ?$ & 1 & 0 & 0 & 0 & 0 & 0 & $\mathrm{~L}$ & 0 & 0 & 0 & 0 & 0 \\
\hline dispar & 0 & 1 & 0 & 1 & 0 & 1 & 1 & 0 & $\mathrm{~L}$ & 0 & 0 & 3 & 1 & 0 \\
\hline brouni & 0 & 1 & 0 & 0 & 0 & 1 & 1 & 1 & 1 & 0 & 0 & 1 & 1 & 0 \\
\hline torquatus & 0 & 1 & 0 & 0 & 0 & 1 & 1 & 1 & 0 & 0 & 0 & 1 & 1 & 0 \\
\hline tonsor & 0 & 1 & 0 & 0 & 0 & 1 & 1 & 1 & 0 & 0 & 0 & 1 & 1 & 0 \\
\hline solus & 0 & 1 & 0 & 0 & 0 & 1 & 1 & 1 & 0 & 0 & 0 & 1 & 1 & 0 \\
\hline
\end{tabular}

\begin{tabular}{|l|l|l|l|l|l|l|l|l|l|l|l|l|l|l|}
\hline Character & $\mathbf{1 5}$ & $\mathbf{1 6}$ & $\mathbf{1 7}$ & $\mathbf{1 8}$ & $\mathbf{1 9}$ & $\mathbf{2 0}$ & $\mathbf{2 1}$ & $\mathbf{2 2}$ & $\mathbf{2 3}$ & $\mathbf{2 4}$ & $\mathbf{2 5}$ & $\mathbf{2 6}$ & $\mathbf{2 7}$ & $\mathbf{2 8}$ \\
\hline adustus & 0 & 0 & 1 & 1 & 0 & 1 & 0 & 1 & 1 & 1 & 0 & 0 & 1 & 1 \\
\hline hamifer & 0 & 0 & 1 & 1 & 0 & 1 & 0 & 1 & 1 & 1 & 0 & 0 & 1 & 1 \\
\hline setiger & 1 & 0 & 0 & 1 & 0 & 1 & 0 & 1 & 1 & 1 & 0 & 0 & 1 & 1 \\
\hline longispinosus & 1 & 0 & 0 & 1 & 0 & 1 & 0 & 1 & 1 & 1 & 0 & 0 & 0 & 1 \\
\hline brevispinosus & 1 & 0 & 0 & 1 & 0 & 1 & 0 & 1 & 1 & 1 & 0 & 0 & 0 & 1 \\
\hline insulanus & 1 & 0 & 0 & 1 & 0 & 1 & 0 & 1 & 1 & 1 & 0 & 0 & 0 & 1 \\
\hline brookesi & $0-1$ & 0 & 0 & 1 & 0 & 0 & 0 & 1 & 1 & 1 & 0 & 0 & 0 & 1 \\
\hline hammondi & 0 & 0 & 0 & 1 & 0 & 0 & 0 & 1 & 1 & 1 & 0 & 0 & 0 & 1 \\
\hline pubescens & $\mathrm{L}$ & 0 & 0 & 1 & 0 & 0 & 0 & 1 & 1 & 1 & 0 & 0 & 0 & 1 \\
\hline effeminatus & $\mathrm{L}$ & 0 & 0 & 1 & 0 & 0 & 0 & 1 & 1 & 1 & 0 & 0 & 0 & 1 \\
\hline pectinatus & $\mathrm{L}$ & 1 & 2 & 1 & 0 & 0 & 0 & 0 & 1 & 0 & 0 & 0 & 1 & 1 \\
\hline puncticeps & $\mathrm{L}$ & 0 & 0 & 1 & 1 & 0 & 0 & 1 & 1 & 1 & 0 & 0 & 0 & 1 \\
\hline coalitus & $\mathrm{L}$ & 0 & 0 & 1 & 1 & 1 & 0 & 1 & 1 & 1 & 0 & 0 & 0 & 1 \\
\hline tridens & $\mathrm{L}$ & 0 & 0 & 1 & 1 & 0 & 0 & 1 & 1 & 1 & 0 & 0 & 0 & 1 \\
\hline volans & $\mathrm{L}$ & 0 & 0 & 1 & 1 & 2 & 0 & 0 & 1 & 0 & 0 & 1 & 1 & 1 \\
\hline dispar & $\mathrm{L}$ & 0 & 0 & 1 & 1 & 1 & 1 & 0 & 1 & 0 & 1 & 0 & 0 & 1 \\
\hline brouni & $\mathrm{L}$ & 0 & 0 & 0 & 0 & 1 & 1 & 0 & 0 & $\mathrm{~L}$ & 0 & 1 & 2 & 0 \\
\hline torquatus & $\mathrm{L}$ & 0 & 0 & 0 & 0 & 1 & 1 & 0 & 0 & $\mathrm{~L}$ & 0 & 1 & 2 & 0 \\
\hline tonsor & $\mathrm{L}$ & 0 & 0 & 0 & 0 & 1 & 1 & 0 & 0 & $\mathrm{~L}$ & 0 & 1 & 2 & 0 \\
\hline solus & $\mathrm{L}$ & 0 & 0 & 0 & 1 & 1 & 1 & 0 & 0 & $\mathrm{~L}$ & 0 & 1 & 2 & 0 \\
\hline
\end{tabular}

\begin{tabular}{|l|l|l|l|l|l|l|l|l|l|l|l|l|}
\hline Character & $\mathbf{2 9}$ & $\mathbf{3 0}$ & $\mathbf{3 1}$ & $\mathbf{3 2}$ & $\mathbf{3 3}$ & $\mathbf{3 4}$ & $\mathbf{3 5}$ & $\mathbf{3 6}$ & $\mathbf{3 7}$ & $\mathbf{3 8}$ & $\mathbf{3 9}$ & $\mathbf{4 0}$ \\
\hline adustus & 0 & 0 & 1 & 1 & 1 & 0 & $\mathrm{~L}$ & 0 & 0 & $\mathrm{~L}$ & $?$ & 1 \\
\hline hamifer & 0 & 0 & 1 & 1 & 1 & 0 & $\mathrm{~L}$ & $?$ & $?$ & $\mathrm{~L}$ & $?$ & 1 \\
\hline setiger & 0 & 0 & 1 & 1 & 1 & 0 & $\mathrm{~L}$ & 0 & 0 & $\mathrm{~L}$ & 0 & 1 \\
\hline longispinosus & 0 & 0 & 1 & 1 & 0 & 0 & $\mathrm{~L}$ & 0 & 0 & $\mathrm{~L}$ & $?$ & 1 \\
\hline brevispinosus & 0 & 0 & 1 & 1 & 0 & 0 & $\mathrm{~L}$ & $?$ & $?$ & $\mathrm{~L}$ & $?$ & 1 \\
\hline insulanus & 0 & 0 & 0 & 1 & 0 & 0 & $\mathrm{~L}$ & 1 & 0 & $\mathrm{~L}$ & 0 & 1 \\
\hline brookesi & 0 & 0 & 1 & 1 & 0 & 0 & $\mathrm{~L}$ & 2 & 0 & $\mathrm{~L}$ & 0 & 1 \\
\hline hammondi & 0 & 0 & 1 & 1 & 0 & 0 & $\mathrm{~L}$ & $?$ & $?$ & $\mathrm{~L}$ & $?$ & 1 \\
\hline pubescens & 0 & 0 & 1 & 1 & 0 & 0 & $\mathrm{~L}$ & $?$ & $?$ & $\mathrm{~L}$ & $?$ & 1 \\
\hline effeminatus & 0 & 0 & 1 & 1 & 0 & 0 & $\mathrm{~L}$ & 0 & 0 & $\mathrm{~L}$ & 0 & 1 \\
\hline pectinatus & 0 & 0 & 1 & 1 & 2 & $\mathrm{~L}$ & $\mathrm{~L}$ & $?$ & $?$ & $\mathrm{~L}$ & $?$ & 1 \\
\hline puncticeps & 0 & 1 & 2 & 0 & 0 & 0 & $\mathrm{~L}$ & 0 & 0 & $\mathrm{~L}$ & 0 & 1 \\
\hline coalitus & 0 & 1 & 1 & 0 & 0 & 0 & $\mathrm{~L}$ & 0 & 0 & $\mathrm{~L}$ & 0 & 1,2 \\
\hline tridens & 0 & 1 & 1 & 0 & 0 & 0 & $\mathrm{~L}$ & 0 & 0 & $\mathrm{~L}$ & 0 & 1 \\
\hline volans & 0 & 0 & 0 & 0 & 2 & $\mathrm{~L}$ & $\mathrm{~L}$ & 0 & 0 & $\mathrm{~L}$ & 0 & 1 \\
\hline dispar & $\mathrm{1}$ & 0 & 3 & 0 & 2 & $\mathrm{~L}$ & $\mathrm{~L}$ & $?$ & $?$ & $\mathrm{~L}$ & $?$ & 2 \\
\hline brouni & 0 & 0 & 0 & 0 & 0 & 1 & 0 & 1 & 1 & 1 & 1 & 2 \\
\hline torquatus & 0 & 0 & 0 & 0 & 0 & 1 & 1 & 1 & 1 & 0 & 0 & 2 \\
\hline tonsor & 0 & 0 & 0 & 0 & 0 & 1 & 0 & 1 & 1 & 0 & 0 & 2 \\
\hline solus & 0 & 0 & 0 & 0 & 0 & 1 & 1 & 1 & 1 & 0 & 0 & 2 \\
\hline
\end{tabular}




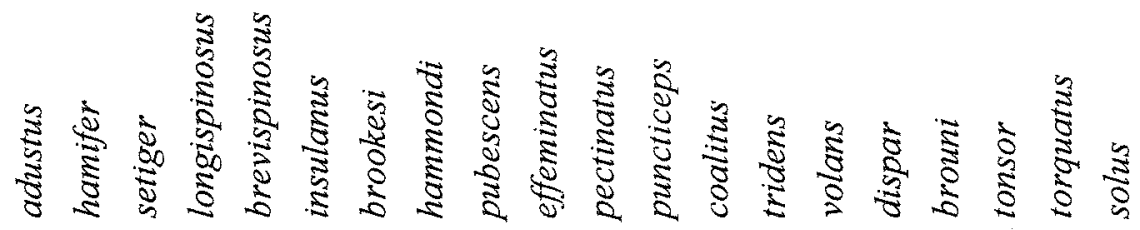

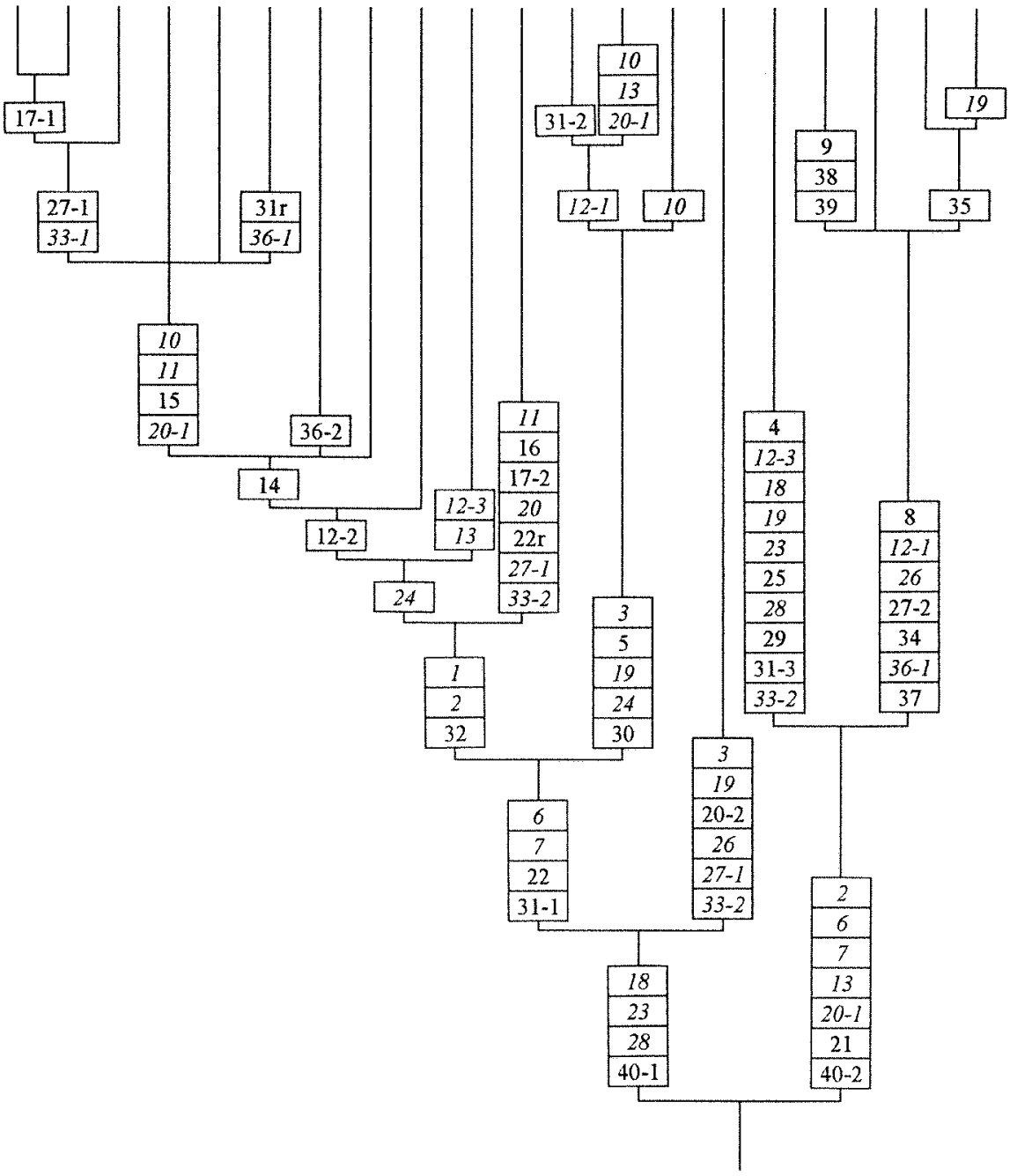

Fig. 2: Phylogenetic tree of Maorothiini based on the character matrix in Tab. 2. Character states occurring more than once in the tree (homoplasies) are given in italics, secondary reductions are marked by an "r".

\section{Discussion}

The phylogenetic tree drawn from the character matrix (Fig. 2) reveals various homoplasies in Maorothiini. The monophyly of some species groups within the tribe is secured by several distinct synapomorphies. This particularly applies to the group of species allied to $M$. adustus comprising (adustus + hamifer) + setiger) + longispinosus + brevispinosus + insulanus $)+$ 
brookesi + hammondi) + pubescens, to the puncticeps-group including (puncticeps + coalitus) + tridens, and especially to the brouni group, which is represented by brouni + tonsor $+($ torquatus + solus). On the other hand, some ramifications are based on single or few presumed apomorphies, which are partly homoplastic or in conflict with other characters. A major difficulty is caused by the doubtful phylogenetic affiliations of three species (pectinatus, dispar, and volans). They are either characterized by numerous, partly highly derived character states (pectinatus, dispar) or predominantly by plesiomorphies (volans), but synapomorphies linking them to other species groups are low in number and in conflict with other characters. This is particularly true for dispar and volans. $M$. dispar shares several presumed apomorphies with the adustus-group, the puncticeps-group, and other species from the North Island. On the other hand, the occurrence of the derived condition of character 21 in both dispar and the brouni. group is remarkable and was given particular weight in the phylogenetic tree, which, however, renders characters 18,23 , and 28 homoplastic. $M$. volans, the only macropterous species in Maorothiini, is characterized by numerous primitive character states. Closer affiliations to the species from the North Island are suggested by three morphological characters. With the puncticeps-group it shares the derived condition of character 3, with dispar that of character 33-2, and with both the puncticeps-group and dispar that of character 19.

Considering the little material of Maorothiini available for the present study, it seems very likely that only a fraction of the species actually occurring in New Zealand has as yet become known. It is to be hoped that the discovery of further species will help to clarify the phylogenetic affiliations within the tribe. Against the background of the systematic conventions generally applied in Staphylinidae, the number and nature of characters separating the monophyletic brouni-group from the species of the North Island would make it seem appropriate to attribute this group generic status. Such a step, however, is here refrained from in view of the uncertainties regarding the phylogenetic status especially of $M$. dispar and $M$. volans.

\section{Maorothius gen. n.}

Type species, here designated: Othius adustus BROUN, 1880

Description (see also the description of Maorothiini)

Moderately large to very large species, only exceptionally of moderate size. Microsculpture of head and pronotum distinct, composed of fine and isodiametric meshes; surface therefore mat or with subdued shine.

Head \pm oblong, usually narrower and shorter than pronotum, usually slightly widened in dorsal view (Fig. 19a); postgenae without or with sparse punctation; frons not delimited by distinct ridges, its anterior margin truncate; frontal punctures usually absent, rarely present; frontal furrows absent or very weakly impressed. Gular sutures in posterior half of head contiguous. Neck approximately $1 / 2$ the width of head or slightly wider; Antennae short in relation to head, usually $1.5 \mathrm{x}$ the width of head or shorter; scape distinctly longer and wider than the following antennomeres, but antennae not geniculate; antennomere X subquadrate to weakly transverse, antennomere XI weakly oblong, slightly longer than X (Fig. 19k); antennal insertions at some distance from lateral margin of head.

Labrum undivided and with distinct anterior angles, chaetotaxy as in Figs $6 \mathrm{~g}$ and 190, anterior margin without membranous extension. Mandibles of moderate length and \pm evenly bent. Maxillary and labial palpi without dense pubescence, apical segment of subconical shape and slightly narrower than preapical segment (Figs 6e-f, 191-m). Mentum strongly transverse, approximately as wide as submentum (Fig. 19n). 
Pronotum with one pair of dorsal punctures near anterior margin, exceptionally with an additional pair of median punctures. Antesternal plate present, distinctly sclerotized and undivided. Prosternum with basisternum strongly transverse and without median carina (Fig. 19b).

Elytra usually distinctly shorter than pronotum, inner margins not overlapping at suture. Mesosternum without distinct median carina, mesosternal process short and apically acute.

Legs relatively short and stout; distinct spines present on whole exterior face of mesotibiae and on posterior half of exterior face of metatibiae. Protarsomeres I - IV strongly dilated in both sexes, usually slightly more so in $0^{\pi} \sigma^{\pi}$ than in $q 9$.

Abdomen subparallel, terga and sterna IV - VI without or with very weak transverse impressions anteriorly.

$\sigma^{*}$ : sternum IX distinctly oblong, its hind margin weakly convex, hind angles not dentate, anteriorly tapering and \pm acute, with distinct, anteriorly converging carinae (as in many Paederinae); posterior pair of macrosetae usually present, their insertions narrowly separated; sometimes with additional pair of median macrosetae. Tergal sclerites IX dorsally fused (in this case tergum $\mathrm{X}$ very short) or separated, in which case tergum $\mathrm{X}$ is distinctly oblong, apically without spine-like process. Aedeagus with parameres separated, either long and \pm symmetric or short and asymmetric; in several species with an asymmetric aedeagus, both left and right asymmetry was observed; median lobe with rather large, dorsally \pm extensively sclerotized (i. e. not membranous) basal bulbus, and with ventral process of variable shape; internal sac of aedeagus without flagellum, with series of \pm sclerotizes spines, which may be reduced in size and number to various extents.

o: sternum IX with central sclerite reduced, lateral sclerites contiguous or fused, flattened in cross-section, and apically with membranous extension carrying one terminal seta. Tergum $X$ very small. Lateral tergal sclerites IX fused. In part of the species, the abdomen contains a partly or fully sclerotized structure of variable shape and of unknown function. It is, as yet, uncertain if it is homologous to the spermatheca or bursa copulatrix in other Staphylinidae. Hereafter, this structure is tentatively referred to as "bursa copulatrix".

Derivatio nominis: Maorothius (gender: masculine) is a compound noun composed of Maori, the original inhabitants of New Zealand, and Othius, the genus to which the previously described species had been attributed.

\section{Distribution and bionomics}

The genus is endernic in New Zealand and currently comprises 20 species. With only few exceptions, the species of Maorothius have a somewhat restricted distribution. Species diversity is distinctly higher in the North Island (16 species), with the vast majority of species occurring in the northern half of the island, than in the South Island ( 5 species), which may be a result of extensive glaciation in the South Island during glacial periods. One species occurs in both the North and the South Island. The presence of one of the species of the phylogenetically isolated and monophyletic $M$. brouni group, which is otherwise confined to the South Island, in the extreme southwest of the North Island, where no other species of Maorothius has been recorded, seems to suggest that the Cook Strait has not been a major biogeographical barrier for the genus. This pattern of distribution may be explained either by a colonization of the South Island through the common ancestor of the brouni-group from the southern North Island (an explanation supported by a north-south gradient of some evolutionary trends in the brouni-group (see section 5), by a colonization of the southern North Island from the South island by the common ancestor of torquatus + solus, or by a (pre-historic) biographical barrier somewhere in the south of the North Island. 
As can be concluded from the data available, species of Maorothius are essentially inhabitants of woodland, where they were usually found in and under rotten logs, in forest litter, or in epiphytic moss. Several specimens, though doubtlessly incapable of flight, were collected with window traps, which suggests that they are active climbers. The vast majority of records are from the period between October and March. Remarkably, several dissected males were observed to have minute mites (endoparasites?) in the abdomen. This would be the first record of endoparasitic mites in Staphylinidae (FRANK, 1982), but the alternative explanation that these mites entered the mounted beetles in the museum collections cannot be ruled out.

\section{The species of Maorothius}

In view of the external similarity of most of the species, a detailed description is given only for few reference species. In the remainder, the diagnoses focus on distinguishing characters, mainly the primary and secondary sexual characters of the males.

The material examined contained several females of which some are unlikely to refer to any of the species described below. However, since the most important characters for identification and discrimination in Maorothius are found in the male sex, descriptions based on females alone would be inadequate and are here refrained from.

The area codes given in the distribution sections and in the maps are based on CROSBY et al. (1998).

\subsection{Maorothius adustus (BROUN, 1880), comb. n.}

(Figs 3a-g, Map 1, p. 29)

Othius adustus BROUN, 1880: 101f.

\section{Types examined}

Lectotype o", present designation: Type [curator label] / 187 / Parua, Whangarei / New Zealand. Broun Coll. Brit. Mus. 1922-482 / Othius adustus / Syntype [curator label] (BMNH) / Lectotypus or Othius adustus Broun, desig. V. Assing 1999/Maorothius adustus (Broun) det. V. Assing 1998 (BMNH).

Paralectotypes, here designated and labelled accordingly: $1 \%$ : N.elle Zélande, Parua / Othius adustus Broun, type / Ex-Typis (IRSNB, coll Fauvel); $10^{\text {: }}$ Nvelle Zélande Parma [sic] / Coll. et det. A. Fauvel, Othius adustus Broun, R.I.Sc.N.B. 17.479 / Ex-Typis (IRSNB).

\section{Comments}

The original description is based on three syntypes collected at Parua (BROUN, 1880). Only one of the syntypes was found in the Broun collection at the BMNH. In the Fauvel collection at the IRSNB, however, there were three specimens, all of them labelled "Ex-Typis". All of them are mounted in the same way and on the same kind of label as the syntype in the BMNH; apparently, Fauvel had received them from Broun. One specimen, a female, carries handwritten labels with the type locality in correct spelling. The other two, both males, were obviously labelled by Fauvel, because the type locality is misspelled ("Parma"). Since, according to the original description, the type series comprises only 3 syntypes, one of the males, which is not conspecific with the lectotype, is here regarded as a non-type specimen. In view of the ambiguous labels of the types, the discrepancy between the number of types indicated in the original description and the number of specimens labelled as types, the consequently somewhat deliberate exclusion of one of the specimens from the type series, and the fact that this specimen is not conspecific with those here designated as lectotype and paralectotypes, respectively, a lectotype designation was indispensible. 

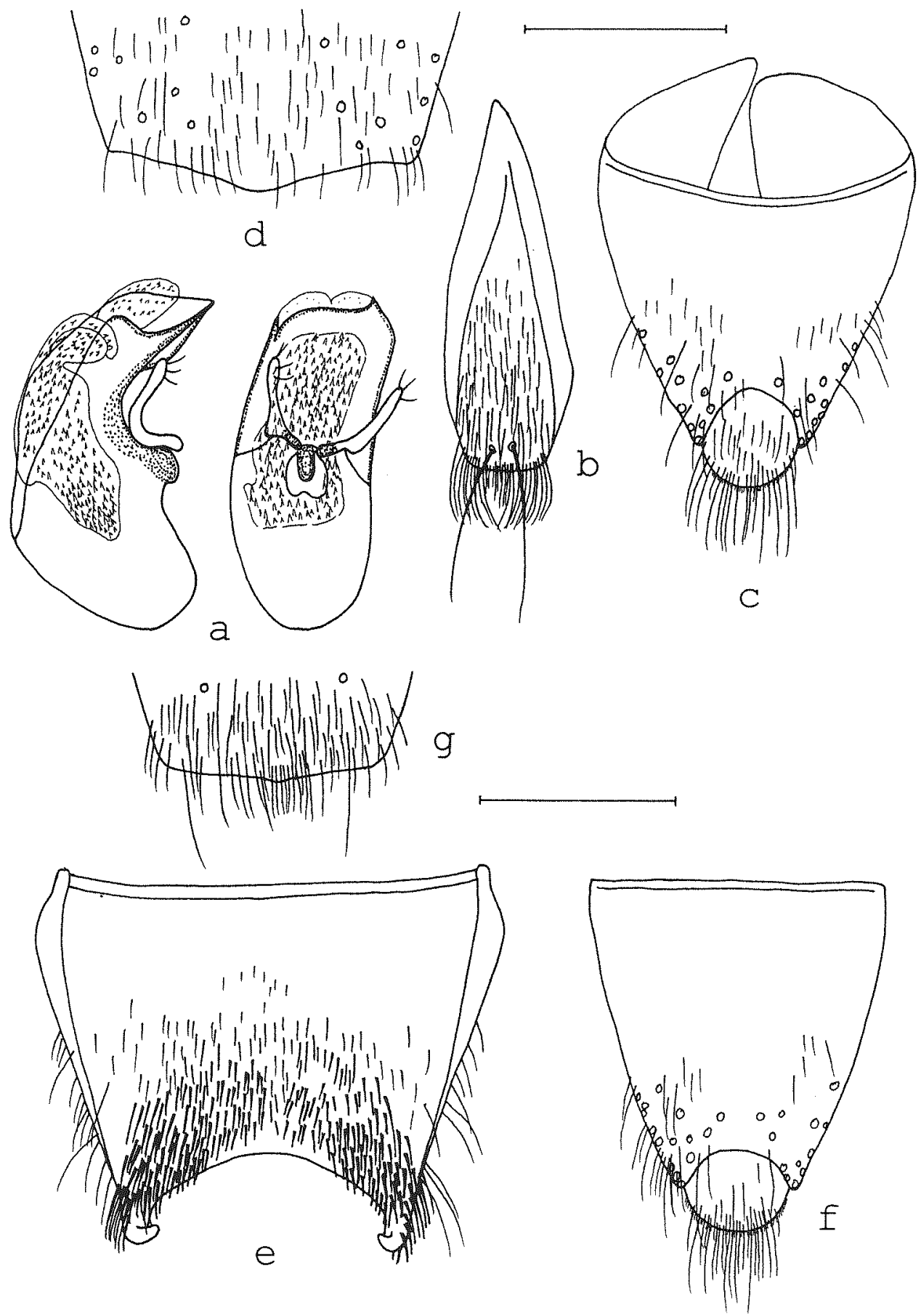

Fig. 3: Maorothius adustus (BRoUN) (PLT): aedeagus in lateral and in ventral view (a); $\sigma^{\pi}$ sternum IX (b); ox terga IX and X (c); posterior part of $\sigma^{x}$ tergum VIII (d); $\sigma^{x}$ sternum VIII (e); o terga IX and X (f); hind margin of 9 sternum VIII $(\mathrm{g})$. Scale: $1 \mathrm{~mm}$. 


\section{Description}

Measurements $(\mathrm{mm})$ and ratios (range; $\mathrm{n}=3$ ): HL: $2.48-2.60 ; \mathrm{HW}: 2.48-2.64 ; \mathrm{PW}: 2.68$ 2.88; PL: 3.44 - 3.52; EL: 1.92 - 1.96; TiL: 2.00 - 2.08; TaL: 1.72 - 1.80; AL: 1.68 - 1.72; TL: 17.4 - 18.5; HL/HW: 0.98 - 1.00; HW/PW: 0.92 - 0.93; PL/PW: 1.22 - 1.28; EL/PL: 0.55 0.57 ; TiL/TaL: $1.13-1.16$.

Colour of body rufous to dark brown; legs and apex of antennomere XI lighter, light brown to reddish brown.

Head widened posteriorly; eyes approximately half the length of postgenae in dorsal view; dorsal surface of head with macropunctation present only near eyes (with one puncture near antero-dorsal, one puncture near medio-dorsal and one puncture near postero-dorsal margin), in posterior area of postgenae and near occiput; with distinct, but very fine and dense microreticulation, and with rather sparse micropunctation; frons with very shallow to indistinct impression; frontal furrows almost obsolete; frontal punctures absent. Antennae short, only ca. $1.3 x$ longer than head width, not distinctly incrassate apically; antennomere I distinctly oblong, longer than II and III; II weakly oblong, III ca. $1.5 x$ the length of II and about $2-2.5 x$ longer than wide; IV much shorter than III and weakly oblong; V weakly oblong or subquadrate; VI$\mathrm{X}$ increasingly transverse and flattened in cross-section; $\mathrm{X}$ moderately transverse; $\mathrm{XI}$ short, ca. $1.5 x$ the length of $X$.

Pronotum widest near anterior angles and weakly tapering posteriorly; microreticulation and micropunctation similar to head; without dorsal macropunctation, except for marginal punctation, and one puncture a short distance from anterior margin on either side, about halfway between median line and lateral margin; near posterior margin with small, but distinct median scratch-like impression, which may anteriorly extend into a very weak stria over all of the posterior half of the pronotal midline.

Elytra distinctly shorter and somewhat narrower than pronotum; punctation moderately dense, interstices ca. 2 - $4 \mathrm{x}$ the diametre of punctures; pubescence short and semi-erect; microsculpture composed of fine and not very dense, irregular scratch-like striae of variable direction; scutellum with transverse microsculpture, but without punctation; hind wings reduced.

Legs short, with relatively long tarsi; mesotarsi usually slightly longer than mesotibiae, metatarsi slightly shorter than metatibiae; metatarsomere I approximately as long as the following tarsomere, metatarsomere V slightly longer than the combined length of III and IV; hind margins of meso- and metatarsomeres I - III ventrally with relatively long and very dense yellowish setae in both sexes.

Abdomen finely and rather sparsely punctate; microsculpture in anterior area of tergal surfaces distinct and isodiametric, in posterior area very shallow or indistinct and composed of transverse meshes and transverse striae.

$\sigma^{*}$ : protarsomeres strongly dilated; sternum VII with moderately concave hind margin, in posterior median area slightly depressed and with dense and stout setae; sternum VIII with strongly concave hind margin, the posterior angles with hook-shaped processes, in central posterior area with fine and moderately dense, in lateral posterior areas with very dense, stout, yellowish setae (Fig. 3e); tergum VIII weakly pointed posteriorly (Fig. 3d); sternum IX with one pair of macrosetae near hind margin and with relatively long and dense dark pubescence (Fig. $3 \mathrm{~b}$ ); tergum IX undivided, tergum X small (Fig. 3c); aedeagus relatively small and asymmetric; ventral process in ventral view bent to the right; parameres short and with three or four apical setae; internal tube of median lobe with numerous small semitransparent spines (Fig. 3a).

\%: protarsomeres almost as strongly dilated as in $\sigma^{\pi}$, sexual dimorphism not pronounced; tergum and sternum VIII (Fig. $3 \mathrm{~g}$ ) weakly pointed posteriorly; tergum IX and X as in Fig. $3 \mathrm{f}$. 


\section{Distribution and bionomics}

M. adustus has become known only from the type locality in Northland (Map 1). Neither the original description nor the labels indicate any details regarding the circumstances of collection.

\subsection{Maorothius hamifer sp. $\mathrm{n}$.}

(Figs 4a-c, Map 1, p. 29)

Holotype or: Waipu, '114 / 187 / A. E. Brookes Collection / ox / Othius adustus Broun, P. M. Hammond det. 1983 / Holotypus Maorothius hamifer sp. n., det. V. Assing 1999 (NZAC).

Fig. 4: Maorothius hamifer sp. n. (HT): aedeagus in lateral and in ventral view (a); $\sigma^{x}$ sternum IX (b); posterior part of $\sigma^{x}$ sternum VIII, pubescence omitted (c). Scale: $1 \mathrm{~mm}$.

\section{Description}

Measurements (mm) and ratios (HT): HL: 2.60; HW: 2.60; PW: 2.76; PL: 3.48; EL: 1.80; TiL: 2.0; TaL: 1.68; AL: 1.84 ; TL: 15.6; HL/HW: 1.00; HW/PW: 0.94; PL/PW: 1.26; EL/PL: 0.52; TiL/TaL: 1.21 .

Externally highly similar and closely related to $M$. adustus; distinguished from that species as follows: Colour of body darker, whole body blackish with the antennae dark brown, the hind margins of the abdominal segments and the legs \pm brown.

Head more strongly widened posteriorly; microreticulation of head and pronotum slightly more distinct.

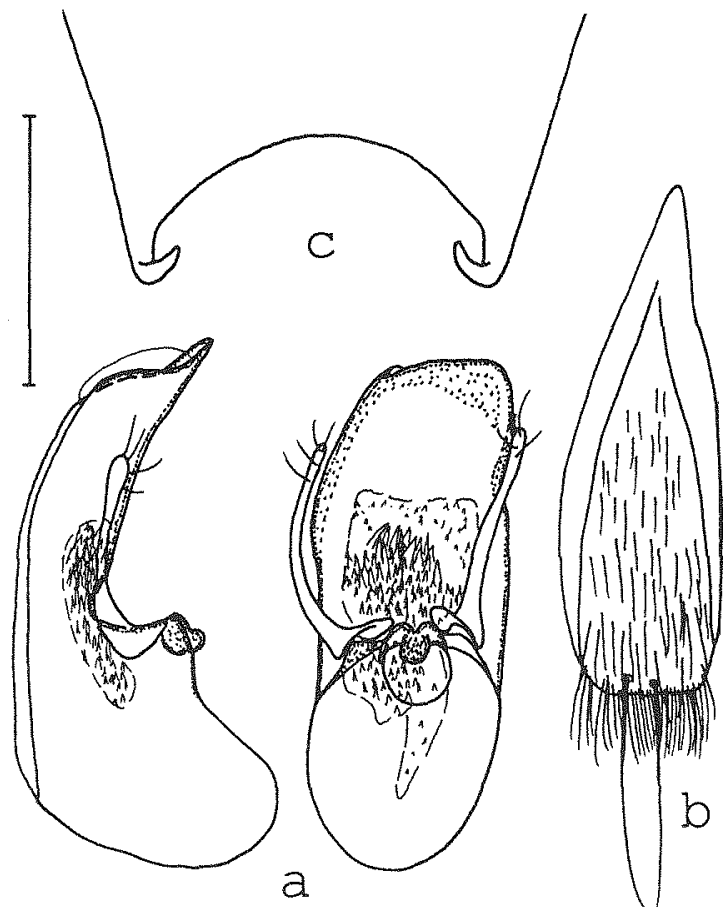

Elytra with somewhat coriaceous microsculpture, punctation therefore less well-delimited. $\sigma^{\pi}$ : posterior angles of sternum VIII with longer hook-shaped processes (Fig. 4c); tergum VIII not pointed posteriorly; hind margin of sternum IX with shorter pubescence (Fig. 4b); median lobe of aedeagus in lateral view less strongly bent; parameres longer; internal tube of median lobe with larger and darker spines (Fig. 4a).

o: unknown.

Derivatio nominis: The name (Lat:: hook-bearing) refers to the distinctive hook-shaped processes of the on sternum VIII.

\section{Comments}

With only one and two males available of M. hamifer and M. adustus, respectively, it is difficult to decide if the distinguishing characters indicated above are really constant. In view of the differences in the $\sigma^{\pi}$ primary and secondary sexual characters, however, M. hamifer is here regarded as a distinct species. More material is needed to ascertain if the observed differences are linked by transitional conditions or not. 


\section{Distribution and bionomics}

The species is only known from the type locality in Northland, not far from the type locality of its sister species, $M$. adustus (Map 1). The labels attached to the holotype indicate no details regarding the circumstances of collection.
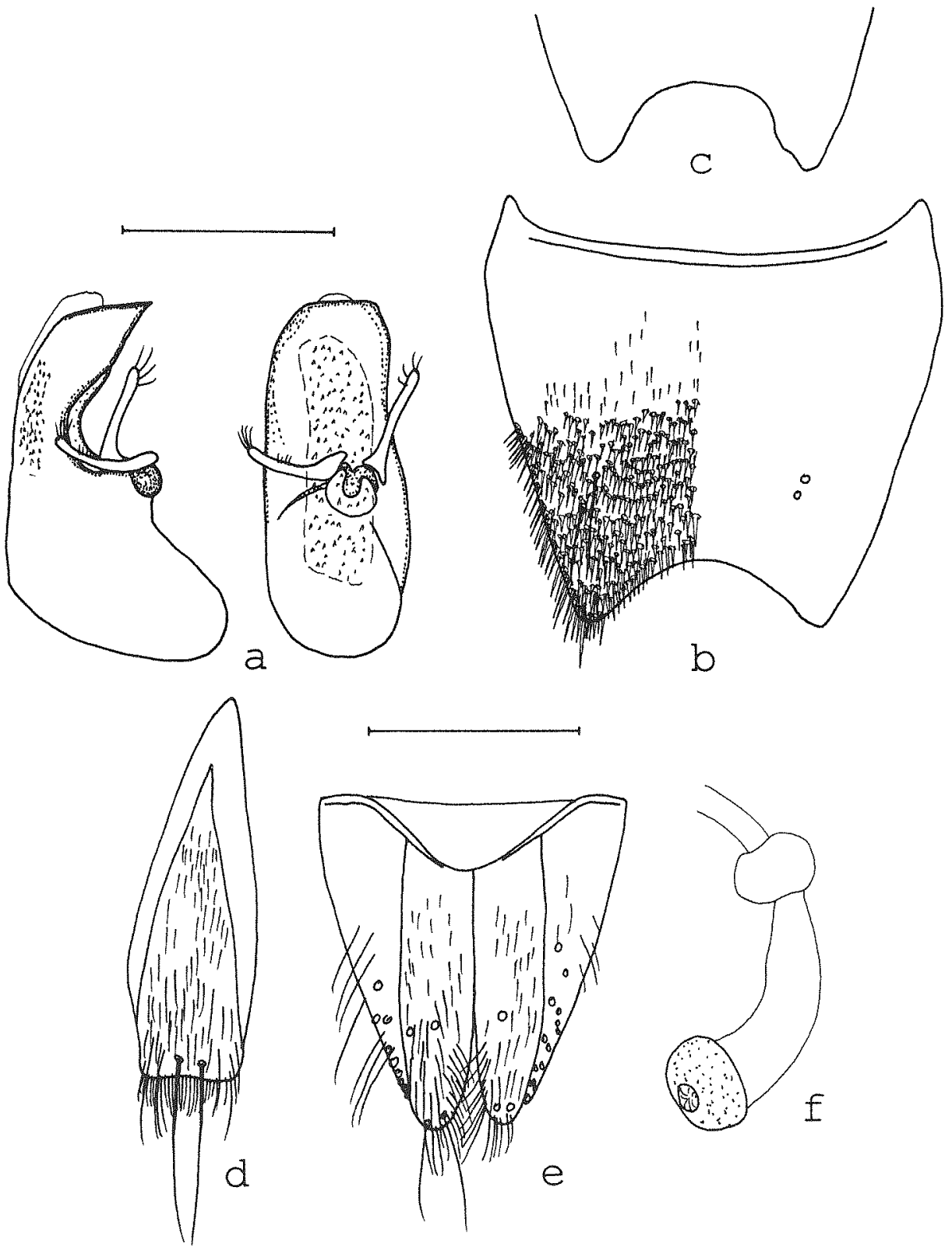

Fig. 5: Maorothius setiger sp. n. (a, b, d: HT): aedeagus in lateral and in ventral view (a); $o^{\star}$ sternum VIII (b); outline of hind margin of $o^{x}$ sternum VIII of PT (c); o sternum IX (d); + segment IX in ventral aspect (e); "bursa copulatrix" (f). Scale: $1 \mathrm{~mm}$. 
Map 1: Distribution of $M$. adustus (BRouN) (1), M. hamifer sp. n. (2), M. setiger sp. n. (3), M. longispinosus sp. n. (4), $M$. brevispinosus sp. n. (5), $M$. insulanus sp. n. (6), M. pubescens sp. n. (7), M. brookesi (CAMERON) (8), and $M$. hammondi sp. n. (9). Scale: $100 \mathrm{~km}$; for area codes see Map 2.

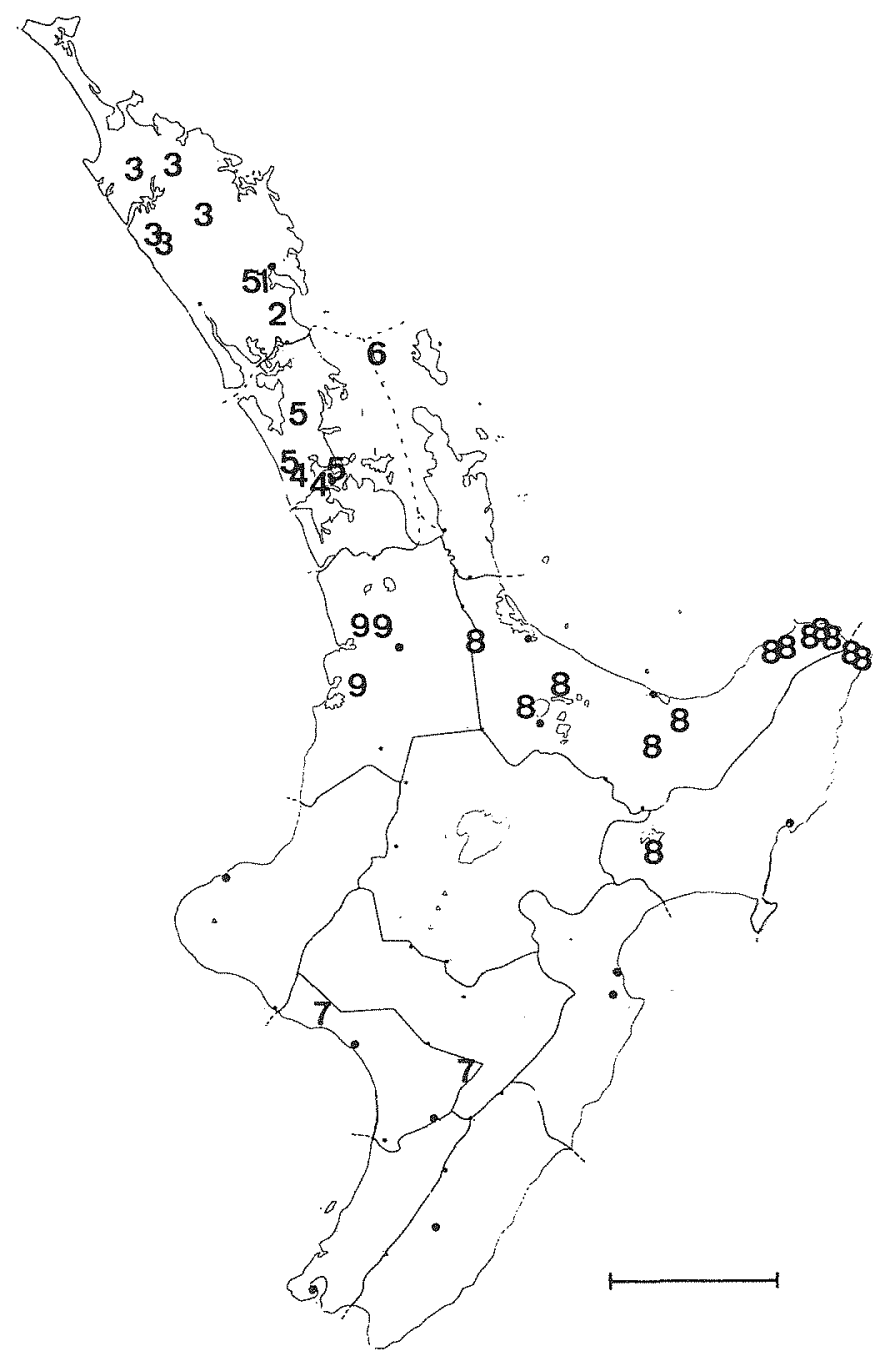

\subsection{Maorothius setiger $\mathrm{sp} . \mathrm{n}$.} (Figs 5a-f, Map 1)

Holotype $\sigma^{x}$ : N.Zeal.: ND; Waipoua For., Waipoua Strm. 70m, 17.III.1978, ber. frass und. bark Kauri log; S. \&J. Peck / Holotypus Maorothius setiger sp. n., det. V. Assing 1999 (FMNH). Paratypes: $10^{*}$, New Zealand ND, Omahuta SF, 9 Oct 1974, J. C. Watt / ex rotten logs / Othius det. A. Newton 1980 / Othius sp. n. 8, P. M. Hammond det. 1983 (NZAC); $10^{*}$ : Mangamuka Saddle, Auckland, 5 Nov 1967 / J. I. Townsend / o (NZAC); $10^{7}$ : Mangamuka, 91 1927, C. F. Clarke / Mangamuka mts., N. Auck. / cf. brookesi (BMNH); $20^{*} 0^{x}$ : New Zealand ND, Waipoua SF, $4 \mathrm{~km}$ W Headquarters, 12 Apr 1980, J. C. Watt / ex Pinus elliottii logs (NZAC, cAss); 1 9 : Waipoua, 14.vi.66, J. I. Townsend/ under pine bark (NZAC); $10^{\pi}$ : ex rotten log, Bluff above Mangakahia R., Gannon's [?] Rd. Block, Matarua State Forest, 24.IX.1985, R. F. Gilbert / AMNZ 25221 Auckland Museum New Zealand (AMNZ). 


\section{Description}

Measurements (mm) and ratios (range; $\mathrm{n}=8$ ): HL: $2.16-2.64$; HW: $2.20-2.64$; PW: 2.48 2.80; PL: 2.92 - 3.52; EL: 1.76 - 2.00; TiL: 1.72 - 2.04; TaL: 1.56 - 1.80; AL: 1.64 - 1.72; TL: 13.1 - 17.1; HL/HW: 0.98 - 1.03; HW/PW: 0.89 - 0.94; PL/PW: 1.18 - 1.26; EL/PL: 0.55 0.60 ; TiL/TaL: $1.10-1.20$.

Externally highly similar to $M$. adustus, but distinguished as follows:

Head slightly more strongly widened posteriorly; frons without median impression, frontal furrows barely noticeable.

Pronotum more distinctly tapering posteriorly.

Elytra with somewhat coarser punctation, and more shining, due to less distinct, very weakly coriaceous microsculpture.

$\sigma^{7}$ : sternum VII as in $M$. adustus; sternum VIII with extremely dense stout yellow setae in practically all of the posterior half, hind margin with pronounced concavity, postero-median area near hind margin impressed, posterior angles without hook-shaped processes (Figs $5 \mathrm{c}-\mathrm{d}$ ); tergum VIII not pointed posteriorly; sternum IX with less dark and shorter pubescence (Fig. 5 b); aedeagus of similar size, but especially in lateral view of different shape; parameres with 4 apical setae (Fig. 5a).

f: tergum VIII truncate posteriorly; sternum VIII with weakly convex hind margin; "bursa copulatrix" and valvifers as in Figs 5e-f.

Derivatio nominis: The name (Lat.: setose) refers to the modified, almost brush-like pubescence of the $\sigma^{\pi}$ sternum VIII.

\section{Distribution and bionomics}

The type specimens were taken in several localities in Northland (Map 1). In the more recently collected material the labels indicate that the beetles were found under bark and in logs, mostly of pine trees.

\subsection{Maorothius longispinosus sp. n.}

(Figs 6a-g, Map 1, p. 29)

Holotype ox: N-Zealand, Aukland [sic], 5.85, leg. Wachtel / Holotypus Maorothius longispinosus sp. n., det. V. Assing 1999 (cAss).

Paratypes: 1\%: same data as holotype (cAss); $10^{*}$ : New Zealand: AK, Waitakere Range, 260m, Nohoanga Scenic Res., 8.xii.1984 - 25.i.85, hdwd.-podocarp forest, A. Newton \& M. Thayer / window trap 679 (FMNH).

\section{Description}

Measurements $(\mathrm{mm}$ ) and ratios (range; $\mathrm{n}=3$ ): HL: $2.16-2.36$; HW: $2.12-2.28 ; \mathrm{PW}: 2.44$ 2.48; PL: 3.00 - 3.20; EL: 1.72 - 1.80; TiL: 1.80 - 1.88; TaL: $1.44-1.64 ;$ AL: 2.40 ; TL: 14.9 15.6; HL/HW: 1.02 - 1.04; HW/PW: 0.87 - 0.92; PL/PW: 1.23 - 1.29; EL/PL; 0.56 - 0.57 ; TiL/TaL: $1.15-1.25$.

Mouthparts as in Figs 6e-g. Externally similar to M. adustus, but distinguished as follows: On the whole smaller (see measurements). Head without median impression on frons, frontal furrows almost obsolete. Elytra with slightly coarser punctation; microsculpture \pm coriaceous. Mesotibiae slightly more slender, not shorter than mesotarsi.

$\sigma^{7}$ : sternum VII with moderately concave hind margin, near hind margin and in posterior median area with dense, moderately stout short setae; sternum VIII with strongly concave hind margin, the posterior angles without hook-shaped processes, whole posterior area with moderately dense and stout yellowish setae (Fig. 6b); tergum VIII not pointed posteriorly; 
sternum IX with two long setae near hind margin, pubescence shorter than in M. adustus (Fig. 6c); aedeagus distinctly larger; both left and right asymmetry was observed; parameres apically with 4 setae; internal sac of median lobe with two rows of long distinctly sclerotized spines (Fig. 6a).
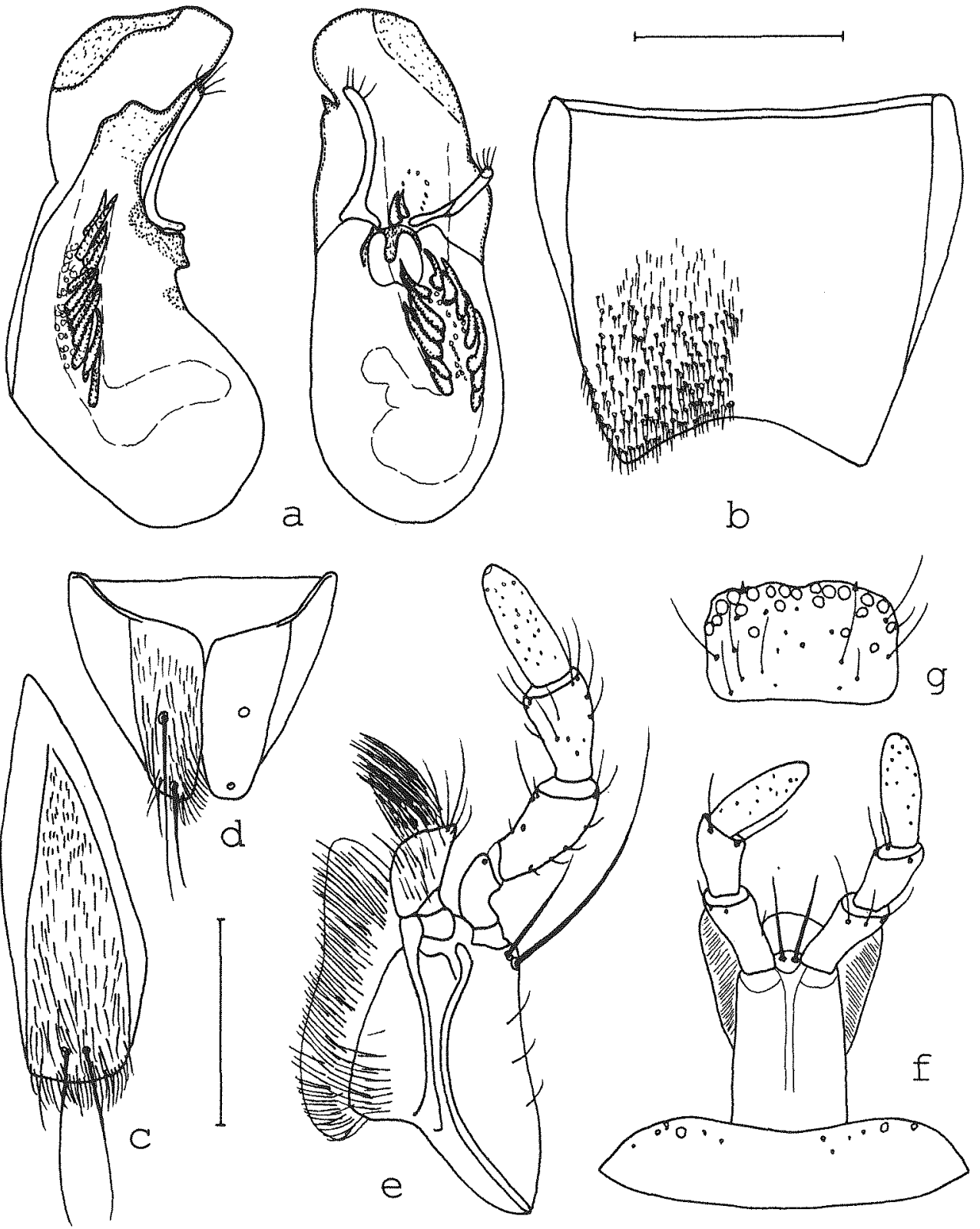

Fig. 6: Maorothius longispinosus sp. n. (a-c: HT): aedeagus in lateral and in ventral view (a); $\sigma^{\pi}$ sternum VIII (b); $\sigma^{x}$ sternum IX (c); q segment IX in ventral aspect (d); maxilla (e); labium (f); labrum, long setae omitted (g). Scale: a-d: $1 \mathrm{~mm}$, e-g: $0.5 \mathrm{~mm}$. 
우 : tergum VIII not pointed posteriorly; hind margin of sternum VIII moderately convex; valvifers as in Fig. 6d.

Derivatio nominis: The name (Lat.: with long spines) refers to the internal structures of the aedeagus.

\section{Distribution and bionomics}

The types were collected in two localities in Auckland (Map 1). The (brachypterous!) specimen from Waitakere was taken in a window trap in a podocarp forest.

\subsection{Maorothius brevispinosus sp. $\mathrm{n}$.}

(Figs 7a-f, Map 1, p. 29)

Holotype $\sigma^{\pi}$ : AK: Ahuroa forest reserve, 15.xi.1983/agaric. / Othius sp. n. 7 P. M. Hammond det. 1984 / Holotypus Maorothius brevispinosus sp. n., det. V. Assing 1999 (BMNH).

Paratypes: $1 \sigma^{\pi}$ : Nvelle Zélande, Parma [sic, incorrect spelling of Parua] / Coll. et det. A. Fauvel, Othius adustus Broun, R.I.Sc.N.B. 17.479 / Ex-Typis (IRSNB); 10: New Zealand: AK, Waitakere Ra., Cascade-Kauri Park, Up. Kauri Tr., 170m, 8.xii.84 - 25.i.85, kauri-podo-hdwd., A. Newton \& M. Thayer, $680 /$ window trap 680 (FMNH); $1 \sigma^{\pi}$ [with minute mite in abdomen]: 187 / New Zealand 93-56/Othius adustus Broun / FM / Gyrohypnus adustus Broun / Exchange ex Collection British Mus. (N.H.) (FMNH); 10*: Swanson, 22-4-26[?] / 187/ A. E. Brookes Collection / $\sigma^{\pi} /$ Othius cf. sp. n. 7, P. M. Hammond det. 1983 (NZAC).

For details regarding the identity of the specimen from the Fauvel collection see comments below $M$. adustus.

\section{Description}

Measurements $(\mathrm{mm})$ and ratios (range; $\mathrm{n}=5$ ): HL: $2.08-2.32$; HW: $2.00-2.20$; PW: 2.20 2.40; PL: 2.84 - 3.08; EL: 1.56 - 1.72; TiL: 1.72 - 1.84; TaL: 1.36 - 1.52; AL: 1.92 - 2.32; TL: 13.8 - 15.6; HL/HW: 1.02 - 1.05; HW/PW: 0.89 - 0.93; PL/PW: 1.27 - 1.31; EL/PL: 0.53 0.56 ; TiL/TaL: $1.13-1.26$.

Very similar and closely related to $M$. longispinosus, from which the species is distinguished as follows:

Eyes slightly smaller, in dorsal view somewhat less than half the length of postgenae. Pronotum more slender; elytra slightly shorter.

$\sigma^{\pi}$ : sternum VII with weakly to moderately concave hind margin; sternum VIII posteriorly moderately to distinctly concave (Figs 7d-e); sternum IX as in Figs 7b-c; terga IX and X as in Fig. 7f; median lobe of aedeagus of very variable size, usually smaller and of slightly different shape; both left and right asymmetry was observed; internal sac with fewer and shorter spines (Figs 7a).

ㅇ: unknown.

Derivatio nominis: The name (Lat.: with short spines) refers to the internal structures of the aedeagus, which distinguish this species from the similar $M$. longispinosus.

\section{Distribution and bionomics}

M. brevispinosus was collected in several localities in Auckland (Ahuroa, Waitakere, Swanson) and Northland (Parua) (Map 1). One (brachypterous!) specimen was taken in a window trap in a kauri-podocarp forest; the holotype was apparently found in association with fungi. The abdomen of one of the paratypes contained a minute mite. 

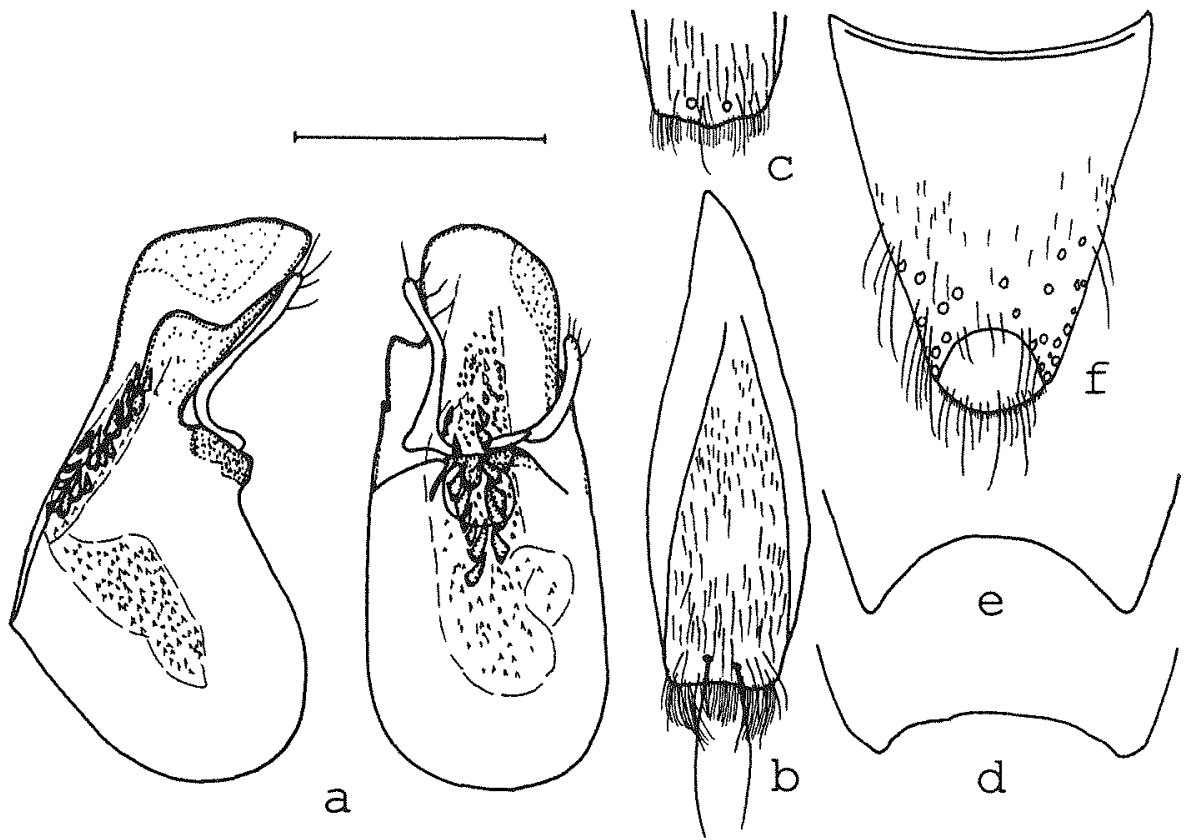

Fig. 7: Maorothius brevispinosus sp. n.: aedeagus in lateral and in ventral view (a); (posterior part of) $\sigma^{\pi}$ sternum IX of two $\sigma^{x} \sigma^{x}(\mathrm{~b}, \mathrm{c})$; outline hind margin of $\sigma^{x}$ sternum VIII of two $\sigma^{*} \sigma^{x}(\mathrm{~d}, \mathrm{e}) ; \sigma^{x}$ terga IX and X (f). Scale: $1 \mathrm{~mm}$.

\subsection{Marothius insulanus sp. $\mathrm{n}$.}

(Figs 8a-e, Map 1, p. 29)

Holotype ơ: Lt Barrier I., 17.XII.83, J. Playfair / New Zealand, P. M. Hammond, B. M. 198480 / Othius sp. n. cf. sp. 5 P. M. Hammond det. 1984 / Holotypus Maorothius insulanus sp. n., det. V. Assing 1999 (BMNH).

Paratypes: $10^{\pi}$ [with minute mite in abdomen]: Little Barrier Island / 29/12/31 - 10/1/32, Collector A. E. Brookes / 187, Othius adustus Broun identified by A. E. Brookes / National Museum Wgtn NZ (cAss); 19: 29/12/31-10/1/32, Collector A. E. Brookes / Little Barrier Island / Gyrohypnus adustus (Broun), W. Steel det. 1949 (MNZW); 1: Little Barrier, N. Zealand, H. Swale, 1913-117 / Gyrohypnus adustus (Brn), W. Steel det. 1948 (BMNH).

\section{Description}

Measurements $(\mathrm{mm}$ ) and ratios (range; $\mathrm{n}=4$ ): HL: $2.20-2.40$; HW: $2.14-2.36$; PW: 2.32 2.56; PL: 2.92 -3.28; EL: 1.64 - 1.80; TiL: 1.84 - 1.92; TaL: 1.64 - 1.68; AL: 2.28 - 2.36; TL: 14.1 - 15.4; HL/HW: 1.02 - 1.04; HW/PW: 0.90 - 0.92; PL/PW: 1.24 - 1.28; EL/PL: 0.55 0.58 ; TiL/TaL: $1.12-1.14$.

Externally similar to $M$. longispinosus and $M$. brevispinosus, but distinguished as follows:

Elytra with slightly sparser punctation; tibiae longer; abdomen on average with denser punctation and pubescence especially on terga V - VII.

$\sigma^{\pi}$ : sternum VII with stout and dense setae in posterior region, its hind margin weakly concave; sternum VIII with strongly concave hind margin, in posterior region with relatively dense, 
yellowish modified setae, which are longer and stouter than in $M$. longispinosus and $M$. brevispinosus, especially near hind margin (Fig. 8c); tergum VIII weakly convex posteriorly (Fig. 8d); sternum IX similar to the related species, its hind margin weakly concave (Fig. 8b); aedeagus with median lobe apically very acute; both parameres very short; internal sac with one row of 8 - 9 larger and one row of 8 - 9 smaller sclerotized spines; internal tube covered with numerous rather long semitransparent spines (Fig. 8a).

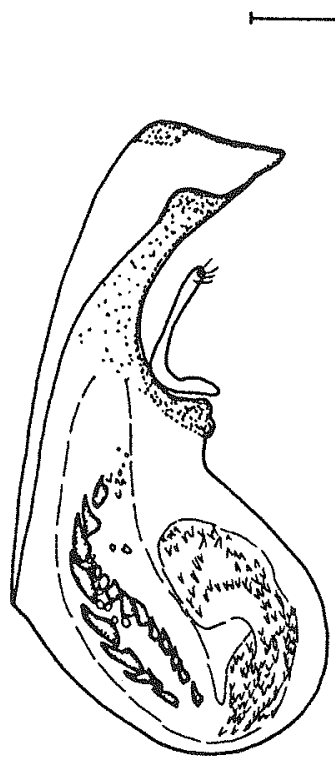

a
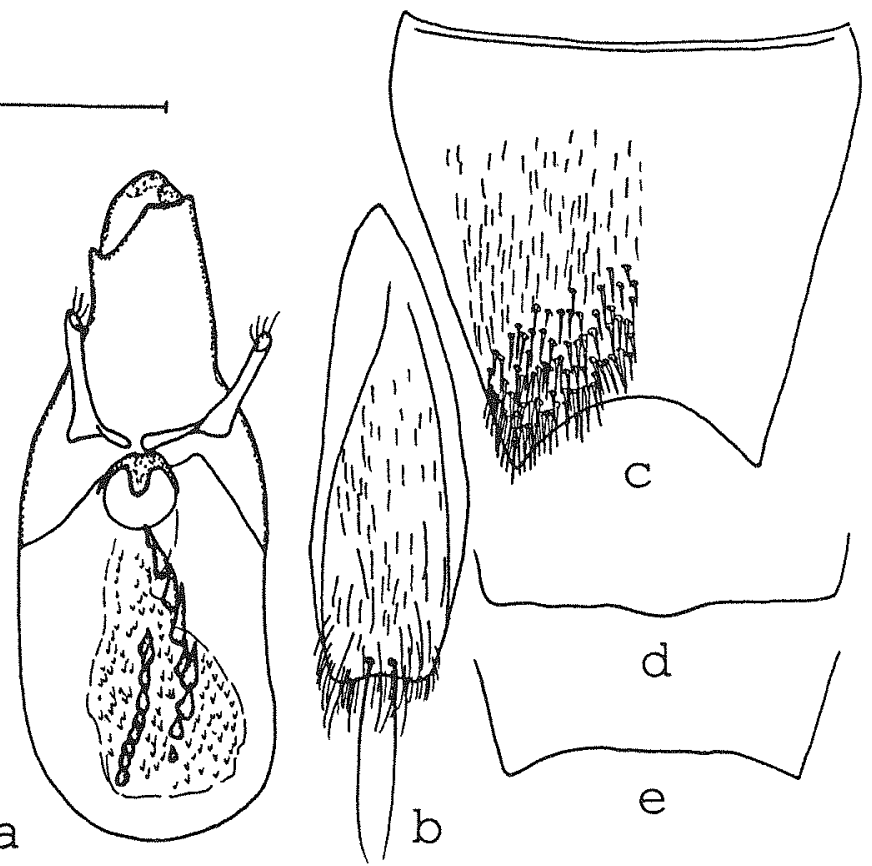

Fig. 8: Maorothius insulanus sp. n. (a-d: HT): aedeagus in lateral and in ventral view (a); on sternum IX $(b) ; o^{x}$ sternum VIII (c); outline of posterior margin $\sigma^{x}$ tergum VIII (d); outline of posterior margin of $q$ tergum VIII. Scale: $1 \mathrm{~mm}$.

9: protarsomeres I - IV as strongly dilated as in $0^{n}$ or only slightly less so; sternum VIII strongly tapering posteriorly, with bluntly pointed hind margin; tergum VIII weakly concave posteriorly (Fig. 8e); segments $\mathrm{IX}$ and $\mathrm{X}$ as in the related species; posterior part of "bursa copulatrix" sclerotized.

Derivatio nominis: The name (Lat.: island inhabitant) refers to the distribution, which is apparently confined to Little Barrier Island.

\section{Distribution and bionomics}

The species is possibly endemic in Little Barrier Island (Map 1). No data regarding its ecology are available. The abdomen of one of the males contained a minute mite.

\subsection{Marothius pubescens sp. n.}

(Figs 9a-c, Map 1, p. 29)

Holotype $\sigma^{\pi}$ [with minute mite in abdomen]: Waitotara, Wanganui, 20.1.1962, R. G. Ordish / National Museum Wgtn. NZ/ Holotypus Maorothius pubescens sp. n., det. V. Assing 1999 (MNZW). 
Paratype $\sigma^{\pi}$ : New Zealand WI, nr Glow-worm Cave, Table Hill Rd nr Apiti, 8/2/97 (FMNH).

\section{Description}

Measurements and ratios (HT, PT) : HL: 2.24, 2.04; HW: 2.12, 1.92; PW: 2.40, 2.08; PL: 2.96, 2.94; EL: 1.68, 1.48; TiL: 1.80, 1.64; TaL: 1.52, 1.40; AL: 2.12, 1.92; TL: 15.4, 12.8; HL/HW: 1.06, 1.06; HW/PW: 0.88, 0.92; PL/PW: 1.23, 1.27; EL/PL: 0.57, 0.56; TiL/TaL: 1.18, 1.17. Externally similar to $M$. longispinosus, but distinguished as follows:

Microreticulation of head and pronotum slightly more distinct; microsculpture of elytra variable. Head with or without small punctures between postocular puncture and occipital margin.

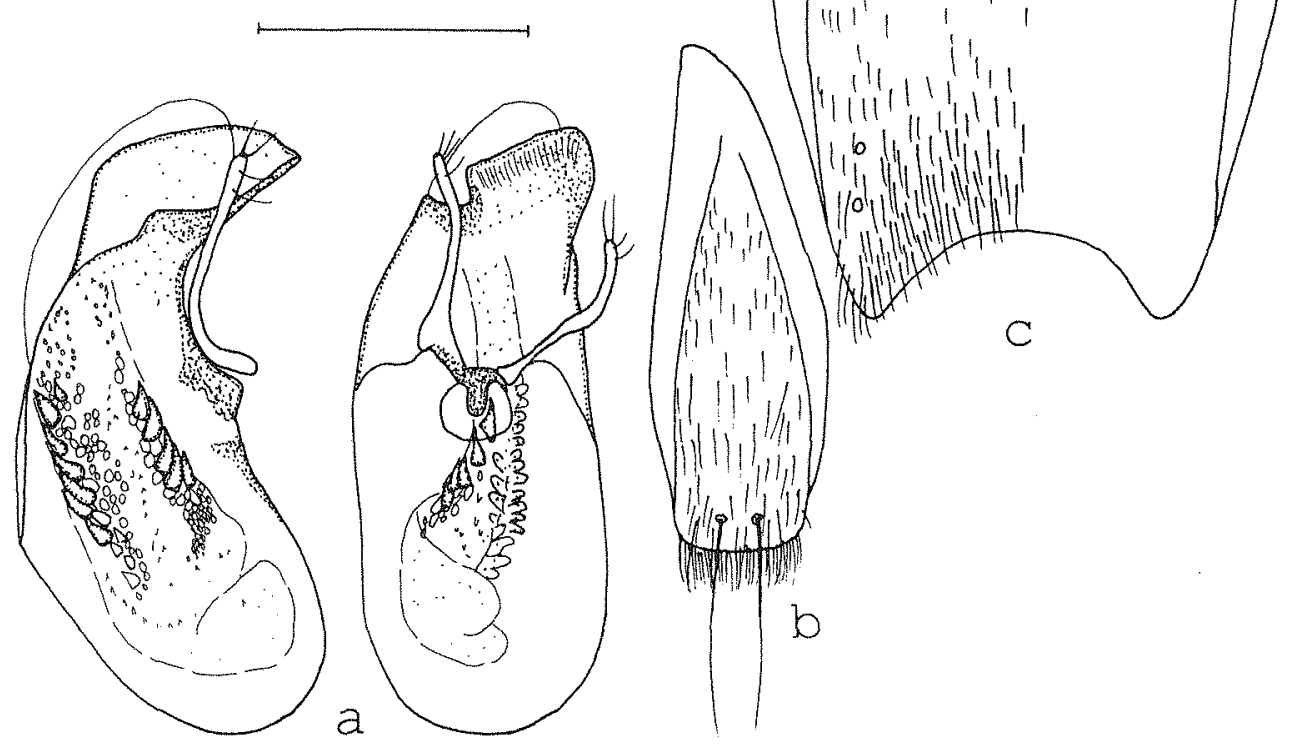

Fig. 9: Maorothius pubescens sp. n. (HT): aedeagus in lateral and in ventral view (a); $o^{x}$ sternum IX (b); ox sternum VIII (c). Scale: $1 \mathrm{~mm}$.

$\sigma^{7}$ : sternum VII posteriorly truncate, pubescence near hind margin rather long and unmodified; sternum VIII with strongly concave hind margin, pubescence anteriorly sparse and very short, posteriorly increasing in length and density, but not distinctly modified (Fig. 9c); tergum VIII weakly convex posteriorly; sternum IX similar to the related species, with predominantly yellowish pubescence and one posterior pair of macrosetae, an additional anterior macroseta may be present (Fig. 9b); aedeagus with median lobe in lateral view strongly bent; both parameres rather long and slender, right (ventral view!) paramere with long basal part; internal sac with two short rows of relatively few distinctly sclerotized spines of various sizes and with numerous dark granula (Fig. 9a).

o: unknown.

Derivatio nominis: The name (Lat.) refers to the unmodified pubescence of the ox sterna VII and VIII, which distinguishes this species from the similar $M$. longispinosus and $M$. brevispinosus. 


\section{Comments}

The specimen from Waitotara is somewhat larger than that from Apiti. In addition, the elytral punctures are slightly finer, the elytral microsculpture is more distinct and coriaceous, and the spines in the internal sac of the aedeagus are smaller and fewer in number. Nevertheless, both specimens are here considered to be conspecific, since, in the absence of further material, it is impossible to assess if these characters are constant.

\section{Distribution and bionomics}

M. pubescens was collected in two localities in Wanganui, North Island (Map 1). The abdomen of one of the males contained a minute mite.

7.8. Maorothius brookesi (CAMERON, 1952), comb. n.

(Figs 10a-f, Map 1, p. 29)

Othius brookesi CAMERON, 1952: 42.

\section{Types examined}

Holotype: 1 sex? (abdomen missing): Motu River, Bay of Plenty, North Is. / Coll. A. E. Brookes, March, 1928 / Othius adustus Broun / Othius adustus Broun / Brookes / o / Holotypus Othius brookesi Cameron, rev. V. Assing 1999 / Maorothius brookesi (Cameron), det. V. Assing 1998 (NZAC).

Paratype o: Okauia, Matamata, Waikato / Coll. A. E. Brookes, 25-12-1922 [sic] / Othius adustus Broun? / Othius Brookesi Cam. Paratype, M. Cameron det. 19 / M. Cameron Bequest B.M. 1955-147 / Paratype [round curator label] (BMNH).

\section{Additional material examined}

Bay of Plenty: 10", Motu River, 21.IV.1929, leg. A. E. Brookes (NZAC); 10", same data, but V.1928 (NZAC); 10*, Motu River (FMNH); 10, Ngongotaha, Rotorua, 1903, leg. H. Swale (FMNH); 1 \&, Rotorua, N Otaramarae, in rotten log, 26.X.1967, leg. J. C. Watt (NZAC); $10^{*}$, Whanarua Bay, Bay of Plenty, under stone, 24.I.1962, leg. J. C. Watt (cAss); 1 q, locality not specified (BMNH); $1 \sigma^{\prime \prime}$ : Head of Waioeka, 13.II.57 (NZAC); 1 \% , Orete Forest, Te Puia Hut, ex rotten log, 25.I.1993, leg. R. M. Emberson (LUNZ); $1 \sigma^{*}$, Waenga, under log, 20.X.1992, leg. J. W. M. Marris (LUNZ); 10", Waenga, under log, 27.I.1993, leg. R. M. Emberson (cAss); $10^{*}$, Waenga, ex sieved litter, 28.I.1993, leg. R. M. Emberson (LUNZ); 10*, Waenga, on rotten wood at night, leg. R. M. Emberson (LUNZ); $10^{*}$, Waenga, in rotten log, 20.X.1992, leg. J. W. M. Marris (LUNZ); $10^{\star}$, Waioroho, under rotten log, 21.X.1992, leg. J. W. M. Marris (LUNZ); $10^{*}$, Te Rereauira, under log in Nothofagus truncata forest, 9.III.1993, leg. J. W. M. Marris (LUNZ); $10^{7}$, Rereauira, under log, 20.X.1992, leg. J. W. M. Marris (cAss); $10^{7}, 1$ ㅇ, Papatea, mixed lowland broadleaf forest, 25.I. - 8.III.1993, leg. J. W. M. Marris (LUNZ, cAss); $20^{\pi} \sigma^{\pi}$, Te Koau, 243m, mixed broadleaf/podocarp forest, pitfall trap, 24.X.1992 - 31.I.1993, leg. R. M. Emberson (LUNZ); $10^{x}$, Otanga Bush, under rocks, 12.III.1993, leg. J. W. M. Marris (cAss). Bay of Plenty or Waikato: 1 ㅇ, Okauia, Matamata, Waikato, leg. A. E. Brookes, 1.XI. 1931 (NZAC); 1 ㅇ, Okauia, Matamata, XII.1924, leg. A. E. Brookes (NZAC); 1 ㅇ, Okauia, Matamata, 23.I.1924(BMNH). Gisborne: $10^{\pi}$, Kakanui, $300 \mathrm{~m}$, in rotting Nothofagus truncata, 16.III.1993, leg. R. F. Gilbert (AMNZ); $10^{*}$, Kakanui, 300m, under rotten log in Nothofagus truncata forest, 1.II.1993, leg. J. W. Early (cAss); $10^{\top}, 1$ ㅇ, Kakanui, 300m, under Nothofagus bark, 1.II.1993, leg. R. M. Emberson (LUNZ); 10*, Kakanui, 300m, Nothofagus truncata forest, pitfall trap, 27.X.1992 - 1.II.1993, leg. R. M. Emberson (LUNZ); 1 \%, Taikawakawa site, $280 \mathrm{~m}$, in rotten log, 18.III.1993, leg. R. F. Gilbert (AMNZ); $2 \% q$, Urewera NP, Panekiri Bluffs track, 70-1000m, under logs in Nothofagus forest, 14.XII.1994, leg. R. M. Emberson \& P. Syrett (LUNZ); 1 \%, Lake Waikaremoana, XII.46, leg. R. R. Forster (MNZW). 

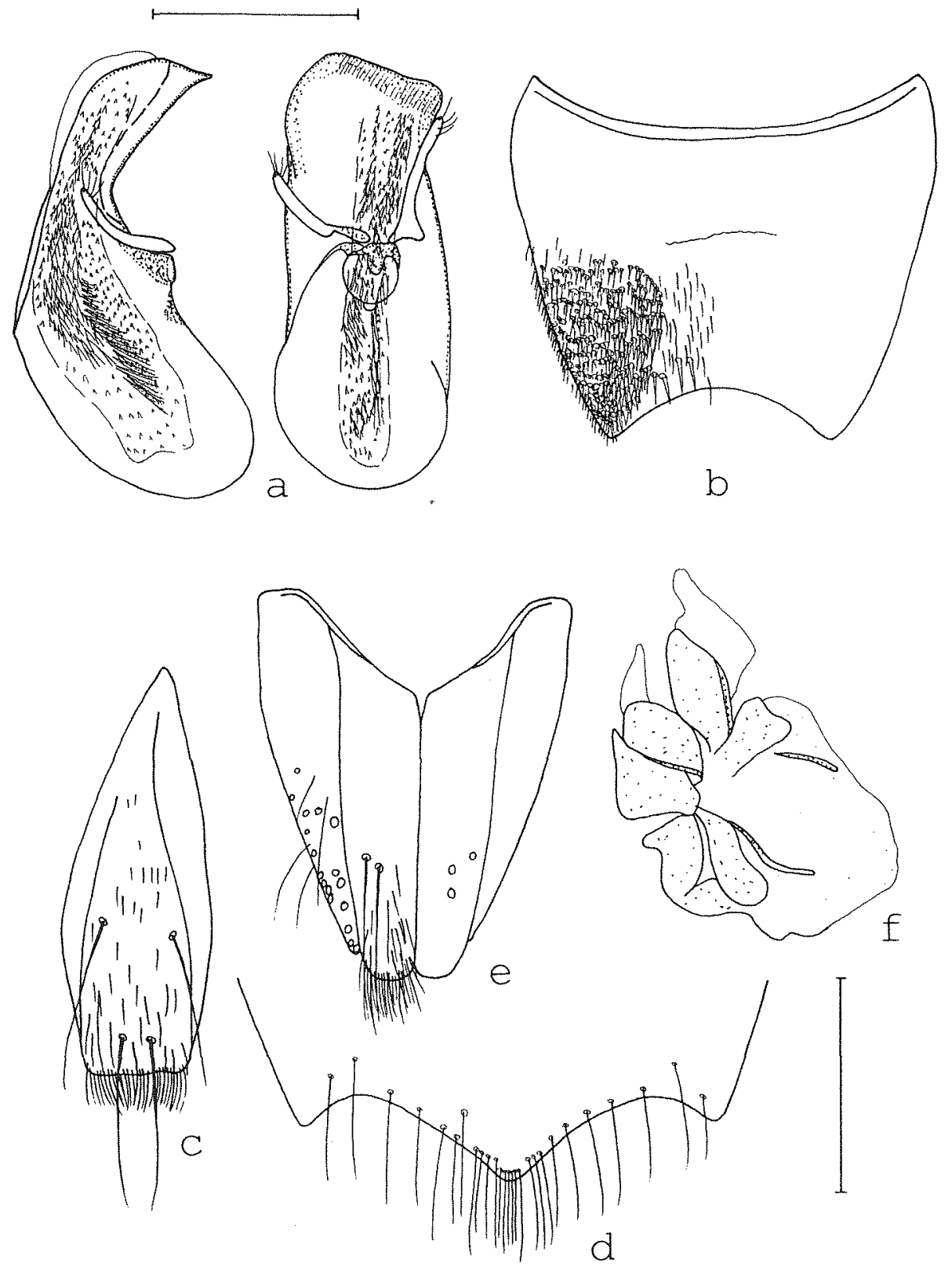

Fig. 10: Maorothius brookesi (CAMERON): aedeagus in lateral and in ventral view (a); $\sigma^{*}$ sternum VIII (b); ơ sternum IX (c); posterior margin 9 sternum VIII (d); ㅇ segment IX in ventral aspect (e); "bursa copulatrix" (f). Scale: $1 \mathrm{~mm}$.

\section{Description}

Measurements $(\mathrm{mm})$ and ratios (range, arithmetic mean; $\mathrm{n}=34$ ): HL: $2.00-2.72,2.23$; HW: 1.88 - 2.64, 2.14; PW: 2.08 - 2.84, 2.37; PL: 2.68 - 3.52, 3.03; EL: 1.48 - 1.88, 1.65; TiL: 1.64 
- 2.12, 1.81; TaL: 1.36 - 1.80, 1.53; AL: 1.84 - 2.16, 2.03; TL: 12.3 - 17.2, 14.4; HL/HW: 0.98

- 1.08, 1.04; HW/PW: $0.87-0.93,0.90$; PL/PW: $1.22-1.33,1.28$; EL/PL: $0.51-0.58,0.55$;

TiL/TaL: $1.09-1.29,1.19$.

Externally highly similar to $M$. adustus, and distinguished from that species as follows:

Colour of body brown to completely black.

Head on average more distinctly widened posteriorly; eyes usually shorter, less than half the length of postgenae in dorsal view; microreticulation more distinct; frons without median impression; frontal furrows present, but very shallow. Antennae slightly shorter, usually less than $1.3 \mathrm{x}$ longer than head width.

Elytra often with more coriaceous microsculpture.

${ }^{x}$ : sternum VII with \pm truncate hind margin, not distinctly depressed, and with \pm evenly distributed thin pubescence; sternum VIII with strongly concave hind margin, the posterior angles without hook-shaped processes, in central posterior area usually with fine and moderately dense, in lateral posterior areas with very dense, stout, yellowish setae (Fig. 10b), occasionally with \pm dense stout setae also in central posterior area; tergum VIII not pointed posteriorly, only very weakly convex; sternum IX with two long setae near hind margin and with or without two additional long setae in anterior area, pubescence shorter and sparser than in M. adustus (Fig. 10c); aedeagus relatively larger; both left and right asymmetry was observed; ventral process apically more acute and of different shape; parameres longer and with four apical setae; internal tube of median lobe with numerous small spines, basally with long and slender spines (Fig. 10a).

\&: tergum VIII truncate or weakly pointed posteriorly; sternum VIII very characteristic, its hind margin distinctly pointed (Fig. 10d); valvifers as in Fig. 10e; "bursa copulatrix" as in Fig. 10f.

\section{Comments}

The original description is based on two types from "Maku River, Bay of Plenty, March, 1928" (holotype) and "Okaula, Margamata, 25.xii.28" (paratype), one of them deposited in the Cameron collection and one in the Brookes collection. There were several specimens in the Brookes collection with the hand-written labels "Motu River" and "Okauia, Matamata", so the spelling in Cameron (1952) is apparently erroneous; the " $\mathrm{t}$ " in Brookes' handwriting in fact rather resembles a " $y$ " or a "k". As the abdomen of the holotype is missing, its sex cannot be assessed; according to the label attached to the pin, however, it is a female. Since two o or from the type locality were available, the present interpretation of the species can be considered safe. The three $q$ of from Okauia are externally very similar to the material from Motu River and here attributed to $M$. brookesi. The ${ }^{\pi}$ from Ngongotaha differs from the other specimens listed above in its \pm completely black colour, its slightly larger size, stouter mesotibiae and relatively longer legs, but since no convincing differences in the $\sigma^{\pi}$ primary and secondary sexual characters could be discovered and in the absence of additional material, it is regarded as conspecific with the holotype.

\section{Distribution and bionomics}

$M$. brookesi has been recorded from various localities in the region from the border between Waikato and Bay of Plenty (Okauia) to the east of Bay of Plenty and from Gisborne, in the northeast of the North Island (Map 1). The examined beetles were collected from October through April. Most specimens were found in and under rotten logs, mostly of Nothofagus truncata; some were caught with pitfall traps, sieved from litter, or found on bark of Nothofagus truncata at night. 


\subsection{Maorothius effeminatus $\mathrm{sp} . \mathrm{n}$.}

(Figs 1la-d, Map 2, p. 40)

Holotype $\sigma^{x}$ : Whangarei, N. Z, 18-20 - 3-31, E. S. Gourlay/Othius adustus Broun, identified by A. E. Brookes / $\sigma^{*}$ / Othius sp. n. 6, P. M. Hammond det. 1983 / Holotypus Maorothius effeminatus sp. n., det. V. Assing 1999 (NZAC).

Paratypes: $10^{7}$ : same date and locality as holotype / Othius adustus / Mouldy when returned (1970) J. C. W/ क (NZAC); 1 i : same date and locality / Othius adustus Brn./ क (NZAC); $10^{*}$ : Maunga, Karamea, Whangarei, 1.1.24, E. Yanburn [?] / Gyrohypnus adustus Broun, W. Steel det. 1949 (MNZW); 10: New Zeal. / Othius antipodum / Pascoe Coll. 93-60/sp. nov. 2 (BMNH); $10^{\pi}$ [teneral]: Tauraroa, N. Auckland, coll. Brairburn, 24-11 [II?]-28/ A. E. Brookes Collection / ㅇ (cAss); 1 ㅇ: Nov Zel / 5/708[?] / Broun / Fry Coll. 1905.100. (BMNH); 10: same labels, but 5/616[?] (cAss); 10", 1 ㅇ: [locality not specified] F. W. Hutton Collection / Othius adustus / Entomology Research Museum (LUNZ), Lincoln University, Canterbury, New Zealand (LUNZ).
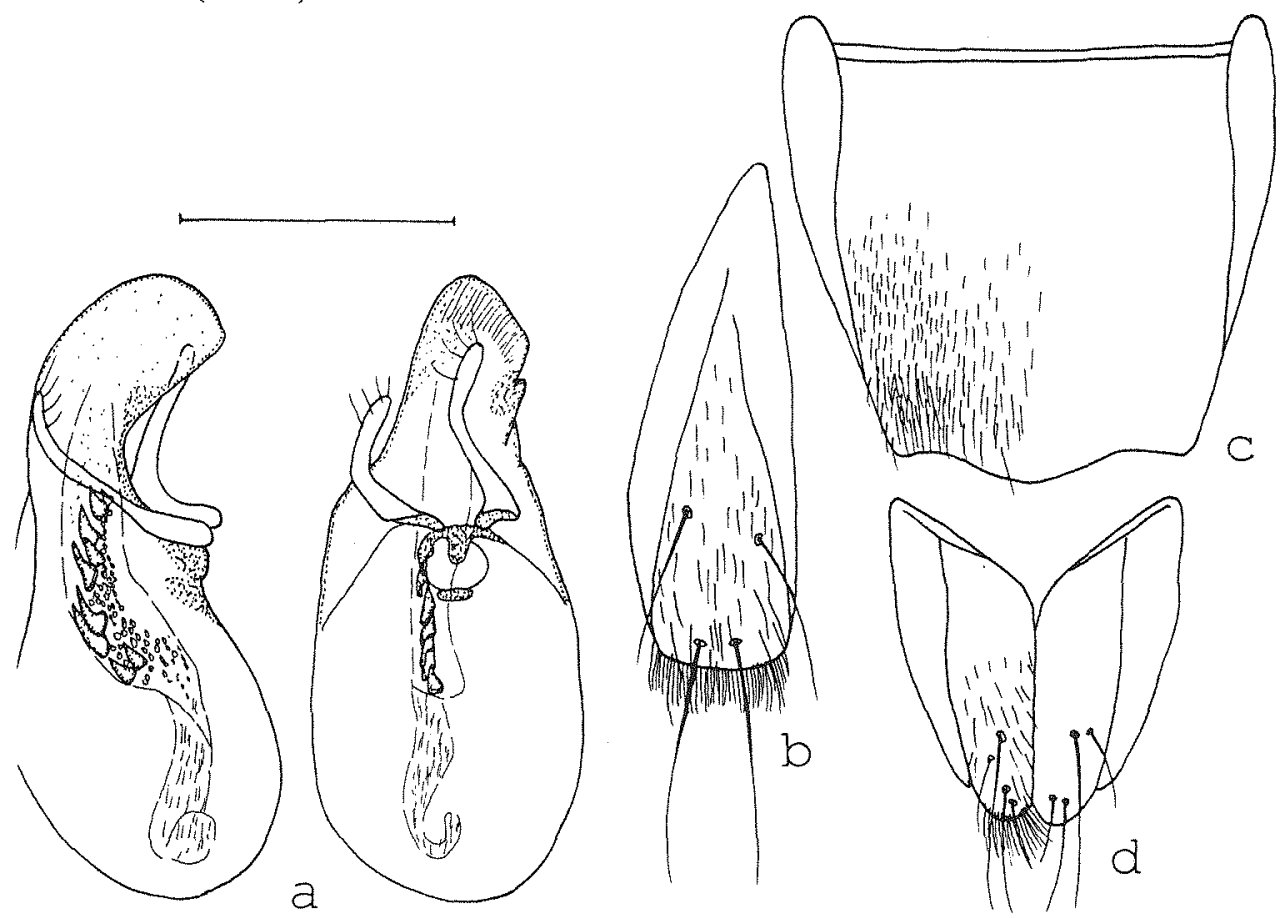

Fig. 11: Maorothius effeminatus sp. n. (a-c: HT): aedeagus in lateral and in ventral view (a); o sternum IX (b); ox sternum VIII (c); ๆ segment IX in ventral aspect (d). Scale: $1 \mathrm{~mm}$.

Material possibly referring to this species, but not included in type series: 1 i : Abour [?], 1930 (BMNH); 19: BP: Mt. Te Aroha, 930-950m, 12-13.xi.1983/leaf litter / NEW ZEALAND B. M. 1984-80, P.M. Hammond/Othius sp. n. 10 P.M. Hammond det. 1984 (BMNH).

\section{Description}

Measurements $(\mathrm{mm})$ and ratios (range; $\mathrm{n}=10)$ : HL: $2.00-2.44 ; \mathrm{HW}: 1.84-2.24 ; \mathrm{PW}: 2.00$ 2.52; PL: 2.56 - 3.16; EL: 1.52 - 1.72; TiL: 1.48 - 1.88; TaL: 1.36-1.56; AL: 2.08 - 2.28; TL: 11.6 - 16.4; HL/HW: 1.06 - 1.10; HW/PW: 0.88 - 0.93; PL/PW: 1.24 - 1.29; EL/PL: 0.54 0.59 ; TiL/TaL: $1.11-1.26$. 


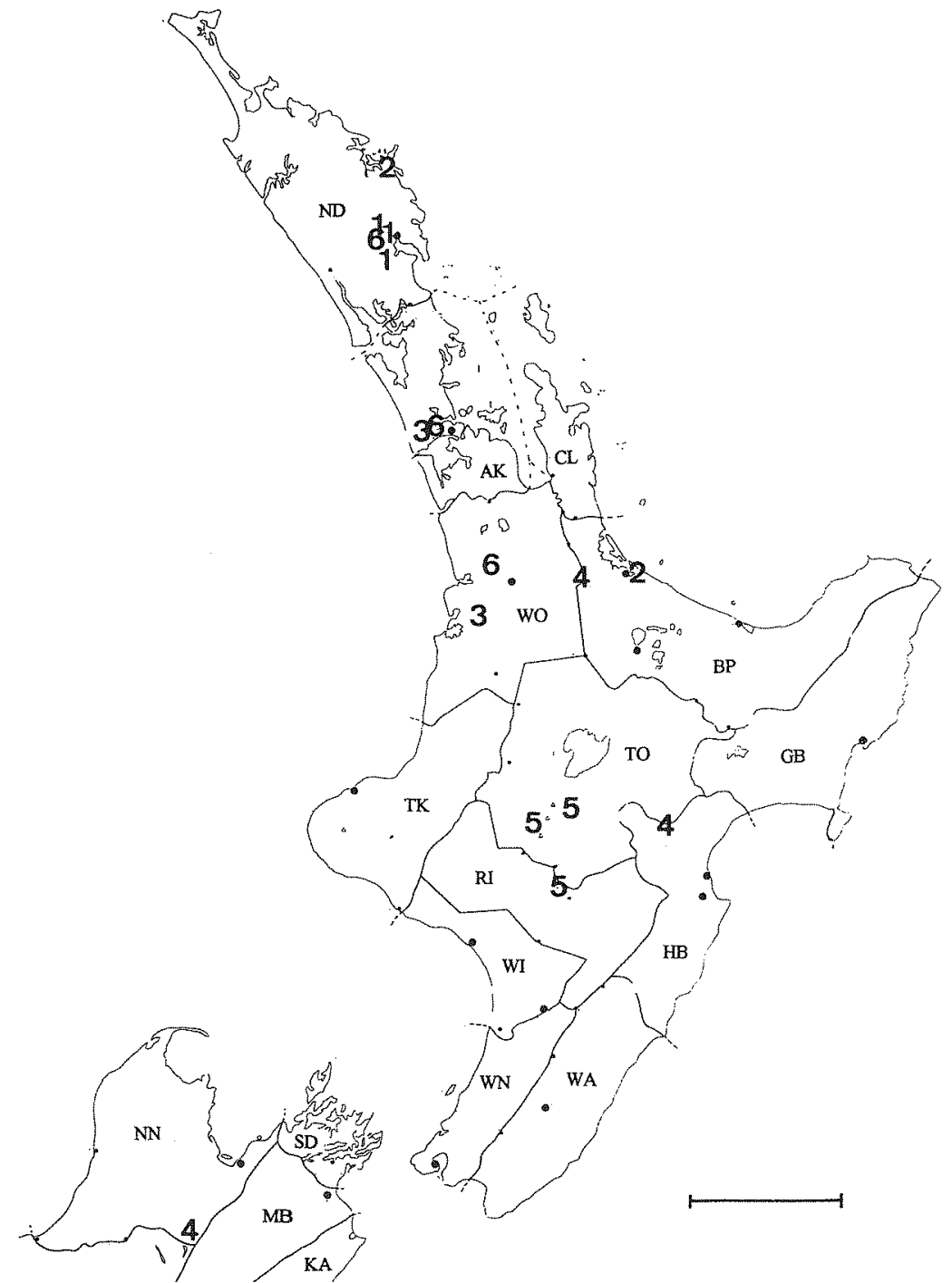

Map 2: Distribution of M. effeminatus sp. n. (1), M. pectinatus sp. n. (2), M. puncticeps (Broun) (3), $M$. coalitus sp. n. (4), M. tridens sp. n. (5), and $M$. volans sp. n. (6). Scale: $100 \mathrm{~km}$. Area codes: AK= Auckland, $\mathrm{BP}=$ Bay of Plenty, $\mathrm{CL}=$ Coromandel, $\mathrm{GB}=$ Gisborne, $\mathrm{HB}=$ Hawkes Bay, $\mathrm{KA}=$ Kaikoura, $\mathrm{MB}=$ Marlborough, $\mathrm{ND}=$ Northland, $\mathrm{NN}=$ Nelson, $\mathrm{RI}=$ Rangitikei, $\mathrm{SD}=$ Marlborough Sounds, $\mathrm{TK}=$ Taranaki, $\mathrm{TO}=$ Taupo, $\mathrm{WA}=$ Wairarapa, $\mathrm{WI}=$ Wanganui, $\mathrm{WN}=$ Wellington, $\mathrm{WO}=$ Waikato.

Externally as in $M$. adustus and $M$. brookesi, but distinguished as follows:

Body on average smaller (see measurements).

Head more oblong, dorso-laterally usually with several $(2-5)$ small punctures between hind margin of eyes and occiput; eyes smaller, ca. 1/3 the length of postgenae in dorsal view.

Elytra with well-defined macropunctation and with weak or indistinct coriaceous microsculpture. $\sigma^{x}:$ sternum VII indistinctly depressed posteriorly, pubescence near hind margin weakly modified; tergum VIII weakly pointed posteriorly; sternum VIII with hind margin not concave, but weakly pointed, and posteriorly with weakly modified, in postero-lateral areas somewhat 
denser pubescence (Fig. 11c); sternum IX with a posterior and an anterior pair of long setae, pubescence relatively short and yellowish (Fig. $11 \mathrm{~b}$ ); aedeagus strongly asymmetric, both left and right asymmetry was observed; parameres relative long and with four apical setae; internal sac with one row of ca. 6 large dark spines (Fig. 11a).

q: tergum VIII weakly pointed; sternum VIII evenly convex posteriorly; valvifers as in Fig. $11 \mathrm{~d}$; posterior part of "bursa copulatrix" sclerotized.

Derivatio nominis: The name (Lat.) refers to the shape of the $\sigma^{x}$ sternum VIII, which is similar to that in 9 ? of other species.

\section{Distribution and bionomics}

M. effeminatus is known from several localities near Whangarei, Northland, North Island (Map 2). Some of the types were collected in January and March; in the remainder, the date of collection was either not clearly legible or not indicated.

\subsection{Maorothius hammondi sp. n.}

(Figs 12a-c, Map 1, p. 29)

Holotype ơ: WO: Kauri Flat, $14 \mathrm{~km}$. SW Waingaro, 26.xi.1983 / rotten log / NEW ZEALAND B. M. 1984-80, P.M. Hammond [overleaf] / Holotypus Maorothius hammondi sp. n., det. V. Assing $1999(\mathrm{BMNH})$.

Paratypes: 10: WO: Hakarimata, ca. 100-300m, 20.xi.1983/rotten log / NEW ZEALAND B. M. 1984-80, P.M. Hammond [overleaf] / Othius sp. n. 5 P. M. Hammond det. 1984 (cAss); 10: Pirongia / T. Broun Collection / A. E. Brookes Collection / $\sigma^{*} /$ Othius sp. n. 10, P. M. Hammond det. 1983 (NZAC).

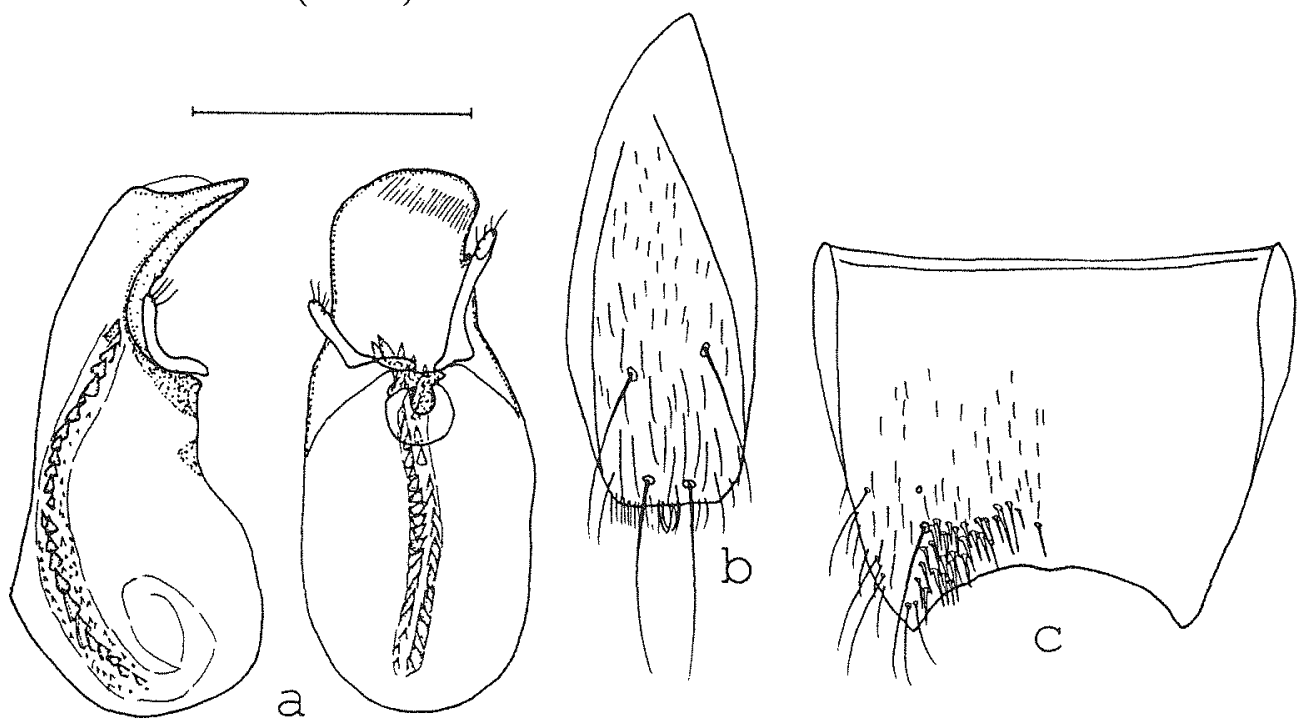

Fig. 12: Maorothius hammondi sp. n.: aedeagus in lateral and in ventral view (a); $\sigma^{x}$ sternum IX (b); $\sigma^{*}$ sternum VIII (c). Scale: $1 \mathrm{~mm}$.

\section{Description}

Measurements $(\mathrm{mm})$ and ratios (range; $\mathrm{n}=3$ ): HL: $2.00-2.20$; HW: $1.88-2.12$; PW: 2.04 2.40; PL: 2.60 - 3.04; EL: 1.40 - 1.64; TiL: 1.52 - 1.80; TaL: 1.28 - 1.48; AL: 2.00 - 2.32; TL: 12.3 - 14.6; HL/HW: 1.04 - 1.06; HW/PW: 0.88 - 0.92; PL/PW: 1.27 - 1.28; EL/PL: 0.54 0.55 ; TiL/TaL: $1.19-1.22$. 
Externally similar to $M$. brookesi, but distinguished as follows:

Size smaller (see measurements).

$\sigma^{x}$ : sternum VII slightly flattened posteriorly, its hind margin weakly concave; sternum VIII with hind margin broadly concave, in the middle with weak convexity, pubescence short and rather sparse, modified setae not very dense and confined to rather small area near hind margin and hind angles (Fig. 12c); tergum VIII weakly pointed posteriorly; sternum IX with mixture of yellowish and dark pubescence, and with two pairs of macrosetae (Fig. 12b); aedeagus with more slender ventral process; both left and right asymmetry was observed; parameres shorter; internal sac with tube containing two rows of numerous rather small dark spines (Fig. 12a).

ㅇ: unknown.

Derivatio nominis: This species is dedicated to Peter Hammond, BMNH, who collected part of the type series and who, in spite of having examined part of the material which this study is based on, kindly left the revision to me.

\section{Distribution and bionomics}

M. hammondi is known from three localities in Waikato, North Island (Map 1). Two of the types were taken in rotten logs in November.

\subsection{Maorothius pectinatus sp. n.}

(Figs 13a-c, Map 2, p. 40)

Holotype o*: New Zealand ND, Russell SF, Runaruku, 17 Jul 1983, J. C. Watt / ex decaying Phyllocladus trichomanoides log / Holotypus Maorothius pectinatus sp. n., det. V. Assing 1999 (NZAC).

Paratype ơ: Mt. Maunganui, 19/11/54/193/sp. nov. 1 (BMNH).
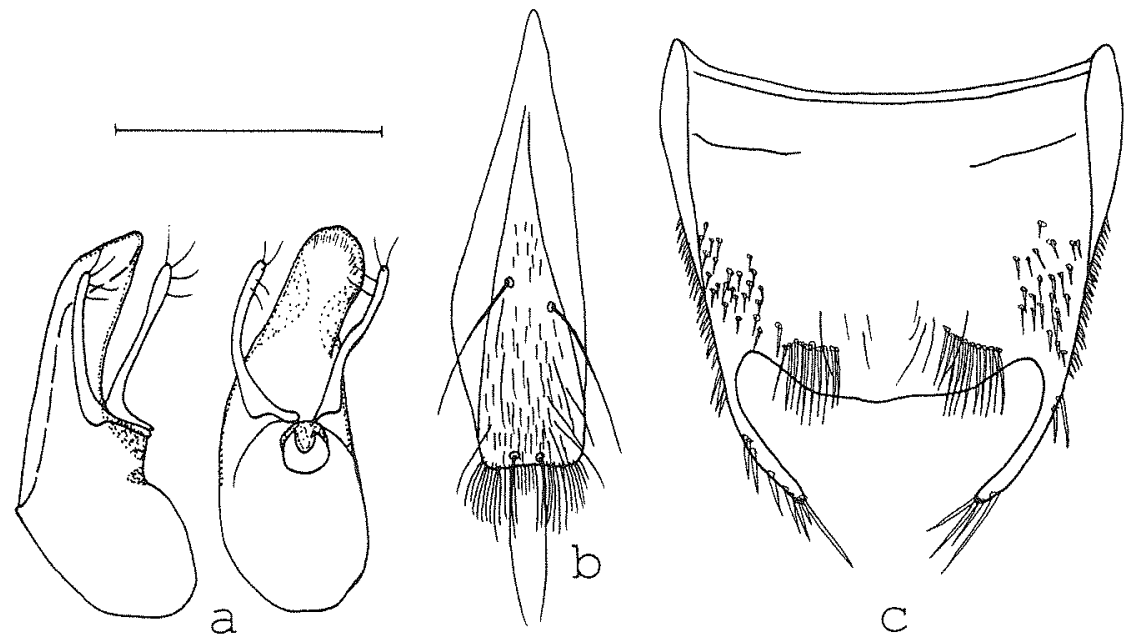

Fig. 13: Maorothius pectinatus sp. n. (HT): aedeagus in lateral and in ventral view (a); $\sigma^{x}$ sternum IX (b); $\sigma^{*}$ sternum VIII (c). Scale: $1 \mathrm{~mm}$.

Material possibly referring to this species, but not included in the type series: $1 \%$ : Nth. of Otaramarae, Rotorua, in rotten log, 26.X.67, J. C. Watt / क (NZAC); 1 \% : NEW ZEALAND, BP, Waiaroho, 80m, 10.iii.1993, J. W. M. Marris. / Under loose bark of fallen log (AMNZ). 


\section{Description}

Measurements (mm) and ratios (HT, PT): HL: 2.08, 2.16; HW: 2.04, 2.08; PW: 2.24, 2.28; PL: 2.80, 2.96; EL: 1.56, 1.60; TiL: 1.72, 1.72; TaL: 1.48, 1.56; AL: 1.40, 1.36; TL: 14.8, 15.3; HL/HW: 1.02, 1.04; HW/PW: 0.91, 0.91; PL/PW: 1.25, 1.30; EL/PL: 0.56, 0.54; TiL/TaL: $1.16,1.10$.

Externally similar to $M$. adustus; distinguished from that species as follows:

Body smaller (see measurements). Postgenae with $1-2$ small punctures between postocular puncture and marginal punctures near occiput. Pronotum with antero-lateral dorsal punctures slightly more distant from front margin. Elytra without or with very weak coriaceous microsculpture, and with well-defined macropunctation.

$\sigma^{x}$ : sternum VII postero-laterally with extensive patches of very dense and stout yellowish setae, hind margin \pm truncate; tergum VIII truncate posteriorly; sternum VIII highly distinctive, posterior angles extending into long processes equipped with long and stout setae, near hind margin with pair of comb-like rows of long stout yellowish setae, median area almost free of pubescence, and postero-lateral area with very dense, stout, and short setae (Fig. 13c); sternum IX with an additional pair of median macrosetae; pubescence composed of a mixture of short yellowish and longer black setae, hind margin with long and thin, yellowish pubescence (Fig. 13b); aedeagus very small, ventral process of median lobe in ventral view bent to the right; parameres long and slender, apically with 4 long setae; internal sac without distinct structures (Fig. 13a).

o: as the of 9 indicated above, but not included in the type series, cannot be referred to this species with certainty, a description of their terminalia is here refrained from.

Derivatio nominis: The name (Lat.) refers to the pair of comb-like rows of setae on the $\sigma^{\prime \prime}$ sternum VIII.

\section{Distribution and bionomics}

In contrast to most other species, $M$. pectinatus appears to be rather widespread, the distance between the localities in Northland and Bay of Plenty amounting to some $300 \mathrm{~km}$ (Map 2). The holotype was found in a decaying $\log$.

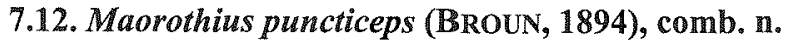

(Figs 14a-d, Map 2, p. 40)

Othius puncticeps Broun, 1894: 419.

\section{Type examined}

Syntype + [with mature egg in ovaries]: 2698 / Pirongia / Othius puncticeps / New Zealand. Broun Coll. Brit. Mus. 1922-482/ Type [round curator label]/ Syntype [round curator label] (BMNH).

\section{Additional material examined}

10 : O. puncticeps / N. Zealand (Broun.) 95-216/Othius puncticeps Broun (BMNH); 1 ; ; New Zealand: AK, Waitakere Range, 260m, Nohoanga Scenic Res., 8.xii.1984 - 25.i.85, hdwd.podocarp forest, A. Newton \& M. Thayer / window trap 679 (FMNH).

The original description is based on two syntypes collected on Mount Pirongia in December 1894. Only one of them could be identified with certainty. Since this syntype is a female, a lectotype designation is here refrained from. There is no locality label attached to the male listed as additional material, which was originally in the Broun collection. Therefore, it appears doubtful if it represents the second syntype. 

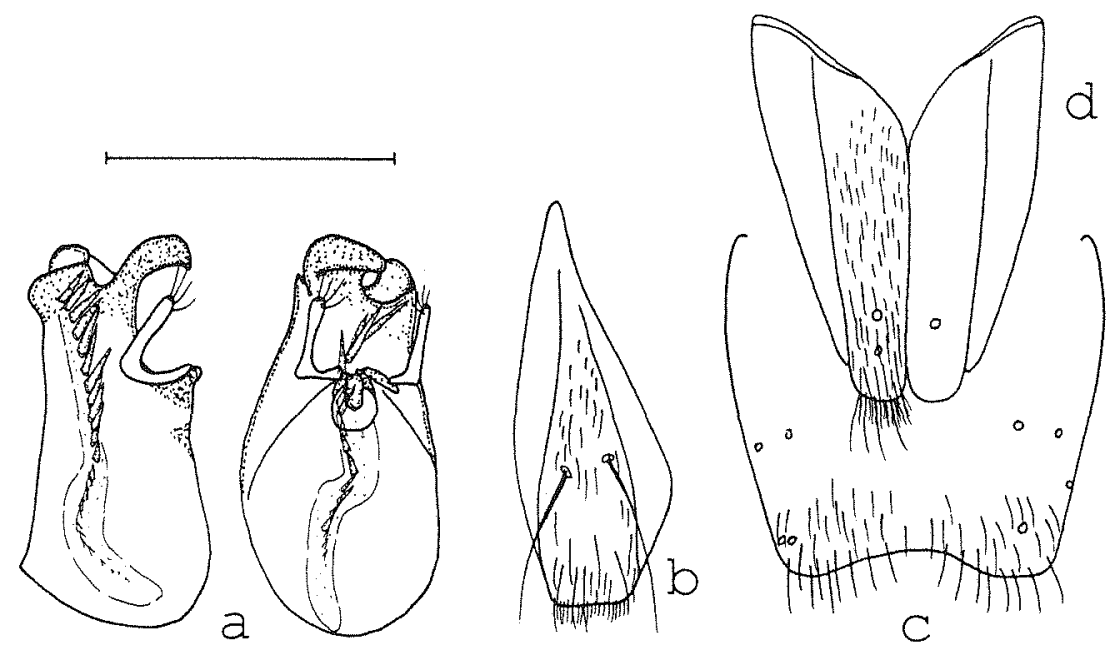

Fig. 14: Maorothius puncticeps (BROUN) (d: ST): aedeagus in lateral and in ventral view (a); $0^{x}$ sternum IX (b); ơ sternum VIII (c); 9 segment IX in ventral aspect (d). Scale: $1 \mathrm{~mm}$.

The specimens here attributed to $M$. puncticeps are in perfect agreement with the original description, which is based on two specimens collected on Mount Pirongia, not far from the locality where the $q$ specimen was taken. In view of the distinctive external characters (punctation of head, pronotum, and elytra; microsculpture of the elytra, eye size, etc.) there is little doubt that the present interpretation of the species is correct.

\section{Description}

Measurements (mm) and ratios (range; $\mathrm{n}=3$ ): HL: 1.56 - 1.60; HW: 1.38 - 1.44; PW: 1.56 1.64; PL: 2.16 - 2.20; EL: 1.08 - 1.16; TiL: 1.04 - 1.12; TaL: 1.04 - 1.06; AL: 1.44; TL: 8.8 11.5; HL/HW: 1.11 - 1.16; HW/PW: 0.88 - 0.90; PL/PW: 1.34 - 1.41; EL/PL: 0.50 - 0.53; TiL/TaL: $1.00-1.08$.

Externally similar to $M$. adustus and related species, but distinguished as follows:

Body distinctly smaller (see measurements).

Head more slender (see ratio $\mathrm{HL} / \mathrm{HW}$ ); with pair of frontal punctures and numerous additional macropunctures; only central dorsal area impunctate; eyes small, only ca. $0.25 \mathrm{x}$ the length of postgenae in dorsal view; frontal furrows completely absent.

Pronotum more slender than in $M$. adustus, only very weakly tapering posteriorly; with pair of antero-lateral dorsal punctures more distant from anterior margin, with an additional pair of pseudopunctures (i. e. not setiferous punctures) a short distance behind these punctures, and with an additional pair of dorso-lateral punctures slightly anterior to middle of pronotum.

Elytra with dense macropunctation, interstices on average as wide as or only slightly wider than diametre of punctures; microsculpture composed of dense micropunctation.

Legs with relatively long tarsi, metatarsi as long as metatibiae or nearly so.

Abdomen with denser and more distinct punctation than in $M$. adustus.

$\sigma^{7}$ : protarsomeres I - IV strongly dilated, slightly more so than in $q$; sternum VII weakly flattened posteriorly, its hind margin very slightly concave; sternum VIII with hind margin concave, centrally not membranous, pubescence yellowish (Fig. 14c); tergum VIII with \pm truncate hind margin; sternum IX with anterior pair of macrosetae, posterior pair of macrosetae apparently absent, longer pubescence predominantly dark, short pubescence yellowish (Fig. 14b); tergum IX undivided; tergum $\mathrm{X}$ small; aedeagus distinctly asymmetric; ventral process of highly 
distinctive shape, its lateral parts dorsally contiguous; parameres short and asymmetric, with 4 thin apical setae; internal sac with tube containing a row of numerous spines increasing in size distally (Fig. 14a).

\%: tergum VIII with \pm truncate hind margin; sternum VIII with yellowish pubescence, its hind margin weakly convex; valvifers as in Fig. 14d.

\section{Distribution and bionomics}

M. puncticeps is known from two localities in Auckland and Waikato in the northeast of the North Island (Map 2). One of the types was collected in a window trap, although the species is doubtlessly incapable of flight.

\subsection{Maorothius coalitus sp. $\mathrm{n}$.}

(Figs 15a-d, Map 2, p. 40)

Holotype $\sigma^{*}$ : NEW ZEALAND NN, Beebys Knob, 1220m, 5 Feb 1978, A. K. Walker / Moss and rotten wood 78/76/ $\sigma^{*} /$ Holotypus Maorothius coalitus sp. n., det. V. Assing 1999 (NZAC).

Paratypes: 10": Ahimanawa Ra, 600m, Hawkes Bay, 14 Jan 72, G. W. Ramsay, litter (cAss); 1 i [with mature egg in ovaries]: Okauia, Matamata, Waikato / Coll. A. E. Brookes, March, 1935 / Othius puncticeps Broun / A. E. Brookes Collection / $q$ / ?puncticeps Broun, P. M. Hammond det. 1983 (NZAC).
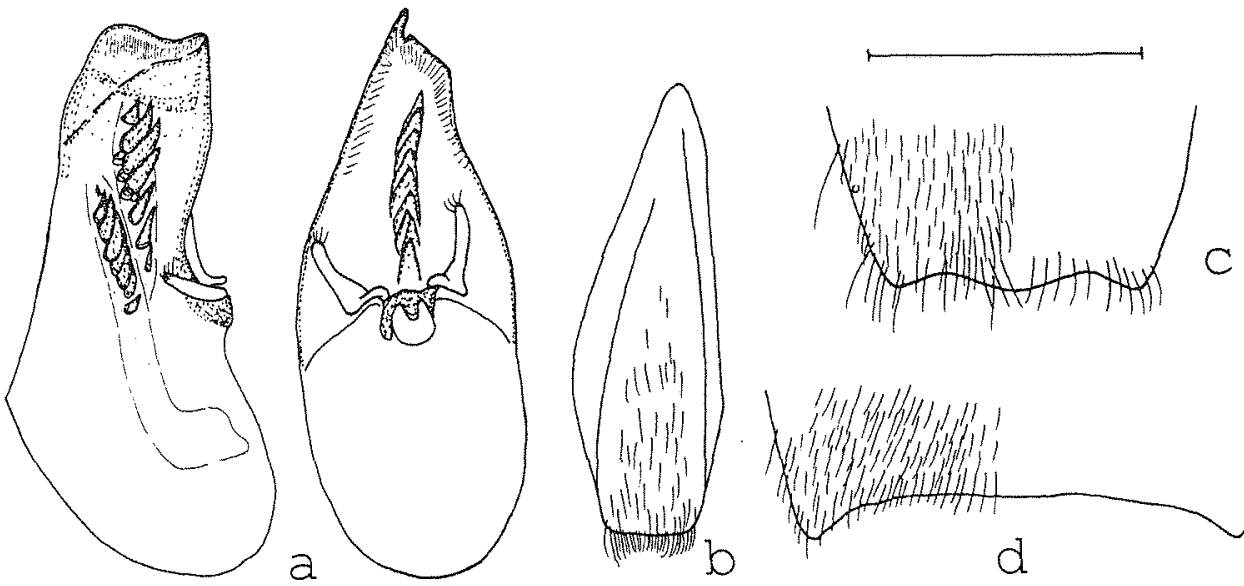

Fig. 15: Maorothius coalitus sp. n. (c-d: HT): aedeagus in lateral and in ventral view (a); o sternum IX (b); ox sternum VIII (c); hind margin of ox sternum VII (d). Scale: $1 \mathrm{~mm}$.

\section{Description}

Measurements $(\mathrm{mm})$ and ratios (range; $\mathrm{n}=3$ ): HL: $1.64-1.74 ; \mathrm{HW}: 1.44-1.56$; PW: 1.66 1.80; PL: 2.28 - 2.48; EL: 1.12 - 1.28; TiL: 1.20 - 1.28; TaL: 1.08 - 1.16; AL: 1.96 - 2.00; TL: 11.6 - 12.6; HL/HW: 1.10 - 1.14; HW/PW: 0.84 - 0.87; PL/PW: 1.33 - 1.38; EL/PL: 0.49 0.53 ; TiL/TaL: $1.03-1.15$.

Externally highly similar to M. puncticeps, but distinguished as follows:

Body slightly larger (see measurements).

Head narrower relative to pronotum (see ratio HW/PW); eyes slightly larger.

Pronotum less slender and more distinctly tapering posteriorly; with or without a pair of pseudopunctures a short distance behind pair of antero-lateral dorsal punctures. 
Elytra with less dense and more well-defined macropunctation, interstices on average as wide as or only slightly wider than diametre of punctures; micropunctation usually less dense, surface therefore more shiny.

$\sigma^{\text {x: }}$ sternum VII with broadly, moderately concave hind margin (Fig. 15d); sternum VIII with hind margin sinuate and centrally membranous, its pubescence yellowish and unmodified, near hind margin with a row of dark and rather long setae (Fig. 15c); tergum VIII with weakly convex hind margin; sternum IX without pairs of macrosetae, its pubescence predominantly dark (Fig. 15b); aedeagus distinctly asymmetric (both left and right asymmetry was observed), apical part of median lobe laterally compressed, with lateral parts of ventral process meeting dorsally; parameres short and asymmetric, with 4 short apical setae; internal sac with two rows of ca. 7 - $8 \pm$ large dark spines (Figs 15a).

$:$ tergum VIII with truncate hind margin; sternum VIII weakly tapering posteriorly, hind margin truncate; valvifers similar to $M$. puncticeps; "bursa copulatrix" apparently unsclerotized.

Derivatio nominis: The name (Lat.) refers to the dorsally fused lateral parts of the ventral process of the aedeagus.

\section{Distribution and bionomics}

$M$. coalitus is the only species of the genus that is known from both the North and the South Island. It has been found in three localities in Hawke's Bay, at the border between Waikato and Bay of Plenty, and in Nelson (Map 2). According to the labels attached to the types, they were collected in litter and rotten wood at altitudes of 600 and $1220 \mathrm{~m}$ from January to March. The ovaries of the 9 contained a mature egg.

\subsection{Maorothius tridens sp. $\mathrm{n}$.}

(Figs 16a-e, Map 2, p. 40)

Holotype o": WN: Desert Rd, S. Turangi, Mangatawai Stm., 13.1.72, litter 72/1, G. W. Ramsay $/ \sigma^{\pi} /$ Othius sp. cf. puncticeps, P. M. Hammond det. 1983 / Holotypus Maorothius tridens sp. n., det. V. Assing 1999 (NZAC).

Paratypes: 2 우: New Zealand RI, Paengaroa SR, Mataroa, 16-Jan-96/Pit trap. J Townsend (FMNH, cAss); 10", 19: Chateau. 3700' National Park, x epiphytic moss, 16-3-58. J. C. Watt / Berlese funnel x alcohol / AMNZ 25229 Auckland Museum New Zealand (AMNZ, cAss).

\section{Description}

Measurements $(\mathrm{mm})$ and ratios (range; $\mathrm{n}=5$ ): HL: $1.56-1.68 ; \mathrm{HW}: 1.44-1.56$; PW: 1.60 1.80; PL: 2.16 - 2.32; EL: 1.08 - 1.16; TiL: 1.08 - 1.28; TaL: $1.00-1.12$; AL: $1.76-1.96$; TL: 10.3 - 12.3; HL/HW: 1.08 - 1.14; HW/PW: 0.82 - 0.90; PL/PW: 1.29 - 1.36; EL/PL: 0.48 $0.52 ;$ TiL/TaL: $1.07-1.14$.

Externally similar to $M$. puncticeps and $M$. coalitus, but distinguished as follows:

Body slightly larger than $M$. puncticeps and smaller than $M$. coalitus (see measurements). Head and pronotum with more distinct microreticulation, surface therefore almost completely mat. Head of similar relative width as in $M$. coalitus, macropunctation sparser and less extensive, median dorsal area largely impunctate; pair of frontal punctures present; eyes larger than in $M$. puncticeps, ca. $0.3 \mathrm{x}$ the length of postgenae in dorsal view.

Pronotum relatively shorter than in $M$. puncticeps (see ratio PL/PW), with or without pair of median dorsal punctures; antero-lateral puncture closer to anterior margin.

Elytra with rugose punctation; micropunctation present, but less distinct and less dense. Abdomen with punctation similar to $M$. puncticeps. 

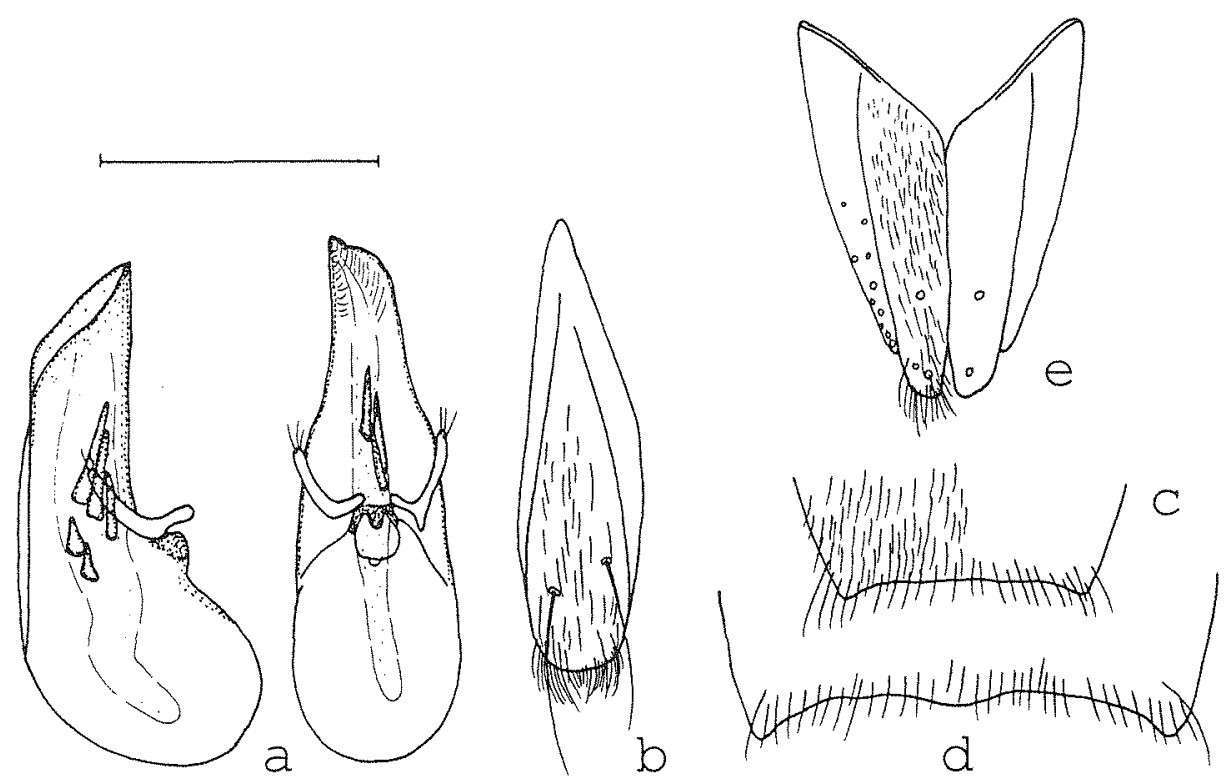

Fig. 16: Maorothius tridens sp. n. (a-d: HT): aedeagus in lateral and in ventral view (a); $o^{*}$ sternum IX (b); $0^{x}$ sternum VIII (c); hind margin of $o^{x}$ sternum VII (d); $q$ segment IX in ventral aspect (e). Scale: $1 \mathrm{~mm}$.

$\sigma^{\pi}$ : protarsomeres I - IV strongly dilated; sternum VII similar to $M$. puncticeps (Fig. 16d); tergum VIII truncate posteriorly; sternum VIII with broadly, but weakly concave hind margin, centrally not membranous and not convex (Fig. 16c); sternum IX with median pair of macrosetae, pubescence relatively sparse and predominantly yellowish (Fig. 16b); aedeagus with median lobe similar to $M$. coalitus, but more slender and with less distinctly modified ventral process; parameres short and with 3-4 short apical setae; internal sac with three very long and two or three shorter, distinctly sclerotized spines (Figs 16a).

q: protarsomeres slightly less dilated than in $\sigma^{\pi}$; sternum VIII weakly convex posteriorly; valvifers similar to $M$. puncticeps (Fig. 16e); "bursa copulatrix" apparently unsclerotized.

Derivatio nominis: The name (Lat., adj.: with three prongs) refers to the three long spines in the internal sac of the aedeagus.

\section{Comments}

In the + paratypes from Mataroa, the head is somewhat less strongly punctate, and the punctation of the abdomen is denser with the interstices about as wide as the diametre of the punctures (in the holotype the interstices are wider than the punctures). Nevertheless, they are here considered to be conspecific, as no additional differences were observed.

\section{Distribution and bionomics}

$M$. tridens is known only from three localities in Tongariro and Wanganui in the central region of the North Island (Map 2). The types were found in litter, pitfall traps, and in epiphytic moss in January and March.

\subsection{Maorothius volans sp. n.}

(Figs 17a-c, Map 2, p. 40)

Holotype o* [slightly teneral]: Maungatapere Bush, 29.11.44, B. Given / $\%$ / Othius sp. n. 2, P. M. Hammond det. 1983 / Holotypus Maorothius volans sp. n., det. V. Assing 1999 (NZAC). 
Paratypes: 19: WO: Hakarimata, ca. 100-300m, 27.xi.1983/leaf litter/New Zealand, P. M. Hammond, B. M. 1984-80/Othius sp. nov. 14, P. M. Hammond det. 1984 (BMNH); 1 ㅇ [hind wings fully unfolded]: New Zealand: AK, Waitakere Ra., Cascade-Kauri Park, Up. Kauri Tr., 170m, 8.xii.84 - 25.i.85, kauri-podo-hdwd., A. Newton \& M. Thayer, 680 / window trap 680 (FMNH).
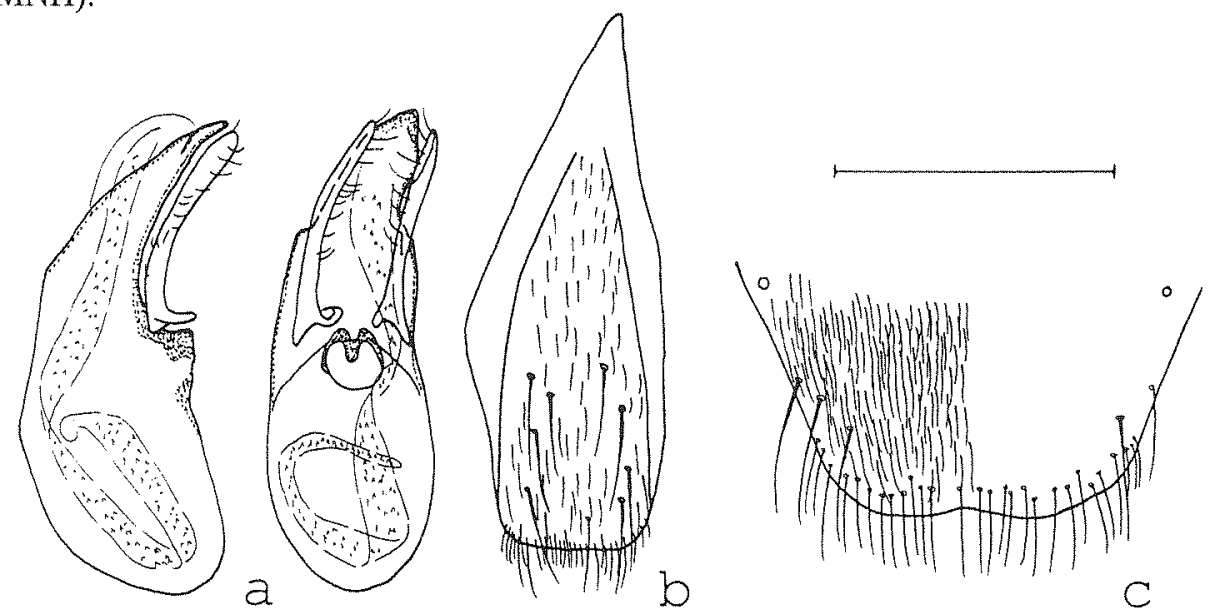

Fig. 17: Maorothius volans sp. n. (HT): aedeagus in lateral and in ventral view (a); $\sigma^{x}$ sternum IX (b); $\sigma^{x}$ sternum VIII (c). Scale: $0.5 \mathrm{~mm}$.

\section{Description}

Measurements $(\mathrm{mm})$ and ratios (range; $\mathrm{n}=3$ ): $\mathrm{HL}: 0.98-1.20 ; \mathrm{HW}: 1.10-1.18 ; \mathrm{PW}: 1.20$ 1.34; PL: 1.44 - 1.68; EL: 1.04 - 1.20; TiL: 0.84 - 0.94; TaL: 0.76 - 0.86; AL: 0.88; TL: 7.2 8.2; HL/HW: 0.98 - 1.02; HW/PW: 0.83 - 0.88; PL/PW: 1.20 - 1.25; EL/PL: 0.71 - 0.79 ; TiL/TaL: $1.05-1.11$.

External morphology highly distinctive; smallest species of the genus (see measurements). Head weakly widened posteriorly, approximately as long as wide; eyes large, only slightly shorter than postgenae in dorsal view; surface with relatively weak microreticulation and sparse micropunctation; whole dorsal surface with denser and more numerous macropunctures than in $M$. puncticeps; frontal punctures not distinguishable; postocular punctures situated very close to hind margins of eyes; frontal furrows absent.

Pronotum without median dorsal puncture, less oblong than in $M$. puncticeps and related species, microsculpture and micropunctation similar to head.

Elytra relatively longer than in other congeners (see ratio EL/PL), with relatively fine punctation, and without distinct microsculpture; hind wings fully developed.

Abdomen with very dense, fine and slightly granulose punctation; pubescence yellowish, decumbent and very dense; tergum VII with palisade fringe.

$\sigma^{\text {: }}$ protarsomeres I - IV strongly dilated; sternum VII unmodified; sternum VIII without median impression, its hind margin with very weak central concavity, almost truncate (Fig. 17c); sternum IX with yellowish pubescence and several longer dark setae, but without distinct pairs of macrosetae (Fig. 17b); terga IX and X similar to $M$. puncticeps; aedeagus slender; ventral process of median lobe weakly asymmetric; parameres long, weakly asymmetric, with 4 stouter apical and several additional finer subapical setae; internal sac with almost transparent tube, but without distinctly sclerotized structures (Fig. 17a).

of: protarsomeres I - IV moderately dilated, somewhat less so than in ${ }^{\text {; }}$; sternum VIII broadly convex, as in $\sigma^{\pi}$ near hind margin with row of relatively long yellowish setae; valvifers not fused, inner margins convex. 
Derivatio nominis: The name (Lat.: flying) refers to the fact that, in contrast to all known congeners, this species is apparently capable of flight.

\section{Distribution and bionomics}

M. volans is known from three localities in the north and northwest of the North Island, from Northland south to Waikato (Map 2). The types were collected at low altitudes from November to December or January. One paratype was caught in a window trap.

\subsection{Maorothius dispar sp. n.}

(Figs 18a-d, Map 3, p. 50)

Holotype $\sigma^{*}$ : L. Rotoroa, 1200', 2-3 - 1 - 39, E. S. Gourlay / q / Othius sp. n. 1, P. M. Hammond det. 1983 / Holotypus Maorothius dispar sp. n., det. V. Assing 1999 (NZAC).

\section{Description}

Measurements (mm) and ratios (HT): HL: 1.88; HW: 1.60; PW: 1.80; PL: 2.24; EL: 1.40; TiL: 1.40; TaL: 1.16; AL: 1.64; TL: 12.1; HL/HW: 1.18; HW/PW: 0.89; PL/PW: 1.24; EL/PL: $0.63 ; \mathrm{TiL} / \mathrm{TaL}: 1.21$.

Distinguished from its congeners by external appearance alone.

Head slender (see ratio HL/HW), of \pm parallel outline, hind angles smoothly rounded; neck slightly more slender than in the preceding species; surface with isodiametric microsculpture, but meshes distinctly larger than in the preceding species; postocular puncture absent; postgenae with $0-1$ small punctures, near occiput only with very few punctures; eyes relatively large, slightly less than half the length of postgenae in dorsal view, with larger ommatidia than in the preceding species; frontal furrows barely noticeable, reduced to extremely shallow oval impressions; antennae longer than in the preceding species, ca. $2 x$ longer than head width; inner margin of mandibles with two distinct median teeth of \pm equal size.
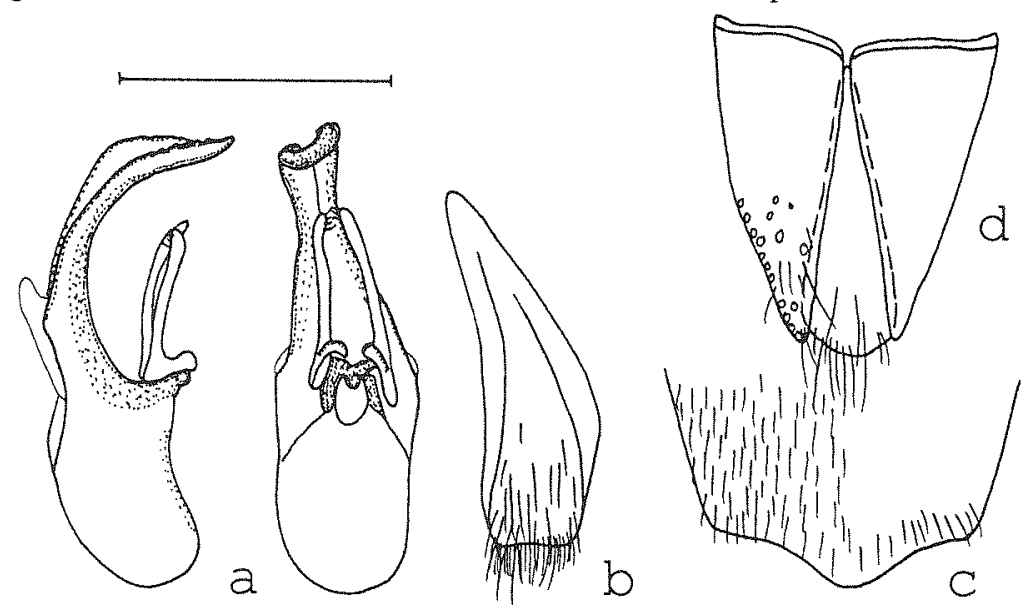

Fig. 18: Maorothius dispar sp. n. (HT): aedeagus in lateral and in ventral view (a); $o^{x}$ sternum IX (b); $\sigma^{x}$ sternum VIII (c); or terga IX and X (d). Scale: $1 \mathrm{~mm}$.

Pronotum with microsculpture similar to head, without median pair of dorsal punctures.

Elytra relatively long (cf. ratio EL/PL); with distinctive microsculpture composed of extremely dense, \pm transversely confluent micropunctation, surface therefore almost completely mat; macropunctation indistinct, pubescence absent; scutellum with microsculpture composed of transverse meshes and with several small punctures.

Abdomen with relatively coarser punctation, otherwise as in the preceding species. 


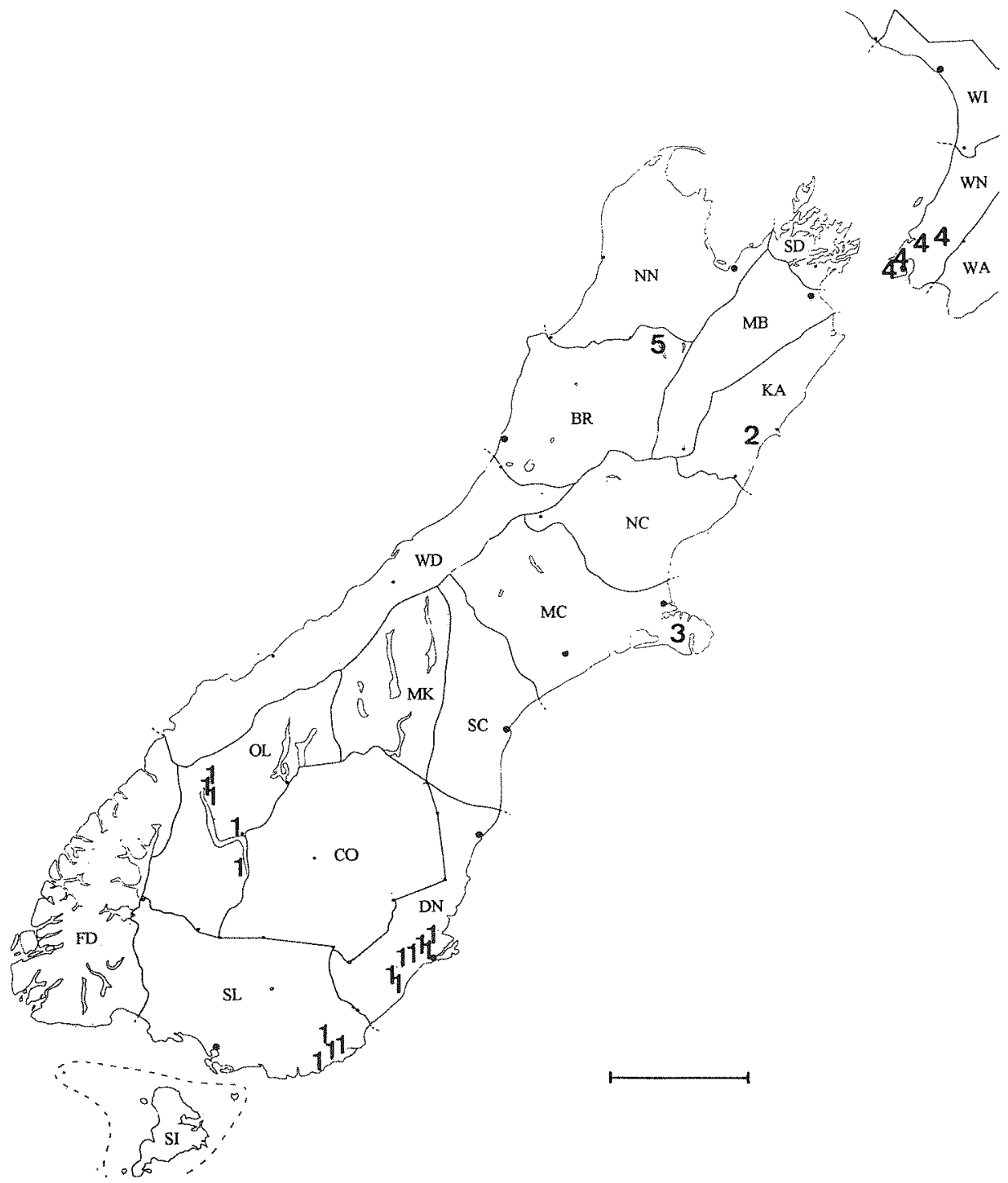

Map 3: Distribution of M. brouni (STEEL) (1), M. torquatus sp. n. (2), M. tonsor sp. n. (3), M. solus sp. n. (4), and M. dispar sp. n. (5) in the south of the North Island and in the South Island. Scale: $100 \mathrm{~km}$. Area codes: $\mathrm{BR}=$ Buller, $\mathrm{CO}=$ Central Otago, $\mathrm{DN}=$ Dunedin, $\mathrm{FD}=$ Fiordland, $\mathrm{KA}=$ Kaikoura, $\mathrm{MB}=$ Marlborough, $\mathrm{MC}=$ Mid Canterbury, $\mathrm{MK}=$ Mackenzie, $\mathrm{NC}=$ North Canterbury, $\mathrm{NN}=$ Nelson, $\mathrm{OL}=$ Otago Lakes, $\mathrm{SC}=$ South Canterbury, $\mathrm{SD}=$ Marlborough Sounds, $\mathrm{SI}=$ Stewart Island, $\mathrm{SL}=$ Southland, $\mathrm{WA}=$ Wairarapa, $\mathrm{WD}=$ Westland, $\mathrm{WI}=$ Wanganui, $\mathrm{WN}=$ Wellington .

o: sternum VII in central posterior area weakly flattened, otherwise unmodified; tergum VIII posteriorly convex; sternum VIII with obtusely pointed hind margin, pubescence unmodified (Fig. 18c); sternum IX strongly asymmetric, without macrosetae, and with predominantly long and black sparse pubescence, its hind margin with dense thin yellowish pubescence (Fig. 18b); tergum IX divided into two sclerites, tergum $\mathrm{X}$ very long and anteriorly acute (Fig. 18d); 
aedeagus very distinctive, with strongly sclerotized, long, and in lateral view strongly curved ventral process; parameres relatively straight and weakly asymmetric, apically with 3 or 4 very short and stout setae; internal sac without distinct structures (Fig. 18a).

क: unknown.

Derivatio nominis: The name (Lat.) refers to the highly distinctive morphology of this species.

\section{Distribution and bionomics}

M. dispar is known only from the type locality in Buller, South Island (Map 3), where it was collected in January.

7.17. Maorothius brouni (STEEL, 1948), comb. n.

(Figs 19a-p, Map 3)

Othius angustus BROUN 1893: 1026.

Gyrohypnus brouni STEEL, 1948: 270; nom. n.

\section{Type examined}

Lectotype $\sigma^{\star}$, present designation: Taieri / 1837 / Othius angustus / New Zealand. Broun Coll. Brit. Mus. 1922-482 / Type [round curator label] / Syntype [round curator label] / Lectotypus Othius angustus Broun desig. V. Assing 1998 (BMNH).

The original description is based on type material from Taieri; the number of specimens is not specified. Therefore, and in view of the external similarity of this species and its congeners, a lectotype designation is deemed necessary to preserve the present interpretation of the species.

\section{Additional material examined:}

Southland: $10^{*}$ [teneral], Owaka, Purakaunui Falls, traps, 20.I.1978, leg. S. B. Peck (FMNH); 1 if [teneral], Owaka, Table Hill Reserve, ber. forest litter, 17.I.1978, leg. S. \& J. Peck (FMNH); 19, Owaka Table Hill, sifted litter and rotten wood, 14.I.1978, leg. Kuschel

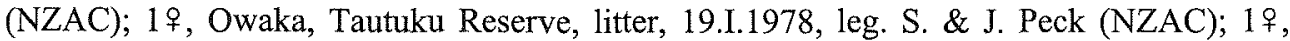
Catlins SF Park, Chloris Saddle, sifted litter, 16.II.1982, leg. Dugdale \& Butcher (NZAC). Dunedin: 10", Dunedin ['Duedin'], 10.XII.1950, leg. Gourlay (NZAC); $10^{*}$ [teneral], Dunedin, Leith V, litter, 12.I.1978, leg. S. \& J. Peck (NZAC); $10^{\star}$, Government Tck, Waipori V, 29.XII. 1995 (cAss); $1 \sigma^{*}, 1$ \% , ca. $10 \mathrm{~km}$ W Henley, Government Track, Waipori Gorge, under rock on forest floor, 4.IV.1998, leg. Nunn (cNun, cAss); 10\%, Mt. Cargill, Dunedin, in wet litter from ditch in forest, 25.VI.1999, leg. Nunn (cNun); 19 , Outram, Woodside Glenn, under rock on forest floor, 11.IV.1999, leg. Nunn (cNun). Otago Lakes: $10^{7}$ [teneral], OL, Paradise N Lake Wakatipu, Nothofagus forest, under log, 2.II.1984 (cAss); 1 ㅇ, Mt. Alfred, 4.II.1914 (BMNH); 10" Mt. Earnslaw, 9.I.1945, leg. Gourlay (cAss); 10, 1 ㅇ, Ben Lomond, 7.III.1914 (BMNH, NZAC); 1 ㅇ, Ben Lomond (BMNH); 1 ㅇ, Mt. Dick, 2200, 17.III.14 (NZAC).

Locality not specified: $20^{\circ} 0^{*}, 1$, , locality not indicated (BMNH); 19 , [according to label attached to the specimen either DN or MC] III.1998 (cAss).

\section{Description}

Measurements (mm) and ratios (range, arithmetic mean; $\mathrm{n}=23$ ): HL: $1.56-1.96,1.77$; HW: 1.40 - 1.84, 1.63; PW: 1.68 - 2.12, 1.90; PL: 2.04 - 2.72, 2.36; EL; 1.12 - 1.36, 1.23; TiL: 1.12 -1.44, 1.25; TaL: $1.00-1.24,1.10$ AL: $2.28-2.88,2.50 ;$ TL: $10.6-14.6,12.0 ; \mathrm{HL} / \mathrm{HW}: 1.04$ - 1.13, 1.09; HW/PW: 0.83 - 0.89, 0.86; PL/PW: 1.17 - 1.33, 1.24; EL/PL: 0.48 - 0.55, 0.52; TiL/TaL: $1.07-1.21,1.13$.

In general appearance similar to $M$. adustus and $M$. brookesi, but somewhat smaller. 
Head weakly to distinctly widened posteriorly (Fig. 19a); eyes relatively small, 1/3 - 1/4 the length of postgenae in dorsal view; surface with distinct microreticulation and sparse micropunctation; frontal punctures absent; postocular punctures present, usually somewhat distant from hind margin of eyes; one additional puncture approximately halfway between eyes and occiput (Fig. 19a); frontal furrows completely absent; mouthparts and antenna as in Figs 19k-o. Pronotum with microsculpture and micropunctation similar to head; dorsal punctures similar to $M$. adustus, usually with small pseudopuncture (i. e. not setiferous puncture) a short distance behind antero-lateral puncture; ventral aspect of pronotum as in Fig. 19b.

Elytra short; microsculpture highly variable, from distinctly rugose (with ill-defined macropunctation) to weakly micropunctate (with well-defined macropunctures); hind wings reduced. Abdomen with punctation relatively dense and coarser than in M. adustus and M. brookesi.
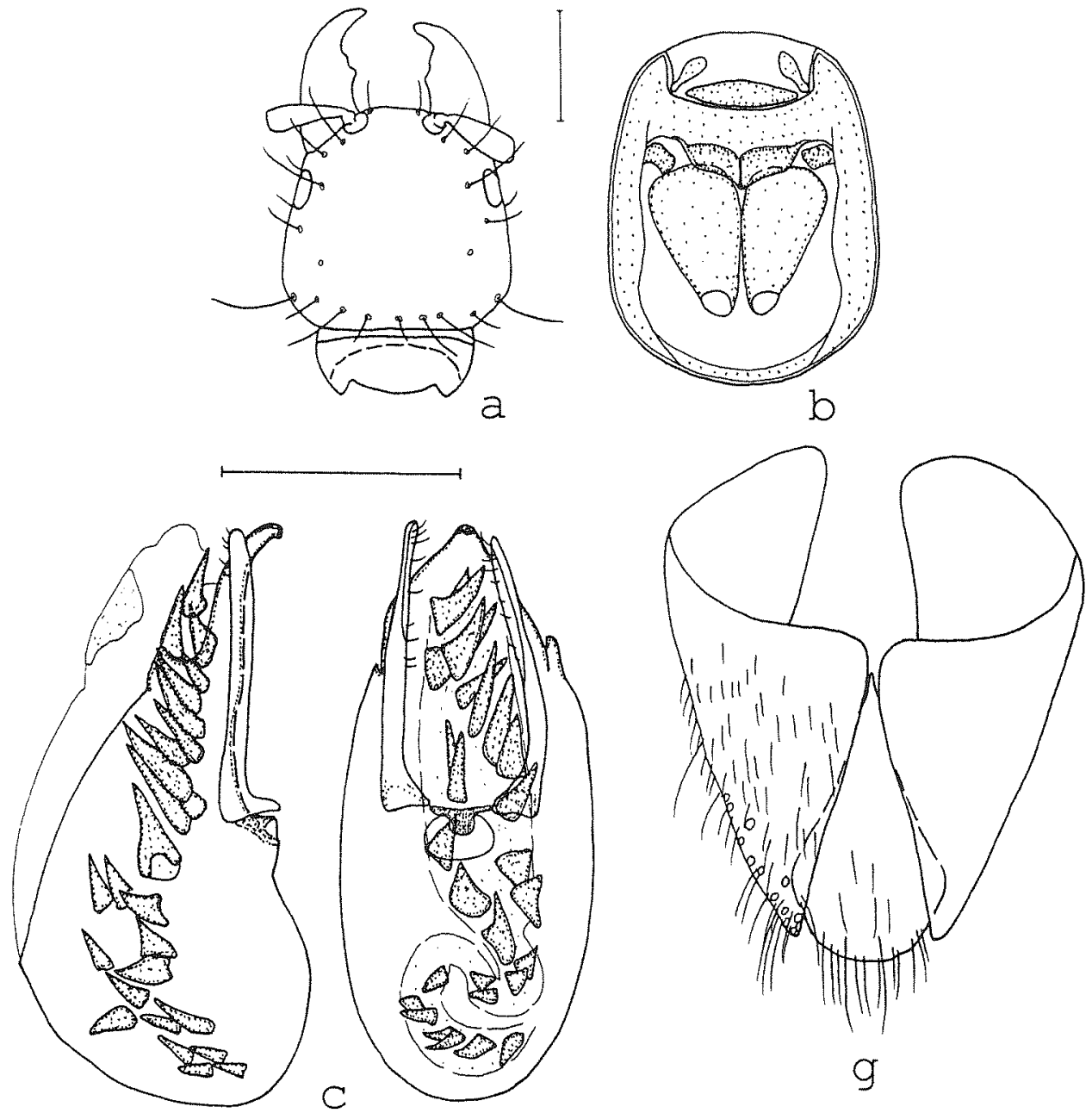

Fig. 19: Maorothius brouni (STEEL): head in dorsal view (a); prothorax in ventral aspect (b); aedeagus in lateral and in ventral view (c); $\sigma^{x}$ sternum IX (d); $\sigma^{x}$ sternum VII (e); $\sigma^{x}$ sternum VIII (f); $\sigma^{x}$ terga IX and $\mathrm{X}(\mathrm{g})$; $q$ terga IX and $\mathrm{X}(\mathrm{h})$; $q$ segment IX in ventral aspect (i); $q$ sternum VIII $(\mathrm{j})$; antenna with pubescence omitted $(\mathrm{k})$; maxilla (l); labium (m); mentum and submentum (n); labrum, long setae omitted (o); "bursa copulatrix" (p). Scales: a-k, p: $1 \mathrm{~mm}$; 1-o: $0.5 \mathrm{~mm}$. 


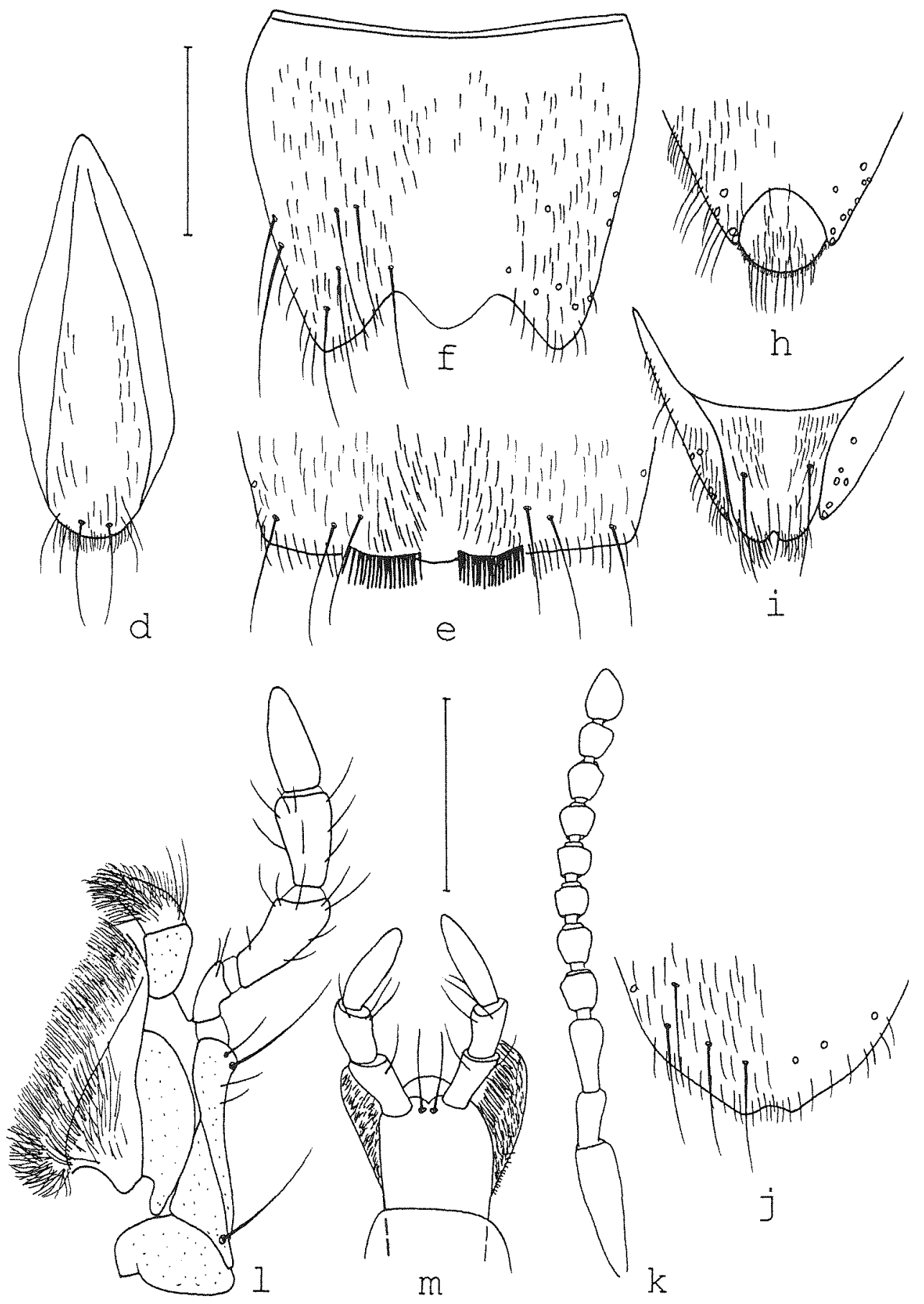




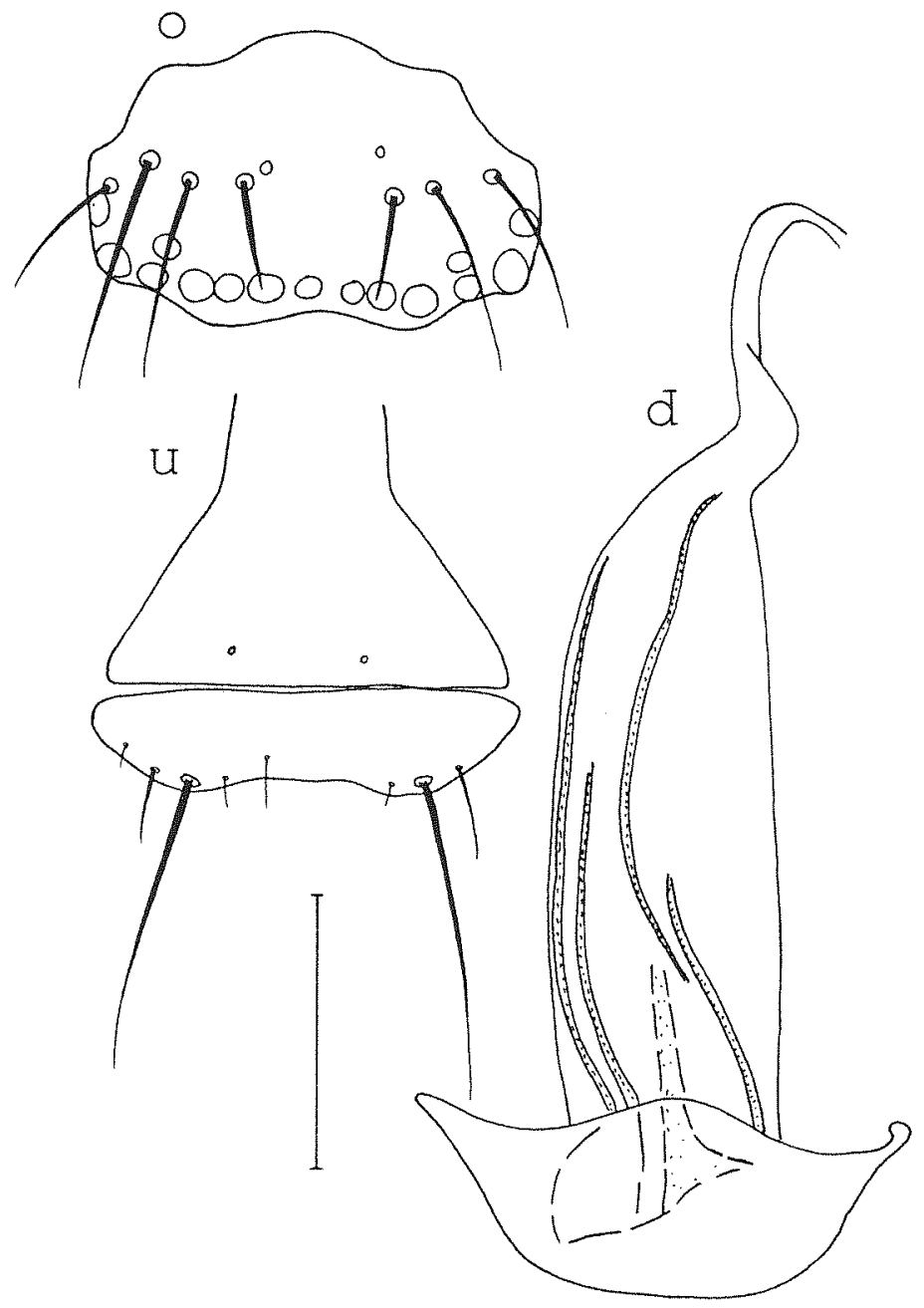

$\sigma^{x}$ : protarsomeres I - IV strongly dilated; sternum VII in central posterior area distinctly impressed, its posterior margin with two cristae of long dark setae (Fig. 19e); sternum VIII with median impression, its hind margin deeply and broadly concave, in the middle strongly convex and membranous (Fig. 19f); sternum IX \pm symmetric, with sparse pubescence and with a posterior pair of macrosetae (Fig. 19d); tergum IX divided into two sclerites, tergum X long and anteriorly acute (Fig. 19g); aedeagus with ventral process weakly asymmetric and of somewhat variable shape; parameres long, not distinctly asymmetric and with subapical setae; internal sac with numerous distinctly sclerotized and rather massive spines of variable size and shape (Fig. 19c).

9: protarsomeres I - IV strongly dilated, only slightly less so than in $0^{*}$; sternum VIII posteriorly obtusely pointed or weakly emarginate in the middle (Fig. 19j); tergum VIII with hind margin centrally weakly convex, posterior lateral parts strongly developed and projecting caudad; tergum IX undivided (Fig. 19h); valvifers almost completely fused, only apically with short incision, median suture obsolete (Fig. 19i); "bursa copulatrix" large and sclerotized (Fig. $19 \mathrm{p})$. 


\section{Distribution and bionomics}

M. brouni is distributed in the south of the South Island: Southland, Otago Lakes, and Dunedin (Map 3). The specimens examined were caught with traps, sifted from litter, collected from rotten wood, under logs, and under deeply embedded rocks in woodland from December through April and in June. Four beetles taken in January and February were teneral.

\subsection{Maorothius torquatus $\mathrm{sp} . \mathrm{n}$.}

(Figs 20a-e, Map 3, p. 50)

Holotype $\sigma^{\text {: }}$ Oaro, N. Canterbury, 25.2.47, L. E. Clarke [written on reverse side of mounting label]/ Oaro / Othius sp. n. 11, P.M. Hammond det. 1987 / Holotypus Maorothius torquatus sp. n., det. V. Assing 1999 (BMNH).

Paraytypes: 1 우: same data as holotype (cAss); 1 웅 Oaro / C. E. Clarke Collection / AMNZ 25263, Auckland Museum New Zealand (AMNZ).
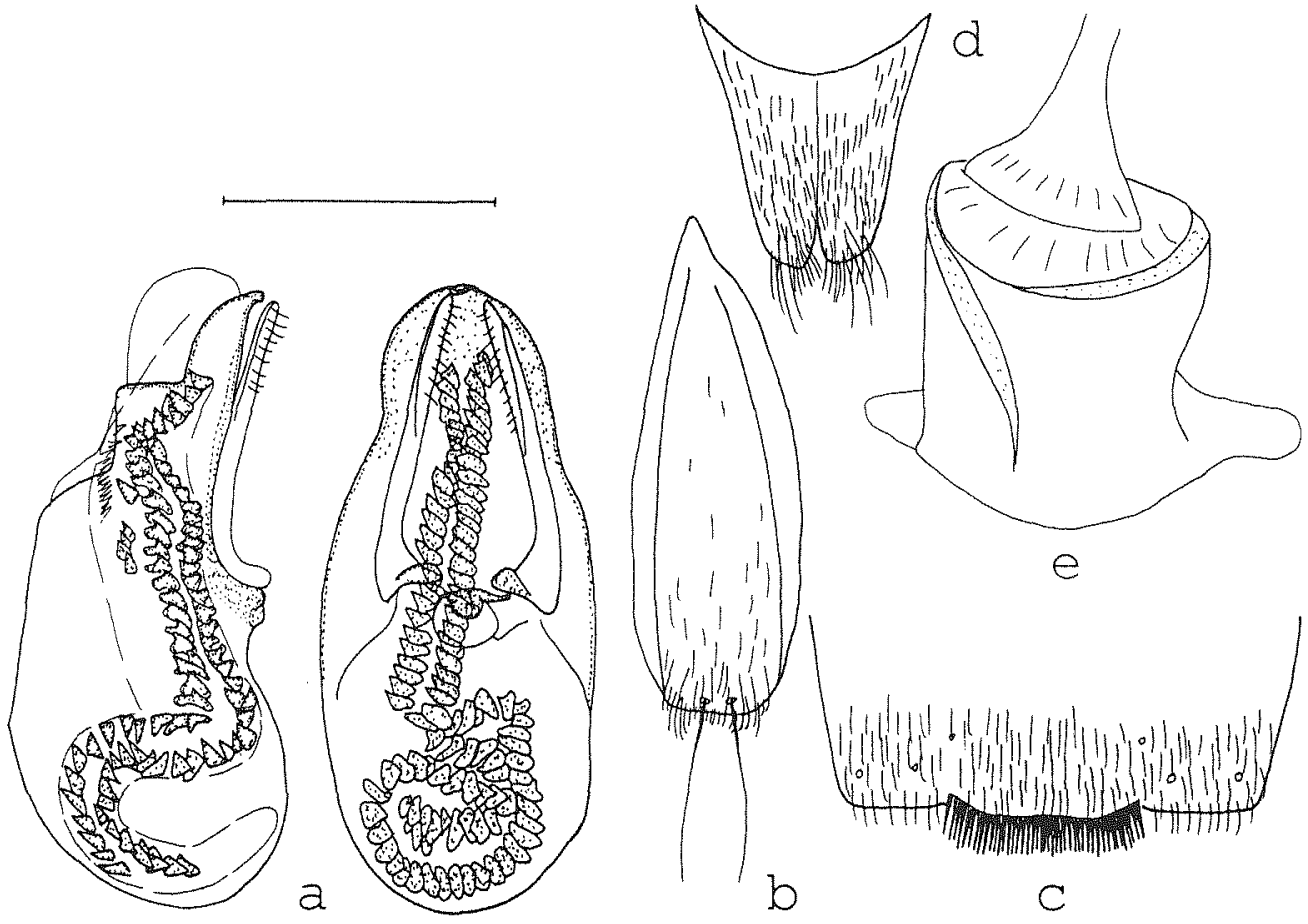

Fig. 20: Maorothius torquatus sp. n. (a-c: HT): aedeagus in lateral and in ventral view (a); o sternum IX (b); posterior part of on sternum VII (c); ; valvifers in ventral aspect (d); "bursa copulatrix" (e). Scale: $1 \mathrm{~mm}$.

\section{Description}

Measurements (mm) and ratios (range; n=3): HL: 1.56 - 1.68; HW: 1.56 - 1.64; PW: 1.72 1.84; PL: 2.12 - 2.28; EL: 1.16 - 1.24; TiL: 1.20 - 1.40; TaL: 1.20 - 1.24; AL: 2.24; TL: 11.5 12.0; HL/HW: $1.00-1.05$; HW/PW: $0.87-0.91$; PL/PW: $1.23-1.24$; EL/PL: $0.52-0.55$; TiL/TaL: $1.00-1.13$.

In general appearance highly similar to $M$. brouni, but distinguished as follows:

Head relatively shorter (see ratio HL/HW), more distinctly widened posteriorly. Tarsi relatively longer (see ratio TiL/TaL). Abdomen with denser and finer punctation. 


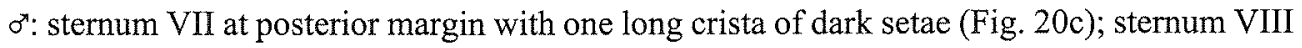
of similar shape and pubescence as in $M$. brouni; sternum IX with sparse pubescence and with a posterior pair of macrosetae (Fig. 20b); terga IX and X as in $M$. brouni; aedeagus with median lobe almost symmetric; parameres long, not distinctly asymmetric and with ca. 10 short apical setae; internal sac with two long rows of numerous sclerotized spines of approximately equal size, very large spines absent (Fig. 20a).

o: secondary sexual characters similar to $M$. brouni, but lateral parts of tergum VIII less strongly developed and not distinctly projecting posteriorly in dorsal view; posterior margin of sternum VIII not emarginate centrally; valvifers fused, but suture visible (Fig. 20d); "bursa copulatrix" much shorter, wider and less extensively sclerotized (Fig. 20e).

Derivatio nominis: The name (Lat:: ornate with a necklace) refers to the long series of small spines in the internal sac of the aedeagus, which somewhat resemble a pearl necklace.

\section{Distribution and bionomics}

$M$. torquatus is known only from the type locality in Kaikoura, southeastern Marlborough, South Island (Map 3), where the types were collected in February.

\subsection{Maorothius tonsor sp. $\mathrm{n}$.}

(Figs 21a-c, Map 3, p. 50)

Holotype $\sigma^{x}$ : New Zeal., S Isl., Banks Penins. Loc. 38., 20.IX.72, Lindroth / Othius sp., A. Newton det. 1976/MCZ / Holotypus Maorothius tonsor sp. n., det. V. Assing 1999 (originally from FMNH, now deposited in NZAC).

Paratype (see also appendix) \&: Canterby, N. Zeal. / Sharp Coll. 1905-313/ New Zealand / Othius zealandicus n. sp. Steel / Othius sp. n. 12, P.M. Hammond det. 1984 (BMNH).

\section{Description}

Measurements (mm) and ratios (HT, PT): HL: 1.50, 1.64; HW: 1.46, 1.60; PW: 1.80, 1.80; PL: 2.24, 2.28; EL: 1.22, 1.24; TiL: 1.20, 1.28; TaL: 1.08, 1.08; AL: 2.40, - ; TL: 11.1, 10.7; HL/HW: 1.03, 1.03; HW/PW: 0.81, 0.89; PL/PW: 1.24, 1.27; EL/PL: 0.54, 0.54; TiL/TaL: $1.11,1.19$.

In general appearance highly similar to $M$. brouni, but distinguished as follows:

Elytra with denser and more distinct punctation.

Abdomen with much denser punctation, interstices narrower than diametre of punctures. $\sigma^{x}$ : sternum VII with large and pronounced impression of triangular shape in posterior median area, with rather dense and dark pubescence, which is longer and slightly stouter in the impression than on remaining sternal surface; hind margin of sternum VII in the middle weakly concave (not convex as in $M$. torquatus) and with one long crista of dark setae (Fig. 21c); sternum VIII of similar shape as in $M$. brouni, also with membranous hind margin, but with weaker median impression and somewhat denser dark pubescence; tergum VIII as in the preceding species with convex hind margin; sternum IX with predominantly dark pubescence; posterior pair of macrosetae present (Fig. 21b); terga IX and X as in M. brouni; aedeagus with median lobe \pm symmetric; parameres long, \pm symmetric, with 4 slightly stouter apical and several additional subapical setae; internal sac with two long rows of numerous sclerotized spines, their shapes, number and arrangement different from those in $M$. brouni and $M$. torquatus (Fig. 21a).

q: protarsomeres almost as strongly dilated as in $\sigma^{*}$, sexual dimorphism very weak; hind margin of sternum VIII damaged in the paratype; valvifers similar to $M$. torquatus, fused, but suture visible; posterior part of "bursa copulatrix" sclerotized. 

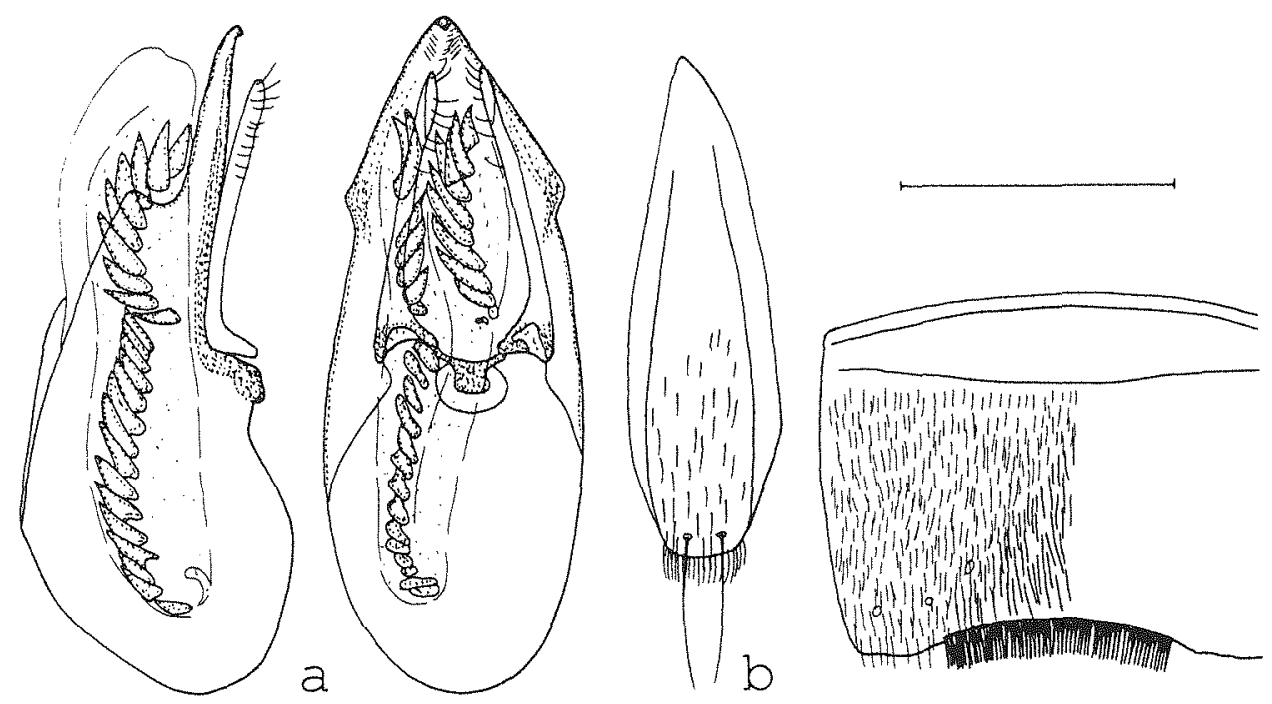

Fig. 21: Maorothitus tonsor sp. n. (HT): aedeagus in lateral and in ventral view (a); $\sigma^{*}$ sternum IX (b); $\sigma^{*}$ sternum VII (c). Scale: $1 \mathrm{~mm}$.

Derivatio nominis: The name (Lat.: hairdresser) refers to the long comb-like crista of black setae at the hind margin of the $\sigma^{x}$ sternum VII.

\section{Distribution and bionomics}

M. tonsor is known from two localities in Mid Canterbury, northeastern South Island (Map 3). The holotype was collected in September.

\subsection{Maorothius solus sp. $\mathrm{n}$.}

(Figs 22a-d, Map 3, p. 50)

Holotype $\sigma^{x}$ : New Zealand WN, Kowhai Park, Brooklyn, 16-Feb-97 / Leg. MR Nunn, Hadrotes wakefieldi / Holotypus Maorothius solus sp. n., det. V. Assing 1999 (FMNH).

Paratypes: $10^{7}$ [slightly teneral]: New Zealand WN, Karori Reservoir, 6-Nov-94 (cAss); 1 운 New Zealand WN, Pakuratahi Forks, 22/01/95 (FMNH); 1 ㅇ: New Zealand WN, Khandallah Domain, 24.12.93 (FMNH); 1 요 New Zealand WN, Battle Hill Res., Pauatahanui, 20.12.92/ Hadrotes wakefieldi det. JTN 5-95/ 1500 (cAss).

\section{Description}

Measurements (mm) and ratios (range; $\mathrm{n}=5)$ : HL: $1.44-1.62$; HW: 1.32 - 1.60; PW: 1.52 1.76; PL: 1.92 - 2.20; EL: 1.04 - 1.20; TiL: 1.08 - 1.24; TaL: 1.08 - 1.12; AL: 2.00 - 2.04; TL: 10.2 - 10.7; HL/HW: 1.01 - 1.09; HW/PW: 0.87 - 0.92; PL/PW: 1.20 - 1.29; EL/PL: 0.52 0.56 ; TiL/TaL: $1.00-1.15$.

Externally similar to $M$. brouni and $M$. torquatus, but distinguished as follows:

Head and pronotum with more distinct microreticulation, surface therefore almost completely mat. Pronotum with posterior median scratch-like sculpture finely extending cephalad to middle of pronotum. (In $M$. brouni and $M$. torquatus, this scratch-like sculpture is present, too, but does not extend to middle of pronotum.) Elytra with more distinct microsculpture, which is composed of \pm rugose or coriaceous micropunctation and microrugae. Abdomen with more distinct microsculpture. 

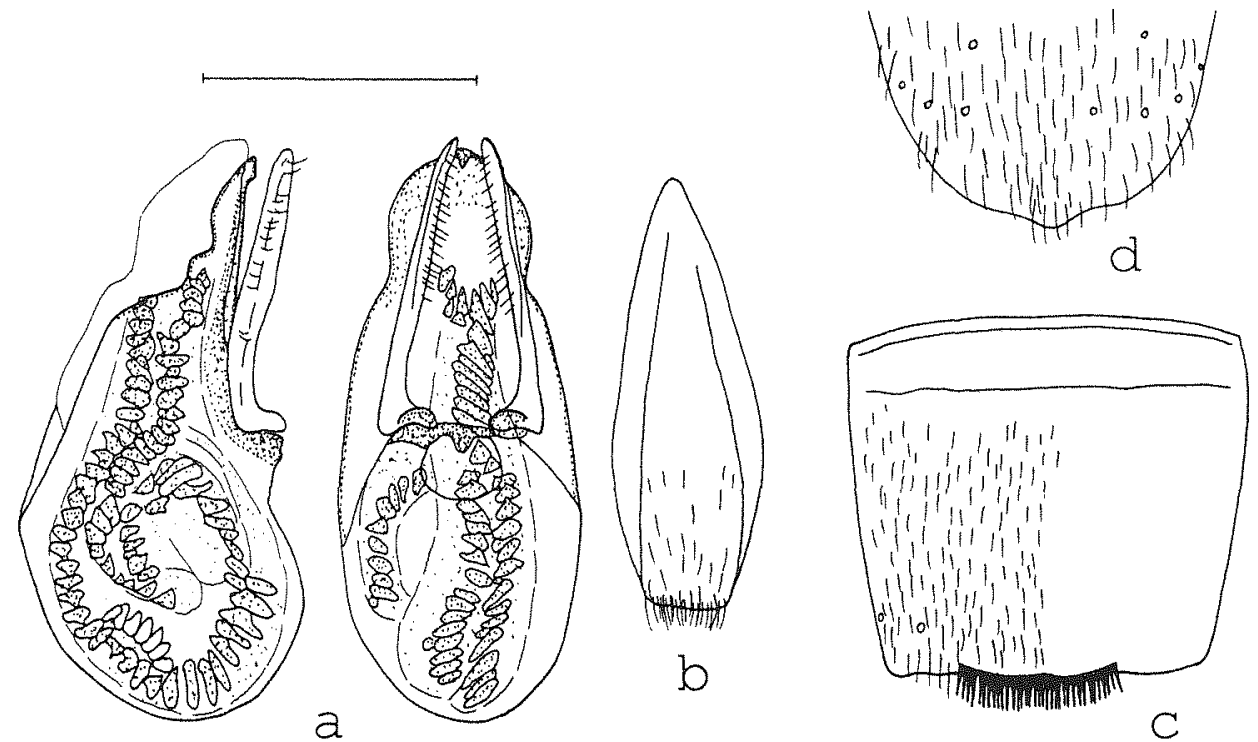

Fig. 22: Maorothius solus sp. n. (a: HT): aedeagus in lateral and in ventral view (a); $\sigma^{x}$ sternum IX (b); $o^{x}$ sternum VII (c); posterior part of 9 sternum VIII (d). Scale: $1 \mathrm{~mm}$.

$\sigma^{*}$ : sternum VII with weak impression in posterior median area, pubescence yellowish, hind margin of sternum VII similar to $M$. torquatus, in the middle weakly convex and with one long crista of dark setae (Fig. 22c); sternum VIII of similar shape as in M. brouni, also with membranous hind margin, but with weaker median impression and with sparser yellowish pubescence; tergum VIII as in the preceding species with convex hind margin; sternum IX without pair of macrosetae, pubescence partly dark and partly yellowish (Fig. 22b); terga IX and X as in M. brouni; aedeagus of similar morphology as in M. torquatus, but relatively smaller; parameres not distinctly asymmetric, relatively longer and with more numerous setae than in $M$. torquatus, the four apical setae not longer and stouter than the subapical ones; ventral process in ventral view more distinctly constricted laterally than in $M$. torquatus; internal sac as in $M$. torquatus with two rows of numerous sclerotized spines (Fig. 22a).

q: protarsomeres I - IV as strongly dilated as in $\sigma^{\prime}$, sexual dimorphism indistinct; sternum VIII posteriorly obtusely pointed (Fig. 22d); valvifers \pm fused, but suture visible; "bursa copulatrix" not sclerotized.

Derivatio nominis: The name (Lat.) refers to the fact that $M$. solus is the only species of the $M$. brouni species group in the North Island.

\section{Distribution and bionomics}

The known distribution of $M$. solus is confined to Wellington in the very southwest of the North Island (Map 3). The types were collected from November through February, some of them were apparently found in urban habitats (parks etc.). One beetle taken in November was teneral.

\section{Key to the species of Maorothius}

While the distinction of species groups is possible based on external characters alone, the separation of most species within those groups mostly relies on the o primary and secondary sexual characters. An identification of $q 9$ is often difficult or even impossible. For an explanation of the abbreviations used in the key see section 2 . 
1. Dorsal surface of head mediad of dorsal margins of eyes, at least laterally, with several $(>10)$ macropunctures; frontal punctures present, though sometimes difficult to distinguish from surrounding macropunctures. $\ldots \ldots \ldots \ldots \ldots \ldots \ldots \ldots \ldots \ldots$ Dorsal surface of head mediad of dorsal margins of eyes largely impunctate (several punctures are present at the posterior margin of head and, occasionally, on postgenae); frontal punctures absent.

2. Smallest species of the genus ( $\mathrm{HW}<1.2 \mathrm{~mm} ; \mathrm{PW}<1.4 \mathrm{~mm}$ ); elytra relatively long (EL/PL $>0.7$ ). Hind wings fully developed; hind margin of tergum VII with palisade fringe.

$\sigma^{\pi}$ : aedeagus weakly asymmetric, with relatively long parameres with subapical setae; median lobe relatively small, lateral parts of ventral process not contiguous dorsally; internal sac without sclerotized spines (Fig. 17a).

North of North Island, south to Waikato.

M. volans sp. $\mathrm{n}$.

Size distinctly larger. Elytra longer; hind wings reduced; hind margin of tergum VII without palisade fringe.

$\sigma^{\pi}$ : aedeagus distinctly asymmetric; parameres short and without subapical setae; median lobe relatively larger, lateral parts of ventral process contiguous dorsally; internal sac with sclerotized structures. . . . . . . . . . . . . . . . . . . . . . 3

3. Dorsal surface of head and pronotum almost completely mat due to distinct (though very fine) microsculpture; punctation of elytra rugose.

$\sigma^{n}$ : hind margin of sternum VIII weakly concave (Fig. 16c); internal sac of aedeagus with three long and 2 or three short sclerotized spines in internal sac; shape of aedeagus as in Fig. 16a.

Central North Island: Tongariro, Wanganui.

M. tridens sp. n.

Dorsal surface of head and pronotum with microsculpture, but somewhat more shining. $\sigma^{x}$ : hind margin of sternum VIII either more strongly concave or with central convexity; internal sac of aedeagus with more numerous sclerotized structures in internal sac; shape

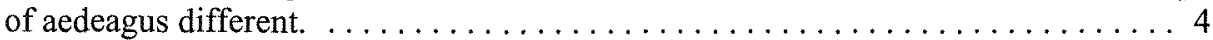

4. Of slightly larger size. Pronotum less slender and more distinctly tapering posteriorly; elytra with less dense and more well-defined macropunctation, interstices on average as wide as or only slightly wider than diametre of punctures.

$\sigma^{x}$ : hind margin of sternum VIII in the middle convex (Fig. 15c); sternum IX without pairs of macrosetae (Fig. 15b); aedeagus as in Fig. 15a.

Relatively widespread species. North Island: Hawke's Bay, Waikato, Bay of Plenty; South Island: Nelson. . . . . . . . . . . . . . . . . coalitus $\mathrm{sp.}$. Slightly smaller species. Pronotum more slender and less distinctly tapering posteriorly; elytra with denser and less well-defined macropunctation, interstices on average narrower than diametre of punctures.

$\sigma$ : hind margin of sternum VIII in the broadly concave (Fig. 14c); sternum IX with median pair of macrosetae (Fig. 14b); aedeagus distinctive (Fig. 14a).

Northeast of North Island: Auckland, Waikato. ........... puncticeps (BROUN)

5. Head slender and of \pm parallel outline (HL/HW $>1.15$ ), hind angles smoothly rounded; postocular puncture absent; eyes relatively large, slightly less than half the length of postgenae in dorsal view and with relatively large ommatidia; antennae ca. $2 x$ longer than head width. Elytra relatively long (EL/PL $>0.6$ ); with distinctive microsculpture composed of extremely dense, \pm transversely confluent micropunctation, surface therefore almost completely mat; macropunctation indistinct, pubescence absent. 
or: sternum VIII with obtusely pointed hind margin, pubescence unmodified (Fig. 18c); sternum IX strongly asymmetric, without macrosetae (Fig. 18b); tergum IX divided into two sclerites, tergum $\mathrm{X}$ very long and anteriorly acute (Fig. 18d); aedeagus very distinctive (Fig. 18a).

South Island: Buller.

M. dispar sp. $\mathrm{n}$.

Head less slender and usually dilated posteriorly, hind angles more distinct; postocular puncture present; eyes smaller, usually $<0.3 x$ the length of postgenae in dorsal view and with finer ommatidia; antennae shorter, usually ca. $1.5 x$ longer than head width. Elytra relatively shorter $(\mathrm{EL} / \mathrm{PL}<0.6)$, microsculpture and punctation different.

$\sigma^{\pi}$ : hind margin of sternum VIII in most species \pm concave, though sometimes with central convexity; sternum IX in most species with pairs of macrosetae; aedeagus of completely different morphology. $\ldots \ldots \ldots \ldots \ldots \ldots \ldots \ldots \ldots \ldots$

6. Moderately large species ( $\mathrm{HW}<1.85 \mathrm{~mm}, \mathrm{PW}<2.15 \mathrm{~mm}$ ).

$\sigma^{\pi}$ : hind margin of sternum VII with crista(e) of spine-like setae; tergum IX separated into two sclerites, tergum $X$ long and anteriorly \pm acute; aedeagus very large, ca. $1.5 \mathrm{X}$ longer than head width, and \pm symmetric; parameres long, symmetric, and with subapical setae; internal sac with long and \pm coiled series of numerous sclerotized spines.

q: valvifers fused.

South Island and the extreme south of the North Island (Wellington).

- $\quad$ Larger species (HW $>1.85 \mathrm{~mm}, \mathrm{PW}>2.00 \mathrm{~mm}$; most species distinctly larger).

$\sigma^{\text {r: }}$ hind margin of sternum VII without cristae of spine-like setae; tergum IX undivided, tergum X short and anteriorly rounded; aedeagus smaller, $<1.3 \mathrm{x}$ longer than head width, and distinctly asymmetric; parameres usually short, asymmetric, and without subapical setae; internal sac with shorter series of sclerotized spines or without sclerotized structures.

\%: valvifers contiguous, but not fused.

Central and northern North Island.

7. Head and pronotum with pronounced microreticulation, surface therefore almost completely mat; abdomen, too, with more distinct microsculpture.

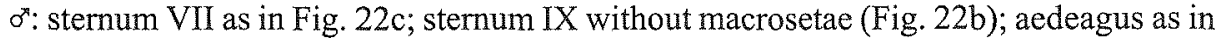
Fig. 22a.

South of North Island: Wellington.

M. solus sp. n.

Head and pronotum with weaker microreticulation and more shine; microsculpture of abdomen shallow.

$\sigma^{r}$ : sternum IX with posterior pair of macrosetae.

South Island.

8. Elytra and especially abdomen with very dense punctation, interstices on abdomen narrower than punctures.

$\sigma^{\text {t: }}$ sternum VII with pronounced impression of triangular shape in posterior median area, its hind margin concave and with long crista of dark stout setae (Fig. 21c); aedeagus as in Fig. 21a.

Canterbury.

M. tonsor sp. $\mathrm{n}$.

- Elytra and abdomen with sparser punctation, interstices on abdomen wider than punctures.

$\sigma^{\text {n: }}$ sternum VII either with pair of cristae of dark stout setae or, if with one crista, hind margin centrally weakly convex; aedeagus with either more numerous or with distinctly larger spines in internal sac. 
9. Head relatively shorter.

$o^{x}$ : sternum VII with one long crista of dark stout setae posteriorly (Fig. 20c); aedeagus with two long rows of numerous sclerotized spines in internal sac; parameres with ca. 10 apical and subapical setae (Fig. 20a).

Northern South Island: Marlborough.

M. torquatus sp. n.

Head more oblong.

o: sternum VII with pair of shorter cristae of dark stout setae posteriorly (Fig. 19e); aedeagus with fewer and distinctly larger spines in internal sac; parameres with clearly less than 10 setae (Fig. 19c).

South of South Island: Southland, Dunedin, Otago Lakes.

M. brouni (STEEL)

$10 \sigma^{\pi}$ : sternum VIII near hind margin with pair of cristae of long stout setae (Fig. 13c), postero-laterally with long brush-like processes; aedeagus small, with relatively long parameres, and without appreciable internal structures (Fig. 13a).

Northland, Bay of Plenty.

M. pectinatus sp. $\mathrm{n}$. o: sternum VIII without such cristae and of completely different shape; aedeagus usually relatively larger, parameres distinctly shorter, internal sac at least with small semitransparent spines.

11. $0^{x}$ : sternum VIII posteriorly distinctly convex (Fig. 11c); sternum IX with two pairs of macrosetae (Fig. 11b); aedeagus as in Fig. 11a.

Northland.

M. effeminatus sp. n.

$\sigma^{x}$ : sternum VIII posteriorly distinctly and broadly concave, in one species with small

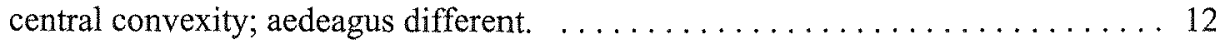

12. $\sigma^{*}$ : sternum VIII postero-laterally with hook-shaped processes; aedeagus relatively small, median lobe distinctly shorter than head width. . . . . . . . . . . . . . . 13 $0^{\text {7: }}$ sternum VIII without such processes; aedeagus larger, median lobe approximately as long as head width or longer. $\ldots \ldots \ldots \ldots \ldots \ldots \ldots \ldots \ldots \ldots \ldots \ldots$

13. Head more strongly widened posteriorly; microreticulation of head and pronotum slightly more distinct. Elytra with somewhat coriaceous microsculpture, punctation therefore less well-delimited.

$\sigma^{7}$ : posterior angles of sternum VIII with longer hook-shaped processes (Fig. 4c); tergum VIII not pointed posteriorly; hind margin of sternum IX with shorter pubescence (Fig. 4b); median lobe of aedeagus in lateral view less strongly bent; parameres longer; internal tube of median lobe with larger and darker spines (Fig. 4a).

Northland.

M. hamifer sp. n. Head less strongly widened posteriorly; microreticulation of head and pronotum less distinct. Elytra with weaker microsculpture, punctation more well-defined.

$0^{\mathrm{x}}$ : posterior angles of sternum VIII with shorter hook-shaped processes (Fig. 3d); tergum VIII pointed posteriorly; hind margin of sternum IX with longer pubescence (Fig. 3b); median lobe of aedeagus in lateral view strongly bent; parameres shorter; internal tube of median lobe with smaller and less strongly sclerotized spines (Fig. 3a).

Northland.

M. adustus (BROUN)

14. $\sigma^{r}$ : internal sac of aedeagus with sclerotized spines. $\ldots \ldots \ldots \ldots \ldots \ldots$

0 : internal sac of aedeagus without sclerotized spines, only with minute semitransparent spine-like structures; sternum VIII with modified pubescence (stout short setae) in all of the posterior half, the posterior margin with pronounced concavity (Figs $5 \mathrm{~b}, \mathrm{c}$ ); sternum IX without median pair of macrosetae (Fig. 5d); shape of aedeagus as in Fig. 5 a. 
\%: hind margin of sternum VIII \pm truncate; "bursa copulatrix" as in Fig. $5 f$.

Northland.

M. setiger sp. n.

15. $\sigma^{2}$ : internal sac of aedeagus basally with slender and weakly sclerotized spines; sternum VIII only postero-laterally with modified pubescence, pubescence of central area unmodified, hind margin of sternum VIII moderately concave (Fig. 10b); sternum IX with median pair of macrosetae (Fig. 10c); shape of aedeagus as in Fig. 10a.

\%: hind margin of sternum VIII acutely pointed (Fig. 10d); sclerotized parts of "bursa copulatrix" as in Fig. 10f.

Eastern Waikato, Bay of Plenty, Gisborne.

M. brookesi (CAMERON)

- $\quad \sigma^{2}$ : internal sac with larger and more distinctly sclerotized spines. 9 : shape of sternum VIII different (note that the of 9 of some species are unknown.) $\ldots \ldots \ldots \ldots \ldots 16$

16. $o^{*}$ : sternum IX with median pair of macrosetae (Fig. 12b); aedeagus with relatively long series of numerous small spines (Fig. 12a).

Waikato.

M. hammondi sp. n. o: sternum IX without median pair of macrosetae; aedeagus with fewer and larger spines.

17. $\sigma^{\pi}$ : sternum VII not distinctly concave posteriorly and without modified pubescence near hind margin; sternum VIII without modified pubescence (Fig. 9c); aedeagus as in Figs 9a.

Wanganui.

M. pubescens sp. n. $\sigma^{x}$ : sternum VII concave posteriorly and with modified pubescence near hind margin; sternum VIII with modified pubescence; aedeagus different. . . . . . . . 18

18. $\sigma^{*}$ : aedeagus with ventral process of median lobe apically pointed in ventral aspect (Fig. 8a).

Little Barrier Island.

M. insulanus sp. n. $\sigma^{*}$ : aedeagus with ventral process of median lobe apically obliquely convex to truncate in ventral view. 19

20. Eyes slightly smaller, in dorsal view somewhat less than half the length of postgenae. $\sigma^{\pi}$ : median lobe of aedeagus usually smaller and of slightly different shape; internal sac with fewer and shorter spines (Fig. 7a).

Northland, Auckland.

M. brevispinosus sp. $\mathrm{n}$.

- Eyes approximately half the length of postgenae in dorsal view. $\sigma^{x}$ : median lobe of aedeagus slightly larger; internal sac with more numerous and longer spines (Fig. 6a).

Auckland.

M. longispinosus sp. n.

\section{Appendix}

After submission of the manuscript, some additional material was kindly made available to me by Dr. JOHN MARRIS (LUNZ) and Dr. J. EARLY (AMNZ). The records are not accounted for in Maps 1-3.

\section{Maorothius setiger sp. $\mathrm{n}$.}

Paratypes: 10\%: Waimatenui 10.12 .33 [handwritten on reverse side of mounting label] / Waimatenui / C.E.Clarke Collection / Othius sp. n. cf. brookesi Cam., P.M. Hammond det. 1984 / AMNZ 26536 Auckland Museum New Zealand (AMNZ); 19: Mangamuka mts. N. 
Auck. 10.1.24 [handwritten on reverse side of mounting label] / Mangamuka C.E. Clarke / C.E.Clarke Collection / Hokianga Co., North Island, New Zealand, Auckland Museum / Othius sp. n. 6 or 8, P.M. Hammond det. 1984 / AMNZ 26541 Auckland Museum New Zealand (AMNZ).

Like the other types, the specimens were collected in Northland.

\section{Maorothius longispinosus sp. $\mathbf{n}$.}

Paratype: $10^{x}$ : Waitakere 21.8.32 [handwritten on reverse side of mounting label] / Waitakere / C.E.Clarke Collection / Waitemata Co., North Island, New Zealand, Auckland Museum / Othius sp. n. 5, P.M. Hammond det. 1984 / AMNZ 26542 Auckland Museum New Zealand (AMNZ).

\section{Maorothius brevispinosus sp. $\mathrm{n}$.}

1 ㅇ [identification uncertain], Parua Bay (ND), 2.I.24 (AMNZ); 1 우 [identification uncertain], Whangarei Co. (ND), Waikaraka valley near Whangarei Heads, 14.I.24 (AMNZ).

\section{Maorothius brookesi (CAMERON)}

1ㅇ, Mamuku, Rotorua Co., 28.XII.20 (AMNZ); 1o", Okauia, Matamata Co., 23.I.24 (AMNZ).

\section{Maorothius effeminatus sp. n.}

Paratype: 10: Mangamuka R., N. Auck. 9.1.24 [handwritten on reverse side of mounting label] / C.E.Clarke Collection / Hokianga Co., North Island, New Zealand, Auckland Museum / Othius sp. n. P.M. Hammond det. 1984 / AMNZ 26540 Auckland Museum New Zealand (AMNZ).

\section{Maorothius brouni (STEEL)}

19, Central Otago (CO), Carrick Range, Watt Rk [ca. $20 \mathrm{~km} \mathrm{SW}$ Cromwell], 1300m, yellow pan trap in tussock grassland, 5.-8.II.1986, leg. Early (LUNZ).

M. brouni is here for the first time recorded from Central Otago.

\section{Maorothius tonsor $\mathrm{sp} . \mathrm{n}$.}

Paratypes: $20^{\circ} 0^{7}, 2 ㅇ ㅜ$ : Coopers Knob Res. [ca. $10 \mathrm{~km}$ SW Lyttelton Port], M.C., 2.2.1977, M.R. Butcher (LUNZ, cAss); 1 \%: pitfall trap, Coopers Knob Res., M.C., 16.2.1978, M.R. Butcher (cAss); 19: same data, but 19.1.1978 (LUNZ).

Like the holotype, the paratypes were collected on the Banks Peninsula in Mid Canterbury.

\section{Acknowledgements}

I am much indebted to the colleagues indicated in the material section for arranging the loan of type and non-type material. Moreover, I would like to express my sincere thanks to ALFRED F. NEWTON, Chicago, for his criticism on the phylogenetics section, to MICHAEL SCHÜLKE, Berlin, for critically reviewing the manuscript, and to LOTHAR ZERCHE, Eberswalde, for providing me with some older hard-to-get literature. Finally, I am most grateful to JOHN MARRIS, Canterbury, for his ceaseless and instantaneous help in identifying localities and clarifying any other questions relating to New Zealand. 


\section{References}

Assing, V. 1997: A revision of Othius STEPHENS, 1829. III. The species of the Western Palaearctic region exclusive of the Atlantic Islands (Coleoptera, Staphylinidae: Xantholininae). - Nova Suppl. Entomol., Berlin 10: 3-130.

ASSING, V. 1998a: A revision of Othius STEPHENS of the Atlantic Islands. III: Further records, new species, phylogenetics, and colonization (Insecta, Coleoptera, Staphylinidae: Xantholininae). Reichenbachia 32: 213-224.

ASSING, V. 1998b: A revision of Othius STEPHENS. V. The species of the Himalayan region (Coleoptera: Staphylinidae, Xantholininae). - Beitr. Ent. Berlin 48: 293-342

ASSING, V. 1999a: A revision of Othius STEPHENS, 1829. VII. The species of the Eastern Palaearctic region east of the Himalayas (Coleoptera: Staphylinidae). - Beitr. Ent. Berlin 49: 3-96.

ASSING, V. 1999b: A revision of Othius STEPHENS (Coleoptera, Staphylinidae). VIII. Further records, new species, and a new synonym. - Linzer biol. Beitr. 31: 661-691.

Broun, T. 1880: Manual of the New Zealand Coleoptera. - Wellington: XIX + $651 \mathrm{pp.}$

Broun, T. 1893: Manual of the New Zealand Coleoptera. - Wellington: XIII + 975-1320.

BRoUN, T. 1894: LIV. - Descriptions of new Coleoptera from New Zealand. - Ann. Mag. Nat. Hist. London 14 (84): 419-428.

CAMERON, M. 1952: A new species of Coleoptera Staphylinidae from New Zealand. - Entomologist's Monthly Mag. 88: 42.

CoIfFAIT, H. \& SAIz, F. 1969: Antarctothius nouveau genre de la Terre de Feu (Col. Staphylinidae). Bull. Soc. Hist. Nat. Toulouse 105: 279-286.

CRosby, T. K.; DUGDALE, J. S. \& WATT, J. C. 1998: Area codes for recording specimen localities in the New Zealand subregion. - New Zealand J. Zool. 25: 175-183.

CROWSON, R. A. 1980: On amphipolar distribution patterns in some cool climate groups of Coleoptera. Entomol. Gener. 6: 281-292.

Crowson, R. A. 1981: The biology of the Coleoptera. - Academic Press, London, New York, Toronto, Sydney, San Franciso: XII + 802 pp.

FAIRMAIRE, L. 1885: Diagnoses de coléoptères nouveaux de la Terre de Feu. - Le Naturaliste 7: 11-12.

FRANK, J. H. 1982: The parasites of Staphylinidae (Coleoptera). A contribution towards an encyclopedia of the Staphylinidae. - Techn. Bull. Agric. Exp. St. Inst. Food Agric. Sci. Univ. Fla. No. 824: 1-118.

JEANNEL, R. 1922: Deux Staphylinides endogés aveugles des monts Bihor. - Buletinul Societăţi de Ştiinţe din Cluj 1: 337-347.

Klimaszewski, J.; Newton, A. F. \& Thayer, M. K.: A review of the New Zealand rove beetles (Coleoptera: Staphylinidae), - New Zealand J. Zool. 23: 143-160.

NEWTON, A. F. 1985: South temperate Staphylinoidea (Coleoptera): their potential for biogeographic analysis of austral disjunctions. - In: BALL, G. E. (ed.): Taxonomy, Phylogeny and Zoogeography of Beetles and Ants, Dordrecht: 180-220.

NEWTON, A. F. \& THAYER, M. K. 1992: Current classification and family-group names in Staphyliniformia (Coleoptera). - Fieldiana Zool., N. S., No. 67: 92 pp.

SMETANA, A. 1982: Revision of the subfamily Xantholininae of America north of Mexico (Coleoptera: Staphylinidae). - Mem. Entomol. Soc. Canada, No. 120: 389 pp.

SmetanA, A. 1995: Rove beetles of the subtribe Philonthina of America north of Mexico (Coleoptera: Staphylinidae) classification, phylogeny and taxonomic revision. - Mem. Entomol., Int. 3: 946 pp.

STEEL, W. O. 1948: Some notes on the nomenclature of the Xantholinini and Othiini (Col,, Staphylinidae). - Entomologist's Monthly Mag. 84: 268-270.

\section{Author's address:}

VOLKER ASSING

Gabelsbergerstraße 2

D - 30163 Hannover

Germany

e-mail: vassing.hann@t-online.de 